\begin{abstract}
Title of Thesis:

SOUND OF THE CITY: CREATING A BALANCED SOUND COMPOSITION IN URBAN GREEN SPACES

Lauren Gray, Master of Landscape Architecture, 2021

Thesis Directed By:

Prof. Jack Sullivan, Associate Professor Department of Plant Sciences and Landscape Architecture

Sounds in the landscape are an important, and an often-ignored aspect of the human experience. In urban landscapes, the sounds in the landscape create a symphony. Combining the beloved sounds of nature and humans, with the often less desirable, but no less important sounds of traffic and sirens. This thesis aims to put that symphony of sounds and its relationship to the landscape under the microscope. By first looking into the theories of composers John Cage and R. Murray Schafer, and then applying those theories to the soundscape and landscape, the exploration and examination of the conscious, subconscious, beautiful, and necessary, as it pertains to soundscape and landscape design, will be revealed.
\end{abstract}




\title{
SOUND OF THE CITY: CREATING A BALANCED SOUND COMPOSITION IN URBAN GREEN SPACES
}

By

\author{
Lauren Gray
}

\author{
Thesis submitted to the Faculty of the Graduate School of the \\ University of Maryland, College Park, in partial fulfillment \\ of the requirements for the degree of \\ Master of Landscape Architecture
}

2021

Advisory Committee:

Prof. Jack Sullivan, Chair

Dr. Christopher Ellis

Prof. Ian Hoffman 
(C) Copyright by

Lauren Gray

2021 


\section{Acknowledgements}

I would like to start by thanking my committee chair, Prof. Jack Sullivan, for all the wonderful guidance and support he has given throughout this process, without whom I could not have considered the so many different parts of this thesis and would not have enjoyed the exploration nearly as much as I had during our weekly zoom meetings.

I would also like to thank my other committee members, Dr. Christopher Ellis, and Prof. Ian Hoffman, for their individual depths of knowledge and time that they so generously shared with me.

Many thanks to my studio mates, who have helped me to grow enormously in every way in the past three years.

Finally, I would like to thank my sisters, my parents, and my partner, for always being supportive and encouraging of finding music in every avenue of life. 


\section{Table of Contents}

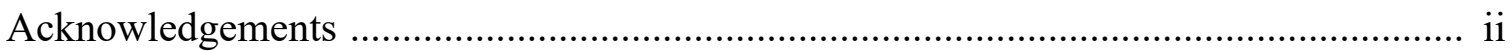

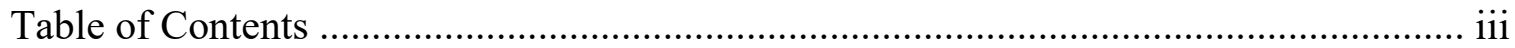

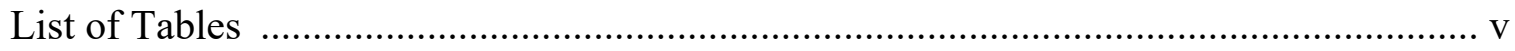

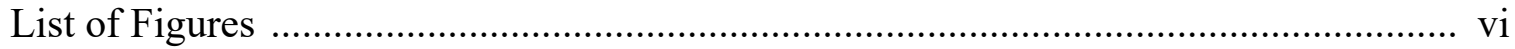

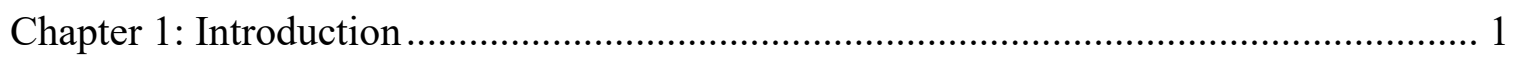

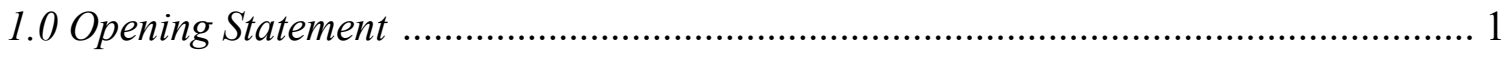

1.1 Why Sound in the Landscape? ........................................................................... 3

Chapter 2: Literature Review …………………………...................................... 5

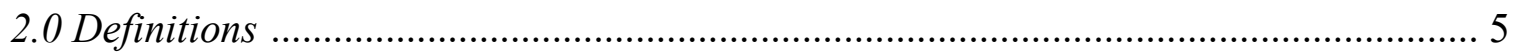

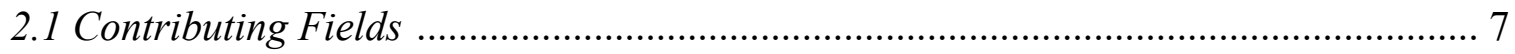

2.2 Human Sound Preference and Comfort ……………......................................... 9

2.3 Perception of Urban Soundscapes and Landscapes ............................................. 10

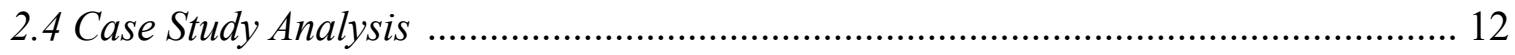

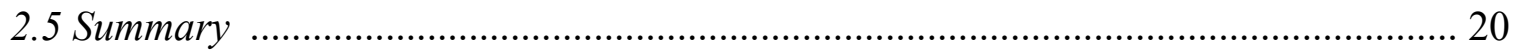

Chapter 3: Site Selection and Analysis ..................................................................... 21

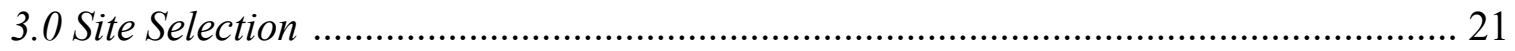

3.1 Site Inventory and Analysis: Large Scale Thinking ............................................... 25

3.2 Site Inventory and Analysis: Establishing a Method to Document Existing

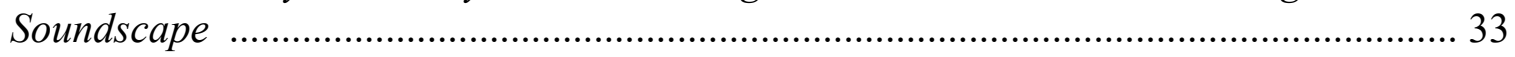

3.3 Site Inventory and Analysis: Existing Soundscape …………………………….... 38

Chapter 4: Composing the Soundscape ……………................................................ 48

4.0 Soundscape Design Goal and Objectives .............................................................. 48

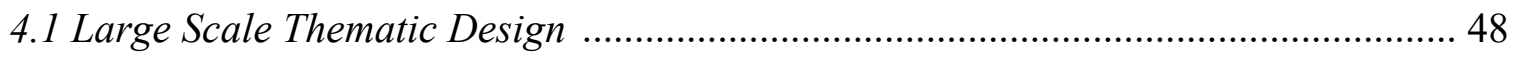

4.2 E Street Park System Soundscape Design Using System Schafer's Sound Categories 
Chapter 5: Composition Through Landscape

5.0 Landscape Design Goals and Objectives ............................................................ 52

5.1 E Street Park System Landscape Design ............................................................... 52

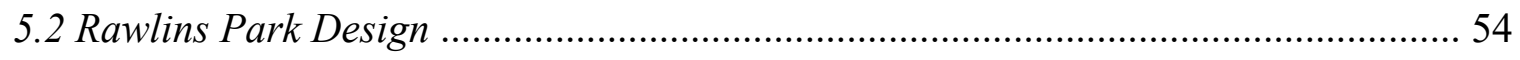

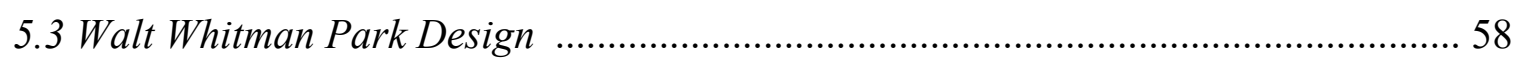

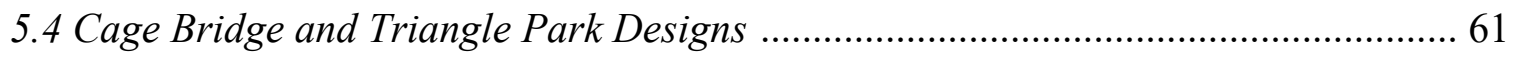

5.5 Virginiana Ave Bus Plaza and Bernardo de Galvez Park Designs ........................... 68

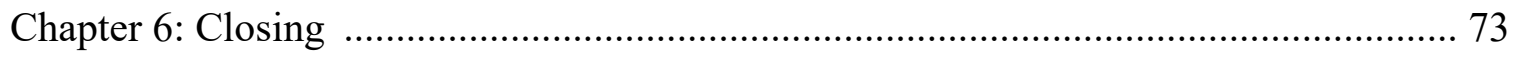

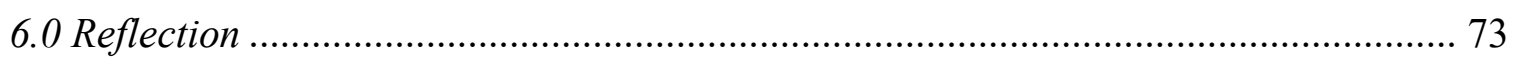

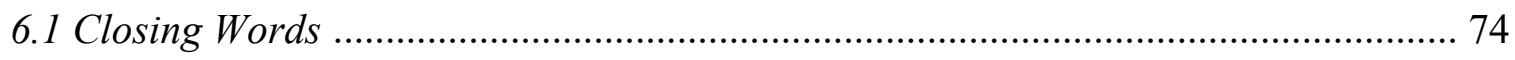

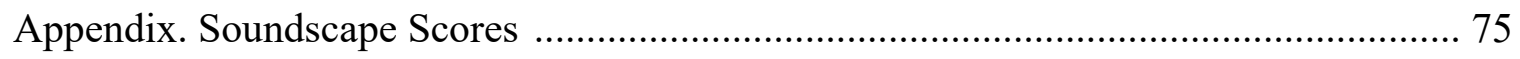

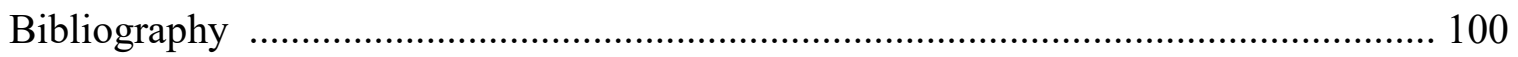




\section{List of Tables}

Table 1. Soundscape Survey Responses (Cerwén, 2016) ............................................ 18 


\section{List of Figures}

Figure 1: Conceptual Diagram of Psychoacoustics (Fastl, 2013) …………………........ 8

Figure 2: Brooklyn Bridge Park Berm (Michael Van Valkenburgh Associates Inc) ...... 13

Figure 3: Seating Area in Brooklyn Bridge Park (Michael Van Valkenburgh Associates Inc) 13

Figure 4: Aerial View of Bryant Park (The Cultural Landscape Foundation) ................ 15

Figure 5: Seating Area in Bryant Park (The Cultural Landscape Foundation) ................ 15

Figure 6: View of Hills in Miami Beach Soundscape Park (west8) ................................ 16

Figure 7: View of Outdoor Theater in Miami Beach Soundscape Park (west8) ............. 16

Figure 8: View of Waterfall in Paley Park (The Cultural Landscape Foundation) ......... 17

Figure 9: View of Seating Area in Paley Park (The Cultural Landscape Foundation) .... 17

Figure 10: Aerial View Model of Quasi-Experiment (Cerwén, 2016) ............................ 19

Figure 11: View of Quasi-experiment (Cerwén, 2016) ................................................. 19

Figure 12: Sound pollution maps of Baltimore, MD, and Washington D.C. (United States Department of Transportation, 2021) …………………………………………...... 22

Figure 13: Maps possible sites in Baltimore, MD, and Washington, D.C. (Gray) .......... 23

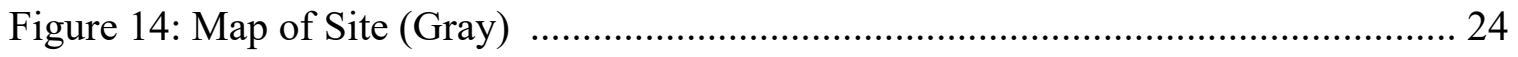

Figure 15: Site with Labeled Spaces (Gray) ………………………………………..... 24

Figure 16: Map of Federal Buildings Near Site (Gray) ................................................... 25

Figure 17: Institutions on and Near Site (Gray) ………................................................ 26

Figure 18: Viñoly Plan for the Kennedy Center (Reprinted with permission from Rafael

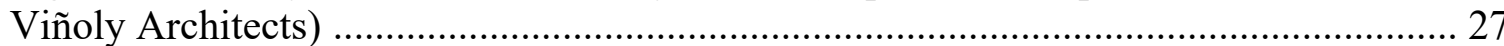

Figure 19: Aerial Perspective of Viñoly Plan for the Kennedy Center (Reprinted with permission from Rafael Viñoly Architects) …………………………………………..... 28

Figure 20: Plan for the Reach at the Kennedy Center (The REACH) ............................. 29

Figure 21: Map of Design Boundaries (Gray) ……………………………................ 30

Figure 22: Topographic Map of Site (Gray) ……………….................................... 31

Figure 23: Image of Building North of Rawlins Park (Gray) ………………………..... 32

Figure 24: Image of Existing Trees Near Bus Stations off Virginia Avenue (Gray) ...... 32

Figure 25: Map of Public Transportation (Gray) ……………………………….......... 33 
Figure 26: Brahms Symphony No. 1. (Brahms, 1876) ................................................. 34

Figure 27: Score of Solo for Piano (Cage, 1958b) ………………………………....... 35

Figure 28: Score of Fontana Mix (Cage, 1958a) ………………………………….... 35

Figure 29: Schafer's Visual Descriptions of Sounds (Schafer, 1977) ............................. 36

Figure 30: Schafer Sound Map (Schafer, 1977) .......................................................... 36

Figure 31: Score of Fountain Movement (Halprin, n.d.) ……………………................ 37

Figure 32: Perimeter Soundscape of Rawlins Park (Gray) ............................................... 39

Figure 33: Perimeter Soundscape of Walt Whitman Park (Gray) ................................... 40

Figure 34: Perimeter Soundscape of E Street Expressway Under Pass (Gray) ................ 41

Figure 35: Perimeter Soundscape of Triangle Park (Gray) ............................................... 41

Figure 36: Perimeter Soundscapes of Virginiana Avenue Bus Hub \& Bernardo De Galvez Memorial Park (Gray) ………………………………............................................. 42

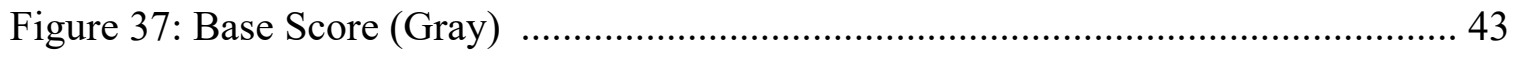

Figure 38: Filled Out Score of de Galvez Park on Saturday, in the Late Afternoon (Gray)

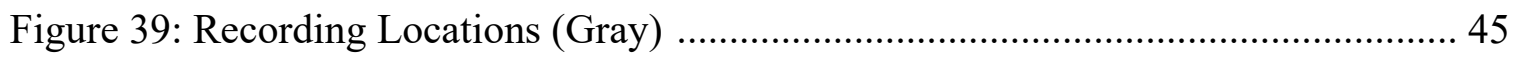

Figure 40: Symphonic Form Diagram (Gray) ……………....................................... 49

Figure 41: E Street Park System Schafer's Sound Category Diagram (Gray) ................ 50

Figure 42: E Street Park System Site Plan (Gray) …………………………………..... 53

Figure 43: Aerial View of E Street Park System Site Plan Over Rawlins Park Looking

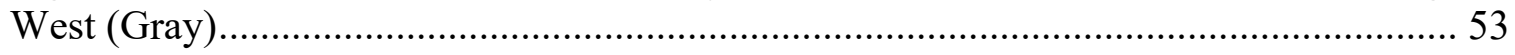

Figure 44: Site Plan for Rawlins Park (Gray) .............................................................. 55

Figure 45: Perspective of Sound Barrier Seating Walls in Rawlins Park (Gray) ............ 56

Figure 46: North-South Section of Existing Rawlins Park (Gray) ……............................ 56

Figure 47: North-South Section of Proposed Soundscape and Landscape Interventions

Rawlins Park (Gray) ……………………………….............................................. 57

Figure 48: Perspective of Terraced Seating and Schafer Stage (Gray) ............................57

Figure 49: Perspective of Schafer Stage and Fountain (Gray) …………....................... 57

Figure 50: Perspective of Linear and Clear Pathways (Gray) ………................................ 57

Figure 51: Site Plan for Walt Whitman Park (Gray) ………………………………...... 59

Figure 52: North-South Section of Existing Walt Whitman Park (Gray) ......................... 59 
Figure 53: North-South Section of Proposed Soundscape and Landscape Interventions

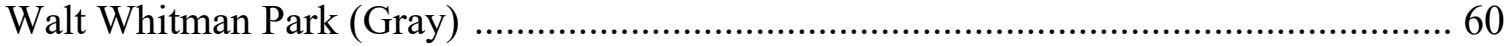

Figure 54: Perspective of Sounds Mounds with Seating in Walt Whitman Park (Gray) 60 Figure 55: Perspective of Plaza and Vegetation Walt Whitman Park (Gray) .................. 61

Figure 56: Site Plan for Cage Bridge and Triangle Park (Gray) ……………................. 63

Figure 57: West East Section of Existing E Street Expressway Underpass (Gray) ......... 64

Figure 58: West East Section of Proposed Cage Bridge Ascending Through Existing E

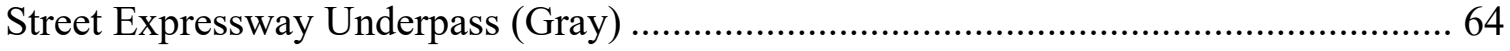

Figure 59: Eastern Entrance to Cage Bridge (Gray) …………………......................... 65

Figure 60: View of Different Wall Heights on Cage Bridge (Gray) ................................ 66

Figure 61: View over Y Intersection on Cage Bridge (Gray) …………………….......... 66

Figure 62: West View from General Jose De San Martin Memorial Plaza in Triangle Park (Gray).

Figure 63: View of General Jose De San Martin Memorial Plaza in Triangle Park (Gray)

Figure 64: Site Plan for Virginia Avenue Bus Plaza and Bernardo de Galvez Memorial Park (Gray).

Figure 65: View of Grand Stairs in Virginia Avenue Bus Plaza (Gray) ......................... 71

Figure 66: Aerial View West from Virginia Avenue Bus Plaza (Gray) .......................... 71

Figure 67: View of Plaza in Bernardo De Galvez Memorial Park (Gray) ....................... 72

Figure A1: Sound Index for Soundscape Scores (Gray) …………………………........ 75

Figure A2: Sound Score for Rawlins Park: Tuesday Morning (Gray) ............................... 76

Figure A3: Sound Score for Rawlins Park: Tuesday Afternoon (Gray)........................... 77

Figure A4: Sound Score for Rawlins Park: Tuesday Late Afternoon (Gray)................... 78

Figure A5: Sound Score for Rawlins Park: Saturday Morning (Gray)............................. 79

Figure A6: Sound Score for Rawlins Park: Saturday Afternoon (Gray) ........................... 80

Figure A7: Sound Score for Rawlins Park: Saturday Late Afternoon (Gray) ………....... 81

Figure A8: Sound Score for Walt Whitman Park: Tuesday Morning (Gray) .................... 82

Figure A9: Sound Score for Walt Whitman Park: Tuesday Afternoon (Gray) ................ 83

Figure A10: Sound Score for Walt Whitman Park: Tuesday Late Afternoon (Gray) ...... 84

Figure A11: Sound Score for Walt Whitman Park: Saturday Morning (Gray) ................ 85 
Figure A12: Sound Score for Walt Whitman Park: Saturday Afternoon (Gray)............. 86

Figure A13: Sound Score for Walt Whitman Park: Saturday Late Afternoon (Gray)..... 87

Figure A14: Sound Score for Triangle Park: Tuesday Morning (Gray)......................... 88

Figure A15: Sound Score for Triangle Park: Tuesday Afternoon (Gray) ...................... 89

Figure A16: Sound Score for Triangle Park: Tuesday Late Afternoon (Gray) ................ 90

Figure A17: Sound Score for Triangle Park: Saturday Morning (Gray) ........................ 91

Figure A18: Sound Score for Triangle Park: Saturday Afternoon (Gray)....................... 92

Figure A19: Sound Score for Triangle Park: Saturday Late Afternoon (Gray)............... 93

Figure A20: Sound Score for Bernardo De Galvez Memorial Park: Tuesday Morning

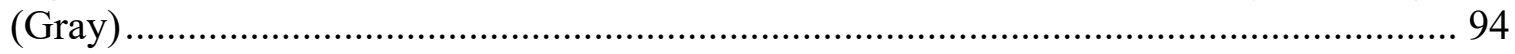

Figure A21: Sound Score for Bernardo De Galvez Memorial Park: Tuesday Afternoon

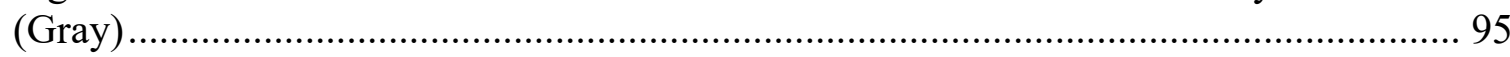

Figure A22: Sound Score for Bernardo De Galvez Memorial Park: Tuesday Late

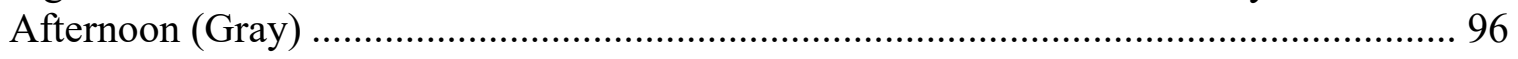

Figure A23: Sound Score for Bernardo De Galvez Memorial Park: Saturday Morning

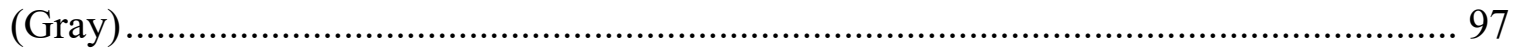

Figure A24: Sound Score for Bernardo De Galvez Memorial Park: Saturday Afternoon

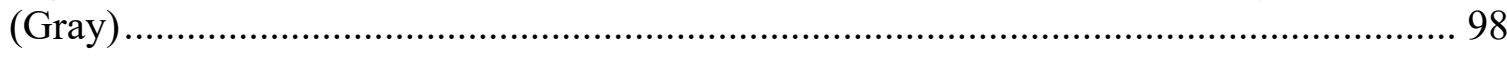

Figure A25: Sound Score for Bernardo De Galvez Memorial Park: Saturday Late Afternoon (Gray) 


\section{Chapter 1: Introduction}

\subsection{Opening Statement}

Recall a time you were standing at a bus stop off the side of a traffic circle, waiting for your bus to take you to the train station for your daily commute. While you are not focusing on anything beyond making it to your destination, sounds of cars and trucks passing by unnoticed. Other sounds make up the symphony of your daily commute: the rustling of wind through the trees along the circle, the occasional bird call from the trees, the footsteps from people passing you. Even the odd car horn adds to the melody that you would experience every day while waiting at that bus stop. If asked about what it sounds like at that bus stop, you may not be able to describe it. But you do recognize it as normal for that landscape, and what would be expected should you go there. All those sounds from the bus stop create the soundscape for the landscape of the bus stop. Whether consciously or unconsciously, you link the soundscape to the landscape, and it helps to establish your views and experiences within the space. So, what happens if the soundscape of the bus stop changes and it no longer seems to match the landscape? Or if the landscape of the bus stop changes and the soundscape no longer seems to work with the visual aspects of the landscape? I will investigate and explore questions such as these and create a system for designing urban spaces so that the soundscape and landscape can be composed in harmony with one another.

The relationship between the soundscape and the landscape has long been neglected. This field of research is important as it touches on aesthetics, comfort, culture, and human safety. The sound experience in a park can greatly affect the perception of a space. Sounds such as moving water, birdsong, and human conversation can make a space more inviting and enjoyable, while 
the sounds of construction, vehicular traffic, and car horns, can instantly detract and become unwelcoming. Cultural differences also change the types of sounds in the soundscape and what would be perceived as pleasant and unpleasant. To a city dweller, silence can be eerie, while someone in a more rural area would find the silence comforting. Safety between the soundscape and landscape occurs in 2 ways,

1) The sounds in the landscape become too loud and can cause negative effects to human health in both a psychological and a physical way.

2) A miss-match of signals between the aural soundscape and the visual landscape, can create a space that does not properly warn users of the dangers within the landscape.

For these reasons and more, further research and design of the soundscape and landscape relationship will be conducted in this thesis.

Washington D.C.'s unique layout, design, and uses blend together and offer a distinct set of soundscape and landscape typologies that are ideal for this thesis. The site for this investigation and exploration is in the northwestern portion of Washington D.C., almost due west of the White House. The site is comprised of a series of memorial parks strung along E Street, NW, along with the John F. Kennedy Center for the Performing Arts at the terminus of this axis. These sites showcase the unique soundscape and landscape characteristics of Washington D.C., providing an ideal starting point for this work. Using this series of parks and streetscapes, this thesis aims to accomplish the following,

1. Establish the current state of the relationship between soundscape and landscape in the landscape architecture design field; 
2. Create a way to accurately document and design the soundscape the site, in both visual and aural styles;

3. Develop a methodology and design process that synthesizes the work of landscape architect Lawrence Halprin and the work of composers and music theorists R. M. Schafer and John Cage, for the purpose of better acknowledging and recording characteristics of soundscape and landscape.

4. Use these methods and design processes to redesign the E Street Park system and its connection to the John F. Kennedy Center for the Performing Arts.

\subsection{Why Sound and Landscape Architecture?}

Sound holds a unique position within the landscape, as it can affect humans in many ways.

Sound can conjure both great beauty and ugliness, touching a range of emotions and feelings from listeners. This occurs in sounds that have been specifically organized, such as in compositions from musical composers. As well as the sounds created in landscapes themselves, such as the combination of birdsong, water, and wind in the trees. Aesthetics created by sound are an important experience in any given space.

Sound can play an important role in human health. Humans face a wide range of health issues from sounds that exceed a certain decibel $(\mathrm{dB})$ range. According to the World Health Organization, noise pollution is the second largest polluter in Europe, and a serious issue in urbanized areas (World Health Organization, 2018). Health issues from noise pollution include, hearing impairment, annoyance, loss of sleep, interference of communication, and loss of focus, which can occur if the weekly decibel allowance of $80 \mathrm{~dB}$ over 40 hours is exceeded (World 
Health Organization, 2019). The human voice sits around $60 \mathrm{~dB}$, while a subway train and heavy traffic experienced from inside the vehicle reside at $100 \mathrm{~dB}$ and $85 \mathrm{~dB}$ respectively (World Health Organization, 2019). These examples begin to show how humans within a city could easily exceed the healthy amount of exposure time causing health issues. It is easy to say that the solution would be to lower the volume of sound from cars and trains, but this could also result in issues to human health. Care must be taken as to not lower the volume of traffic in spaces near traffic so much so that they cause possible human harm from lack of auditory cues of danger.

Sound can also be an important signifier of place and wayfinding. As referenced in the opening statement, certain groupings of sounds can be indicative of where a person is whether in an urban or rural environment. Beyond that, certain sounds can work as important indicators of certain locations within larger ecosystems, such as a church bell signifying proximity to a religious institution. Or hearing the faint sounds of waves of water crashing into land, whose volume grows as the movement heads towards the beach.

While only three reasons are stated here, it is important to know that there are many reasons to study sound in the landscape. These three reasons, however, will be the underlying sound-based ideologies that will shape this thesis. 


\section{Chapter 2: Literature Review}

\subsection{Definitions}

Establishing definitions and terminology is imperative for this work, as it helps to describe sounds in constructive ways. Because of this, definitions will serve as the beginning of this literature review.

Soundscape: The soundscape is the combination of sound and noise, within a defined physical space. The soundscape is defined as "the sonic environment" by R. Murray Schafer, a Canadian composer of the $20^{\text {th }}-21^{\text {st }}$ Centuries, and theorist that popularized the term of soundscape in the 1970s. Schafer's seminal work, The Tuning of the World, creates the baseline for the field of the soundscape as it establishes terminology, categorization of sound types, a robust description of acoustic design and acoustic ecology, all helping to create the theoretical framework in which soundscapes are categorized and learned.

Acoustic Design \& Acoustic Ecology: Acoustic design melds the work of many disciplines in the sciences, social sciences, and the arts, so that the quality of the sonic environment or soundscape, may be improved (Schafer, 1977). Schafer spoke of acoustic design similarly to that of a composition, in that sounds are meant to be orchestrated and formed to create a more pleasurable and richer soundscape. Part of acoustic design must be done while ensuring that human health and safety are a high priority factor.

Soundscape Terminology Definitions: Some terminology that Schafer defines includes clairaudience, "literally clear hearing" (Schafer, 1977) the trained method of hearing the takes in the entire soundscape but is particularly environmental sounds. Keynote sound, a sound that a society or culture has become so accustomed to hearing that it becomes the basis or context in 
which the listener bases other sounds. Because of this, the keynote sound may not be actively perceived or acknowledged to by those who frequently hear it (Schafer, 1977). Noise, while this term can have multiple definitions, the most commonly accept definition would be "unwanted sound" (Schafer, 1977). Sacred noise, a remarkable noise that marks a large sound that is exempt from social control, examples of this type of noise would include thunder or a bell for a religious organization. Sound event is something that places a sound within time and space and implies something larger than itself (Schafer, 1977). A soundmark is a sound that would be treated in the same fashion as a physical landmark, in that it signifies a distinct sense of place. Sound object, the singular sound of a thing, a small sound that is independent. Sound signal, a sound that calls attention to itself and stands out from the soundscape (Schafer, 1977).

Soundscape Sound Categorization: There are multiple ways that sounds can be categorized, whether from duration, or association, but Schafer (1977) organizes sound into 6 categories. The first would be "Natural Sounds", this would include but not be limited to the sounds of the wind, water, fire, birds, and other animals. The second category would be "Human Sounds" which includes but is not limited to the human voice, footsteps, and sounds of clothing and accessories worn by humans. The third category is the "Sounds of Society", which includes but are not limited to the sounds of cities, offices or places of work, musical performance, and ceremonies and/or festivals. The fourth category is "Mechanical Sounds" which includes but is not limited to the sounds of cars, trains, airplanes, jackhammers, and other tools for construction. The fifth category is "Quiet and Silence", which is a lack of sound or noise. The sixth and final category is "Sounds as Indicators" which includes but is not limited to the bells or gongs of a church or clock, the horns or whistles of cars or trains, the ticking of a clock, and the ring of a 
telephone. These 6 categories comprise the soundscapes of the world, but do not begin to distinguish whether the soundscape is enjoyable or not, for the listener.

Strategies of Soundscape Management: In Hellström's doctoral thesis (Hellström 2006, as cited in Cerwén, 2016) the concept of three types of management strategies for the soundscape are referenced, defensive, offensive, and creative. The defensive strategy works to block or protect human listeners from unwanted noises. The offensive strategy recognizes important or wanted sound in the soundscape and focuses the listener to the intended sounds. Finally, the creative strategy adds pleasant new sounds into the soundscape, covering the less desirable noise. These strategies are the basis of all design choices that can be made.

\section{$\underline{2.1 \text { Contributing Fields }}$}

The work of this thesis sits at the intersection of three distinctive fields merging with Landscape Architecture. These fields include Acoustics, Psychoacoustics, Musical Composition, with each field offers important contributions to designing the sounds in the landscape, and therefore are essential to know.

As defined by the American National Standards Institute in combination with the Acoustical Society of America, acoustic is defined as

“(a) Science of sound, including its production, transmission, and effects, including biological and psychological effects. (b) Those qualities of a room that, together, determine its character with respect to auditory effects." (AMERICAN NATIONAL STANDARD Acoustical Terminology, 2013)

The field of Acoustics works to establish and study the physical characteristics of sound, looking at volume, pitch, timbre, duration, and frequency, of sounds. 
Psychoacoustics is the field of study that establishes relationships between sounds as they exist in a given space and how humans perceive those sounds. As described by Fastl's (2013) work, engineers will describe sounds and acoustic information in physical terms, referring to levels of volume and time functions, while psychologists would be more likely to describe the characteristics of the sounds, psychoacoustics functions as a bridge between those fields working to connect associations with the sound source (Figure 1) (Fastl, 2013).

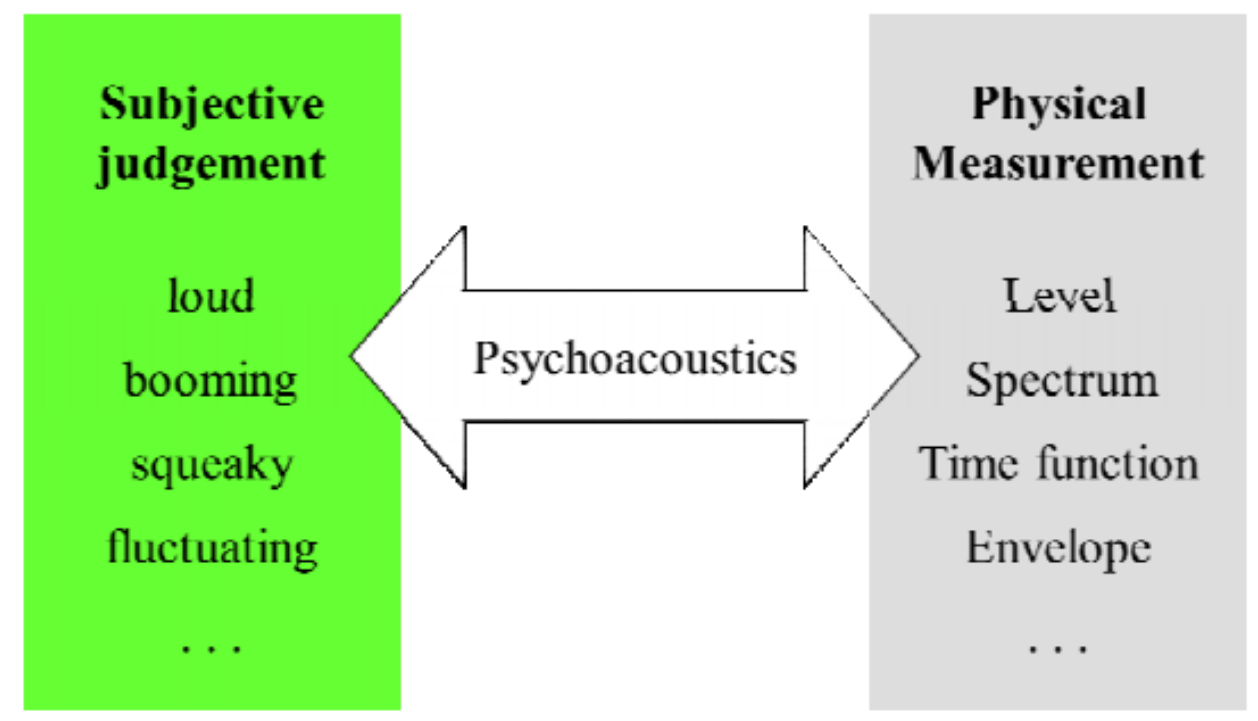

Figure 1: Conceptual Diagram of Psychoacoustics (Fastl, 2013)

The basic scales on which sounds are evaluated through the psychoacoustic lens include loudness, sharpness, fluctuation, and roughness (Fastl, 2006). These scales create ways to verbally describe and allow for the analysis of sounds.

Through musical composition sounds can be cultivated to form aesthetically pleasing masterpieces for the human ear. Looking to music from which much of soundscape theory and terminology sprang forth, is integral and is the basis of all sound design. A cornerstone ideology 
comes from the theories and musical compositions of experimental $20^{\text {th }}$ century composer, John Cage.

"For in this new music nothing takes place but sounds: those that are notated and those that are not. Those that are not music as silences, opening the doors of the music to the sounds that happen to be in the environment notated appear in the written.” (Cage, 2011)

In addition to his compositional works, Cage developed musical theories and philosophies regarding the interpretation and meanings of sound, music, and noise. His revolutionary work, 4'33' directly looks to the sounds of the surrounding environment as the music that is being performed. With this mindset, these seemingly disorganized and random sounds could be brought to the forefront and noticed as inherently musical sounds. Cage's theories would go on to inspire R. Murray Schafer, the composer and soundscape theorist who ideologies would grow through the World Soundscape Project, creating the first method of studying soundscapes (Guo, 2019).

Acoustics, psychoacoustics, and musical composition, show vital parts required for design analysis of soundscapes and the landscape. Through acoustics, the existing sound conditions can be recorded and analyzed. With psychoacoustics the connection of personal meanings to those sounds can be recorded and analyzed. Finally with music composition, the organization and design of the soundscape can be created, and the method with which it can be created would be through landscape architecture.

\section{$\underline{2.2 \text { Human Sound Preference and Comfort }}$}

Sound preference for humans is important to establish when designing and composing soundscapes. Sound preference will dictate what sounds are essential and what will be 
considered aesthetically pleasing to the ear. Overall, when it comes to broader sound groupings, humans tend to prefer sounds that would be categorized in the natural sound category, while disliking the sounds from the mechanical sound category, and having neutral feelings about sounds from the human sound category (Yang et al, 2013). Breaking down preference into individualized sound preference and the rating of a soundscape overall, is a matter that is less agreed upon. In Schafer's Tuning of the world, (1977) a survey across multiple continents and within many different countries, sound preference varied greatly. Other studies found that the influences from cultural and personal experiences shaped the sound preferences substantially (Schulte-Fortkamp et al, 2007; Yang et al, 2005). Other factors in sound preference included the purpose of being in a soundscape by the user (Yang et al, 2005) and levels of comfort with a given soundscape or sound can often be supported by the level of appropriateness. Appropriateness is one of several soundscape descriptors set fourth and described by Aletta, et al. (2016). It can be used to gage whether a soundscape matches the expectations of the visuals of a landscape (Aletta et al, 2016). The factor, while highly important when gaging comfort, should not be a factor considered by itself. While a space may be considered to have an appropriate soundscape, that does mean the soundscape is therefore considered to be a positive soundscape.

\subsection{Perception of Urban Soundscapes and Landscapes}

Of the five senses, sight and hearing are the largest contributors to sensory experience, with sight being the primary form of information consumption (Agapito et al, 2014). With that in mind, it follows a logical train of thought to believe that sound would affect the perception of the landscape, and that the visual landscape would affect the perception of the soundscape. Bramilla, et al (2013) studied the perception of the soundscapes in three parks located in Rome, Italy. 
Acoustically, the parks would not be considered ideal due to higher noise levels, but survey results indicated that, through the presence of vegetation and green space, the landscape had improved the perception of the soundscape in these urban parks (Bramilla et al, 2013). Other studies support this case through testing different changes in the landscape while leaving the soundscape relatively unaltered (Cerwén, 2016; Jo et al, 2020). On the reverse side of things, while less studied, there have also been documented observations of the perception of landscape being affected by the soundscape. In one study that researched the effects of soundscape perception and preference, participants were shown images of different landscapes with differing audio associations (Hong et al, 2013). Researchers found that the preferences between stimuli that were purely visual and audio-visual stimuli that were created with the sounds of traffic, placed around 55dBA, were rated similarly. But once the volume of the traffic sounds was increased to 70dBA the rating of the audio-visual stimuli lowered dramatically (Hong et al, 2013). Another study showed human walking speed through landscapes has also been linked to quality soundscapes, with more natural sounds showing higher rates at a slower pace (Maculewicz et al, 2016). It is also important to note the effects of appropriateness on the perceptions of the landscape and the soundscape. While appropriateness tends to be more of a factor when considering the perception of the landscape than that of the soundscape (Jo et al, 2020), both can feel its effects. In one study, appropriateness in regards to the landscape was often associated with comfort and, with higher levels of comfort in a space, respondents indicated that they would be more likely to spend time within that landscape (Jo et al, 2020). This tends to show that when a soundscape is viewed as appropriate for the landscape, this can lead to increased amounts of time spent in the landscape. 


\section{$\underline{2.4 \text { Case Study Analysis }}$}

The design of urban soundscapes and landscapes is important for city living, and it showcases the ways different concepts identified in this thesis have been embraced by the design industry. Case studies of urban parks will be explored to gain wisdom from previous applications of landscape architecture that alter the soundscape and could be applicable for future design. These case studies will focus on the overall landscape architectural design of the space, the types of sounds within the space, the strategies used to manage the soundscape, and the methods used to alter the soundscape. By identifying these factors within the case studies, lessons can be learned that can be applied to a sound-based landscape design theory.

\section{Brooklyn Bridge Park, Brooklyn, NY, United States}

Situated along the Easter River, in Brooklyn, NY, this 80+ acre park was designed by Michael Van Valkenburgh Associates. Due to the large footprint of this linear park, sections were created in the form of different piers along the park which were completed at different times. Along Piers 3,4, and 5, a large berm roughly 30 feet tall with a range of widths was built in order to block out the noise from the Brooklyn Queens Expressway. Because of the Brooklyn Queens Expressway, mechanical sounds from cars and trucks are the primary form of noise pollution that this site faces. This major throughway for cars places the decibel level in the nearby area in the 70's-80's, while on the park-side of the berm (Counts et al, 2019). To manage this noise source, defensive and creative styles were used. The defensive management style led to the creation of a substantial berm (Figure 2), which blocks much of the conscious sound from the expressway and lowers the decibel levels to the low 50's-mid 60's depends on the width and materials of the berm (Counts et al, 2019). The berm is composed of structural fill, drainage aggregate, horticultural and planting soil, a wire mesh, and jute, all of which sustain many 
different plantings of trees, shrubs, and perennials (Counts et al, 2019). While the berm succeeds in blocking out the sound from the nearby expressway, it also fosters a new soundscape. Through the fostering of this new landscape, the creative management method is used by extensive plantings, a new soundscape that is filled with the rustling of leaves, birdsong, and other natural sounds. The addition of amenities to the park also functions as a creative management strategy, creating human sounds from children playing and people gathering (Figure 3). As well as sounds of society fill the air through local performances that typically occur throughout the season, as well as through other festivals and events held by Brooklyn Bridge Park.
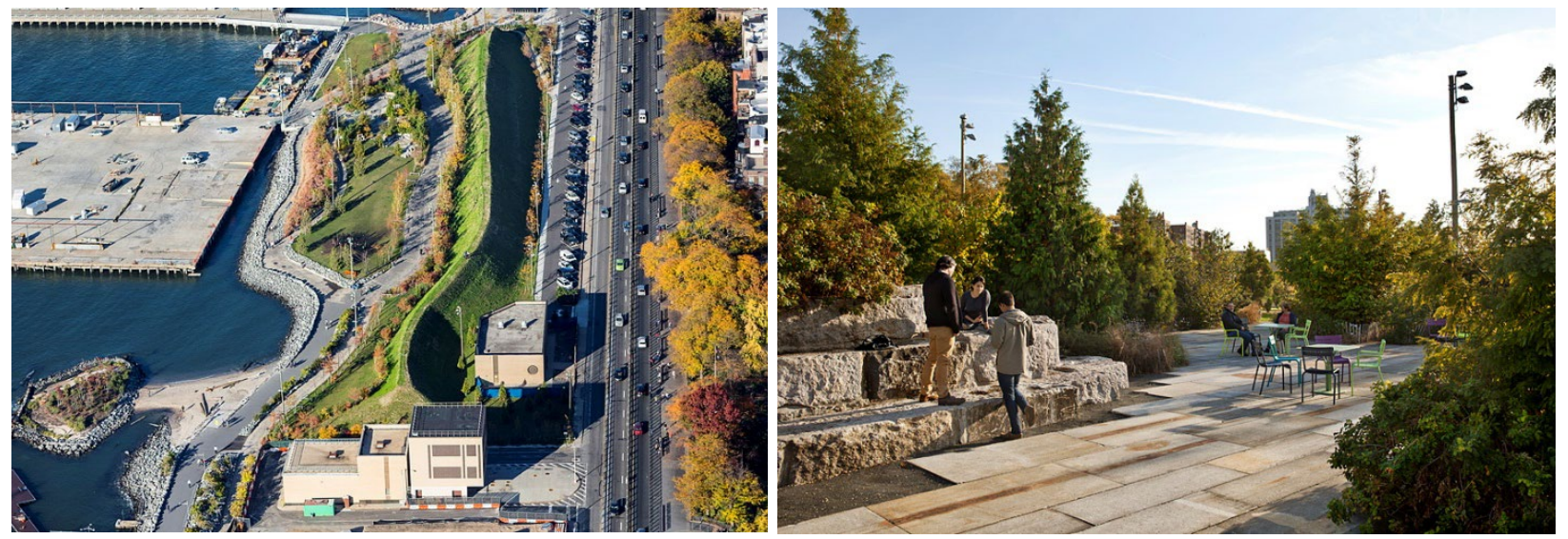

Left: Figure 2: Brooklyn Bridge Park Berm (Michael Van Valkenburgh Associates Inc)

Right: Figure 3: Seating Area in Brooklyn Bridge Park (Michael Van Valkenburgh Associates Inc)

\section{Bryant Park, New York, NY, United States}

Located between $40^{\text {th }}$ and $42^{\text {nd }}$ Streets, and $5^{\text {th }}$ and $6^{\text {th }}$ Avenues, slightly elevated above street level, atop of the stacks of the New York Public Library, sits Bryant Part. This park is primarily comprised of a broad stretching lawn and formal tree plantings. Initially this space was a potter's field in the $19^{\text {th }}$ Century, which would later be renamed after William Cullen Bryant in 1884 (The Cultural Landscape Foundation). After the building of the New York Public Library in the early $20^{\text {th }}$ Century, the space was redesigned by Architect Lusby Simpson in the 1930's 
(The Cultural Landscape Foundation), and then redesigned again by Laurie Olin and Dennis McGlade in 1996. The designs involved the creation of the lawn and tree plantings but with the Olin-McGlade redesign an emphasis on community interaction, programmed activities, and visibility from the street was included. This popular park is used by people throughout the city, attracting visitors from far and wide. Its location is placed in the central area of midtown Manhattan, and from this location suffers from noise pollution created by vehicular traffic, ambulances, and the nearby underground metro system (Counts et al, 2019), showcasing that this site is mostly experiencing noise pollution from mechanical sounds. The decibel measurements taken at street level showed were in the 70s range (Counts et al, 2019). To defensively manage sound pollution, the park itself is raised about 3-5 feet (Figure 4) above street level and is accessible through stairways and ramps at different points in the park. Other defensive strategies include plantings along pathways. The plantings are predominantly comprised of plantings are London Plan Trees (Platanus x acerifolia), these trees grow to be quite large and have dense deciduous foliage. The decibel readings taken at different points within Bryant Park showed to have + /- reading of 20 decibels (Counts et al, 2019). Creative soundscape management was also used through addition of trees as well as the creation of space to foster human engagement have led to the introduction of natural, human, and societal sounds to this urban park (Figure 5). 


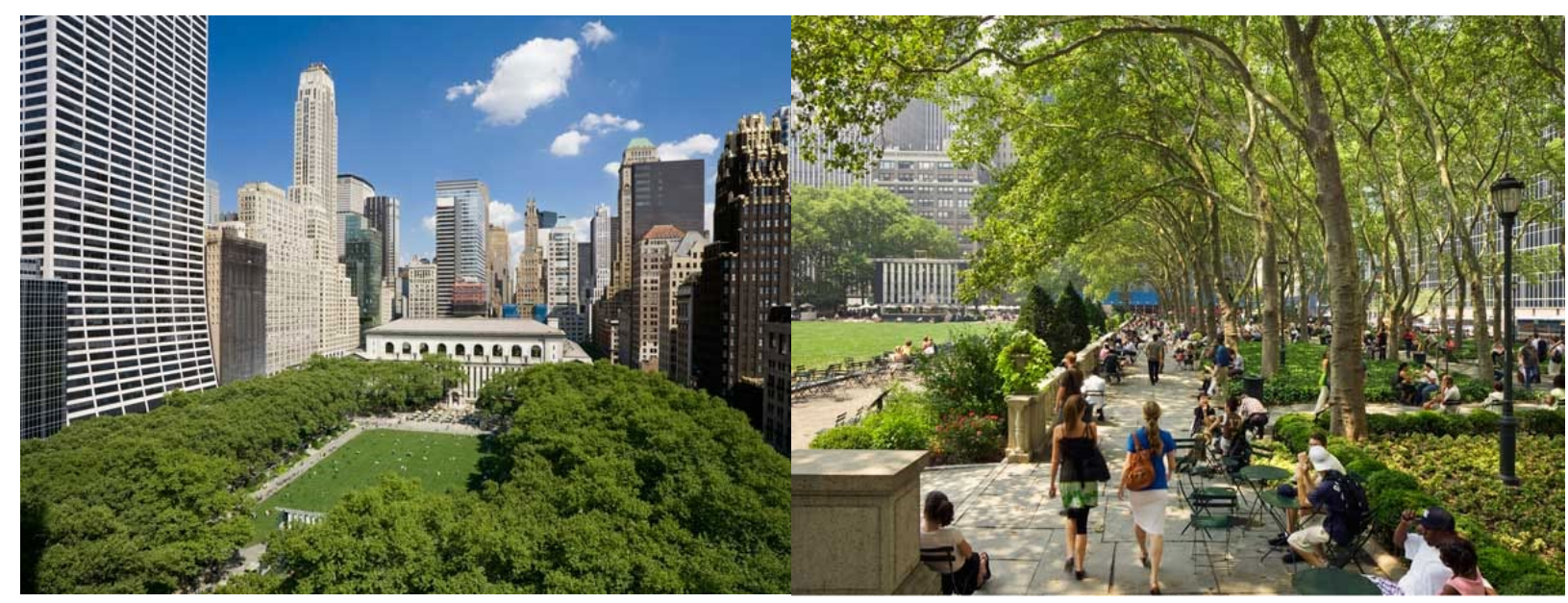

Left: Figure 4: Aerial View of Bryant Park (The Cultural Landscape Foundation)

Right: Figure 5: Seating Area in Bryant Park (The Cultural Landscape Foundation)

\section{Miami Beach Soundscape Park, Miami Beach, FL, United States}

Miami Beach Soundscape Park is located at Washington Avenue and $17^{\text {th }}$ Street in the heart of Miami Beach. This park was created in 2011 and designed by West 8 . Deemed the crown jewel of the urban revitalization plan for Miami Beach, this park was designed to complement the world class attraction of the building for the New World Symphony (west8). The size and shape of the park in an urban setting lends itself to more of a plaza design, but the designers at West 8 created a green space that can function and hold events through day and night. Defensive soundscape management is achieved through the soft, undulating hills of topography (Figure 6). These hills are emphasized through the usage of meandering pathways throughout the park (west8). Palm trees are placed around the park to enhance and conceal certain views, also creating a dappled shade during the day and allowing unobstructed views to the skies in the evening. White pergolas inspired by cumulous clouds (west8) with bright pink bougainvillea vines highlight the entrances and exits to the park. The primary noise source for this urban park is traffic, a sound from the mechanical sound category. The creative soundscape 
management strategy is the main management strategy used in this space. A distinction of this park is the extensive audio and visual systems put into place to allow the park users to listen to high-quality live and prerecorded performances. The Ballet Bar, the Projection Tower, and the Media Hydrants, have been integrated into structures throughout the park, allowing visitors to sit across the lawns and enjoy the performance in any location (Figure 7) (west8). While there have been lesser changes within the park to physically block the sounds from the surrounding streets, masking occurs whenever a performance or sound event is played though the speaker system. Natural, human, and societal sounds have also been introduced into the soundscape both in the day-to-day experience, as well as during sound events put on by Miami Soundscape park.
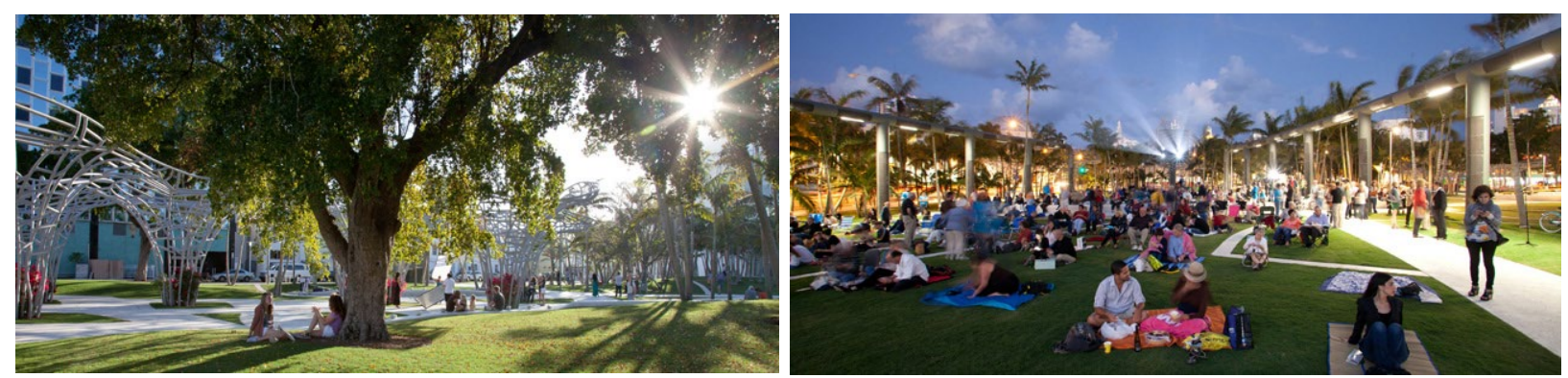

Left: Figure 6: View of Hills in Miami Beach Soundscape Park (west8)

Right: Figure 7: View of Outdoor Theater in Miami Beach Soundscape Park (west8)

\section{Paley Park, New York, NY, United States}

Located on 53rd street in New York, Paley Park, design by Zion and Breen Associates, is an urban oasis from the noisy New York streetscape. After first being proposed at the Architectural League of New York in 1963, Paley Park was built in 1967 as one of the original "vest pocket" parks in New York City (The Cultural Landscape Foundation). Built on the former site of the Stork Club, this site was owned by William Paley and dedicated to his late father Samuel Paley, to be a privately owned public space for the people of New York Coty. Paley 
Park's footprint is $1 / 10$ of an acre and surrounded by walls on three out of four sides.

Mechanical sounds featuring vehicular traffic are the primary noise pollution source. Decibel readings taken on the streetscape just outside of the park were in the 60's-70's, above preferred human decibel levels (Counts et al, 2019). With a slight elevation above street level and the planting of trees, some defensive soundscape management strategies were used. Within this small space is a 20' waterfall that spans the entire back wall of the park (Figure 8). Creative soundscape management strategy was most prominently used in Paley Park, featuring the roar of the waterfall, tree plantings, and the vegetated walls, help to drown out the noise from the nearby street. While the decibel readings taken within the park were like that of the nearby streetscape (Counts et al, 2019), the consistent roar of the water starts to work as white noise establishing a new normal, and therefore an escape for listeners. The natural sounds of water and trees in combination with the human sounds of aural conversation, create a different soundscape from that of the nearby street (Figure 9).

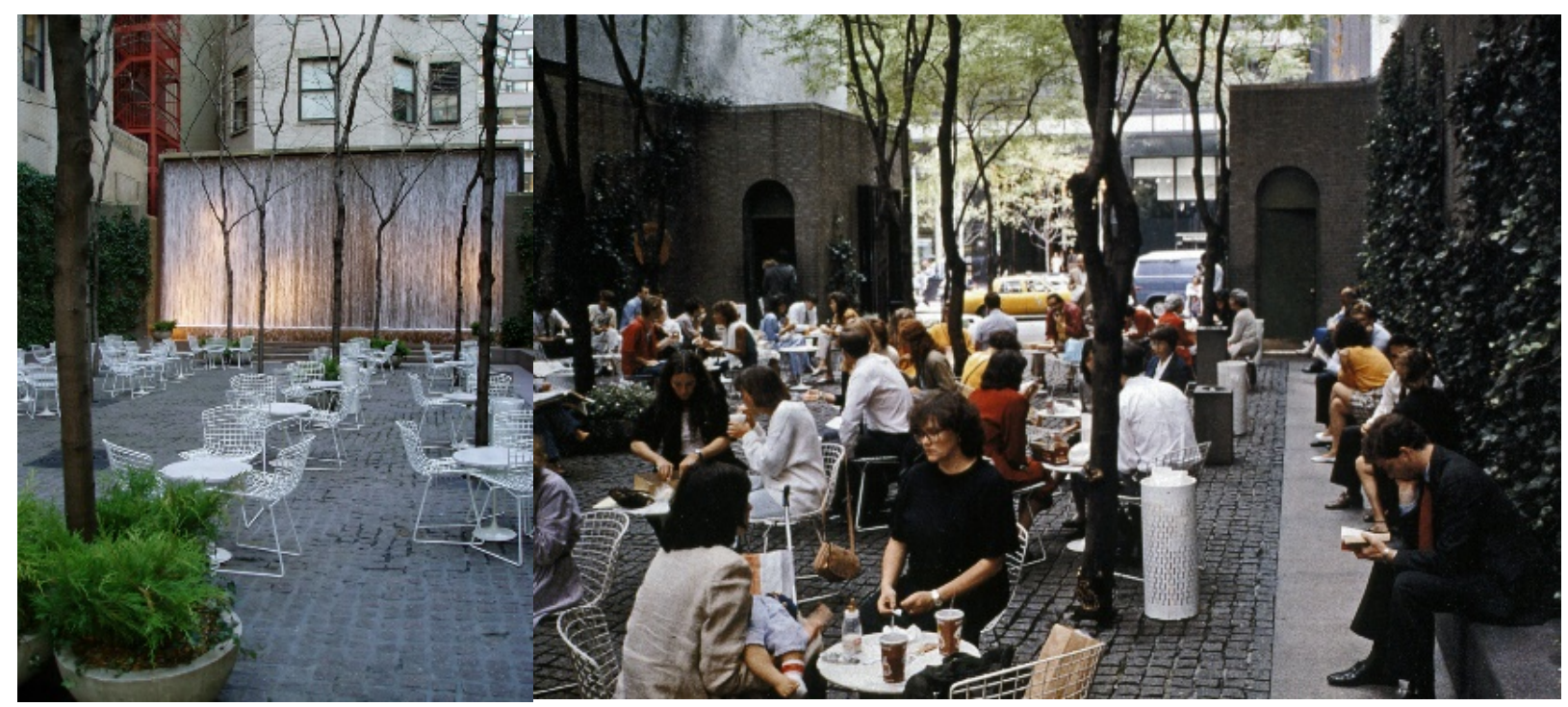

Left: Figure 8: View of Waterfall in Paley Park (The Cultural Landscape Foundation) Right: Figure 9: View of Seating Area in Paley Park (The Cultural Landscape Foundation) 


\section{Soundscape Malmö, Malmö, Sweden}

This “quasi-experiment” (Cerwén, 2016) was implemented in a plaza located in St. Knuts Torg, in a part of Malmö known as Möllevången. St. Knuts Torg is a popular place for people to dine with outdoor seating in the warmer months, while being near a heavily used street for vehicular traffic (Cerwén, 2016). The experiment itself consisted of the creation of a is described as an arbour that blocks the surrounding soundscape, supplying a new soundscape (Figues 10 and 11)(Cerwén, 2016). After blocking some street noise, some user groups experienced recorded natural sounds were filtered in using 6 speakers in the walls of the arbor, playing different loops of natural sounds that lasted 20 minutes each (Cerwén, 2016). Human sounds also filled the space when occupied, adding to the new soundscape. The quasi-experiment was also used to gain data from a survey that included qualitative and quantitative data, looking to gage on the level of human experience within the structure (Table 1).

\begin{tabular}{lcccc} 
& $\begin{array}{c}\text { Sound environment } \\
\text { improved }\end{array}$ & $\begin{array}{c}\text { Sound } \\
\text { environment } \\
\text { unchanged }\end{array}$ & $\begin{array}{c}\text { Sound environment } \\
\text { deteriorated }\end{array}$ & Total \\
\hline Group A. No sound added & $41(42 \%)$ & $49(51 \%)$ & $7(7 \%)$ & $97(100 \%)$ \\
Group B. Forest sounds added & $72(71 \%)$ & $26(26 \%)$ & $3(3 \%)$ & $101(100 \%)$ \\
Total: Groups A and B & $113(57 \%)$ & $75(38 \%)$ & $10(5 \%)$ & $198(100 \%)$ \\
\hline
\end{tabular}

Table 1. Soundscape Survey Responses (Cerwén, 2016)

As shown by Table 1., responses from the survey indicated the structure was effective in changing the perception of the soundscape, both when sounds were added and when they were not. Though it should be noted that the additon of recorded sound correlated with a perceived improvement to the soundscape (Cerwén, 2016). Qualitativly, the addition of sounds seemed to be overall a positive, while some survey responders found that it felt like it was enforcing or creating something that wasn't there (Cerwén, 2016). While the quasi-experiment was only 
installed for a short period of time, the results of the study will have lasting results in the city of Malmö.

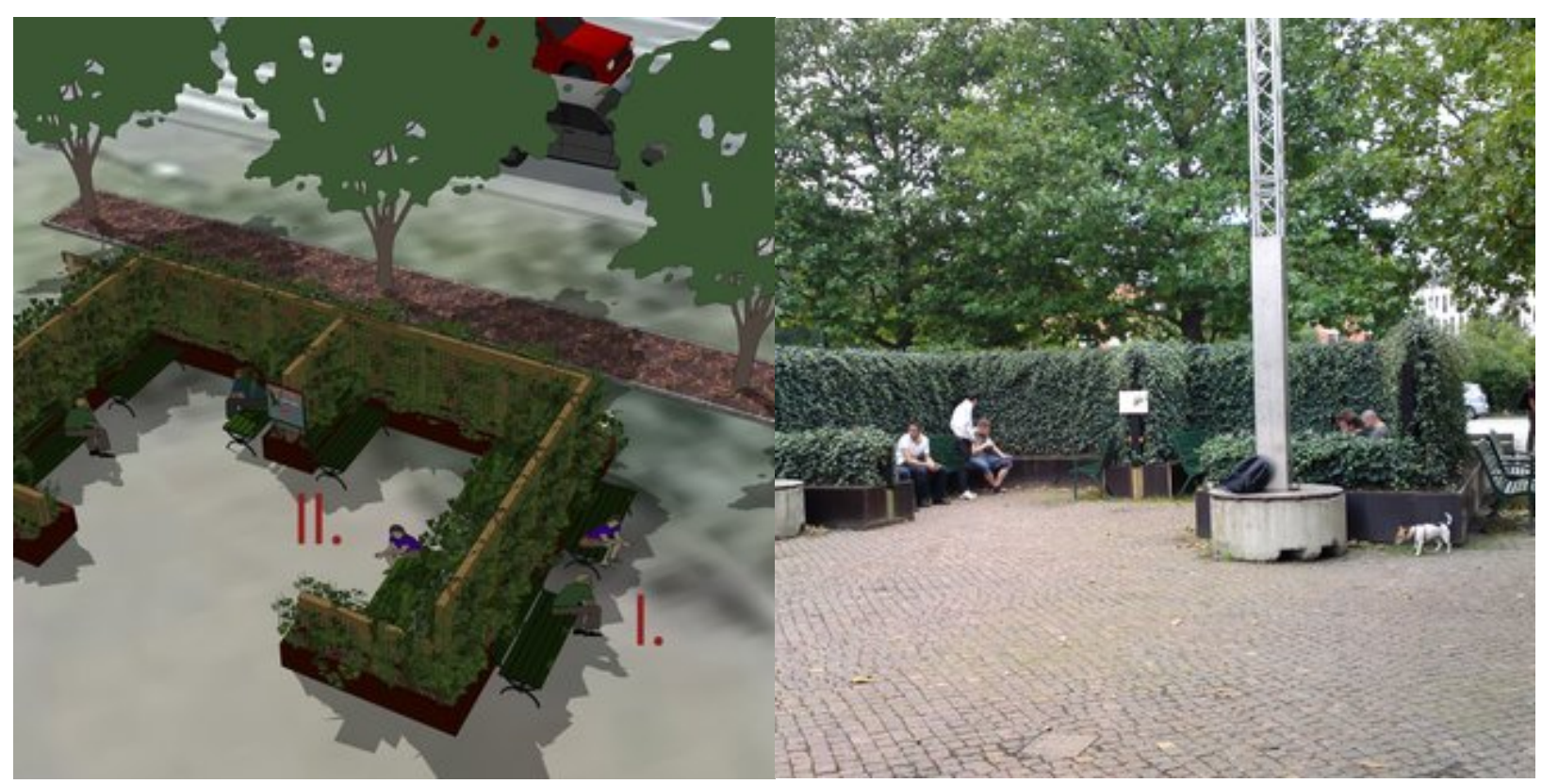

Left: Figure 10: Aerial View Model of Quasi-Experiment (Cerwén, 2016)

Right: Figure 11: View of Quasi-experiment (Cerwén, 2016)

Through the case studies, it can be surmised that soundscape design in urban parks primarily uses two of the three soundscape management practices, defensive and creative management. Within those management types, the strategies for altering the landscape were the following,

- Masking/Covering sounds through the introduction of new sounds (all case studies)

- Blocking/Stopping sounds through the introduction of a structure or change in topography (all case studies)

- Absorption of sound through the usage of different materials (Brooklyn Bridge Park and Miami Beach Soundscape Park) 
Other management types that were not featured in these case studies, but can be seen in management styles that are offensive include,

- Activation and engagement of surrounding sound sources to showcase the unique soundscapes

- Signage to draw attention to certain sounds

\section{$\underline{2.5 \text { Summary }}$}

Through this literature review, definitions of necessary terms have been defined and the contributing fields of Acoustics, Psychoacoustics, and Musical Composition, have been acknowledged. Human sound preferences and the perception based relationships of the soundscape and the landscape have been explored. Finally, case studies have been analyzed with the information established from the literature review. Resulting in a theoretical design framework that can now be applied to design both the soundscape and landscape of urban parks. 


\section{Chapter 3: Site Selection and Analysis}

\section{$\underline{3.0 \text { Site Selection }}$}

To properly showcase the soundscape design theory created from the literature review, site selection was imperative. A set of parameters had to be created to find and select the right site. These parameters were based on four main requirements, proximity to site, noise pollution, site size, and a diverse soundscape.

For the first requirement, multiple trips to the site would be required to fully engage in the soundscape. This would be made more difficult by the COVID-19 Pandemic and would constrict the distances allowed to lower the likelihood of the transmission of the virus. With that in mind, the search was restricted to urban areas in the state of Maryland, and the District of Columbia, as they would both be accessible, and a travel ban between the two was unlikely.

The second requirement, noise pollution. By using the comprehensive noise map created by the United States Department of Transportation, levels of noise pollution created by air traffic and vehicular traffic in Maryland and the District of Columbia were made visible. The focus then shifted towards the cities of Baltimore, MD, and Washington D.C., as they featured high amounts of air traffic and vehicular traffic (Figure 12). 

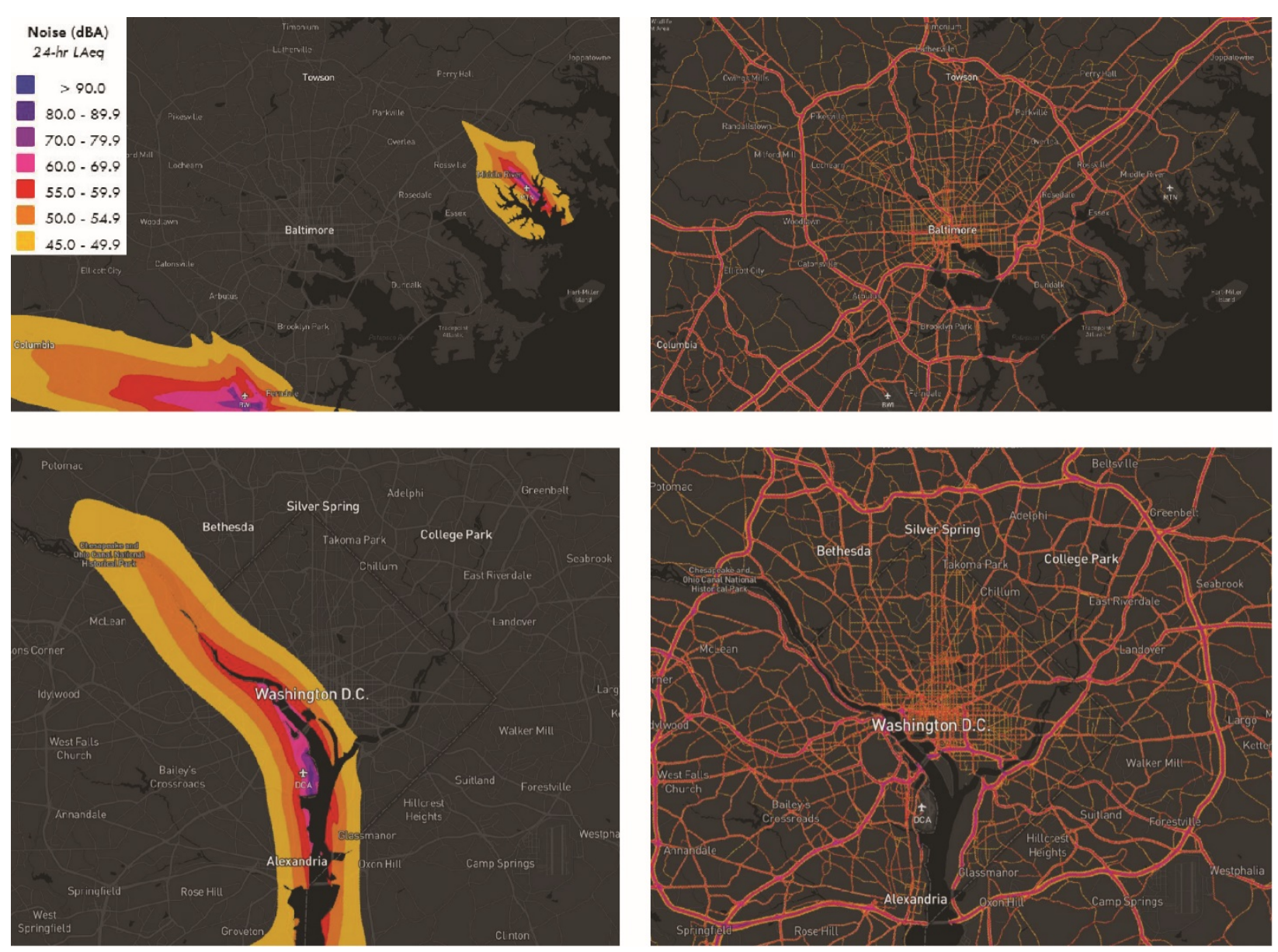

Figure 12: Sound pollution maps of Baltimore, MD, and Washington D.C. (United States Department of Transportation, 2021)

The third requirement, a large space. Given the different types of design for the landscape to alter the soundscape, a larger site would be required to showcase the varieties of alterations. For this step, Google Maps was utilized to locate large green and grey areas within the high noise pollution zones, as shown on the noise maps from the U.S. Bureau of Transportation Statistics.

This produced 5 possible sites (Figure 13),

1. 943-999 Madison Ave Parking and 1000-1098 N Eutaw St Parking

2. The Reach at the Kennedy Center

3. The Kennedy Center 
4. E Street Parks: Rawlins Park, Walt Whitman Park, Triangle Park, \& Bernardo De Galvez Memorial Park

5. John Marshall Park

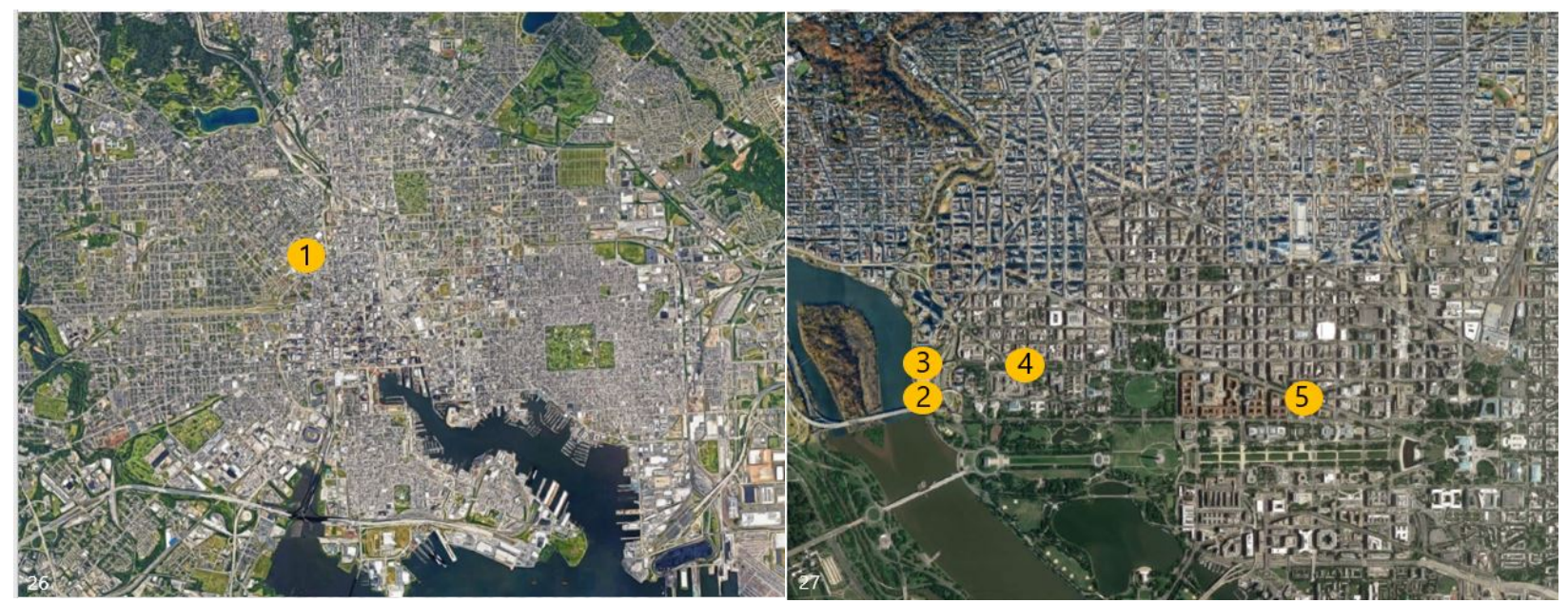

Figure 13: Maps possible sites in Baltimore, MD, and Washington, D.C. (Gray)

The fourth requirement, diverse noises and sounds on site. Once the 5 potential sites had been chosen, further research into site viability was conducted. Immediately site option 1 in Baltimore was removed due to inaccessibility as well as constrictive soundscape conditions. From then on, site visits to the remaining 4 site options in Washington D.C. were conducted so that the soundscape could be experienced in person. Site options 2, 3, and 4, showed promise and featured a variety of sounds. Upon visiting site option 5, construction through the space was apparent. This immediately removed site option 5 from consideration, leaving site options 2, 3, and 4. Ultimately, site options 3 and 4, the Reach at the Kennedy Center, the Kennedy Center, and the E Street Park System, including Rawlins Park, Walt Whitman Park, Triangle Park, and Bernardo De Galvez Memorial Park, were selected for the site for this thesis (Figures 14 and 15). 


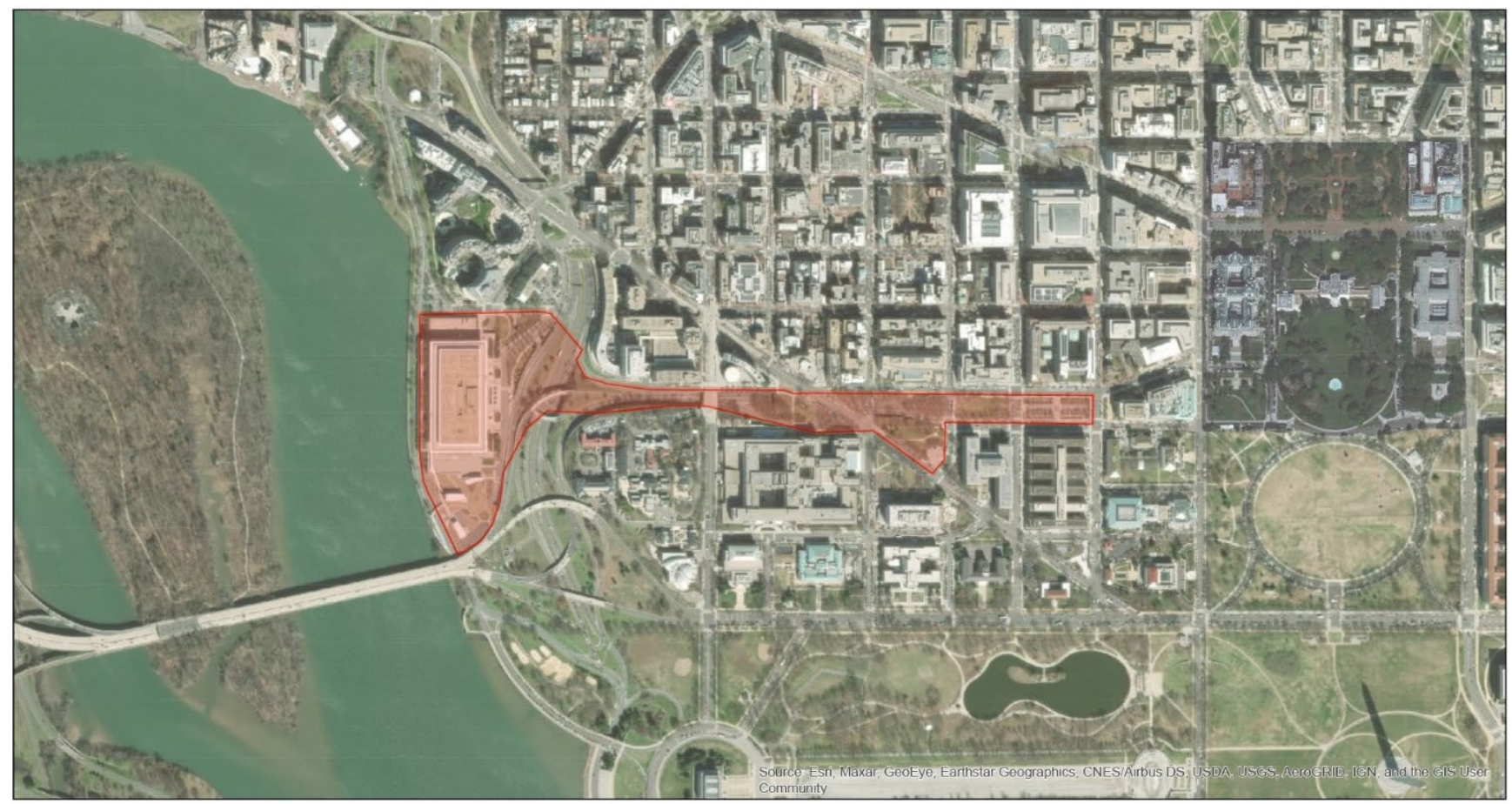

1 inch $=750$ feet \begin{tabular}{lllll}
0 & 375 & 750 & 1,500 & 2,250 \\
\cline { 2 - 2 } & & &
\end{tabular}

Figure 14: Map of Site (Gray)

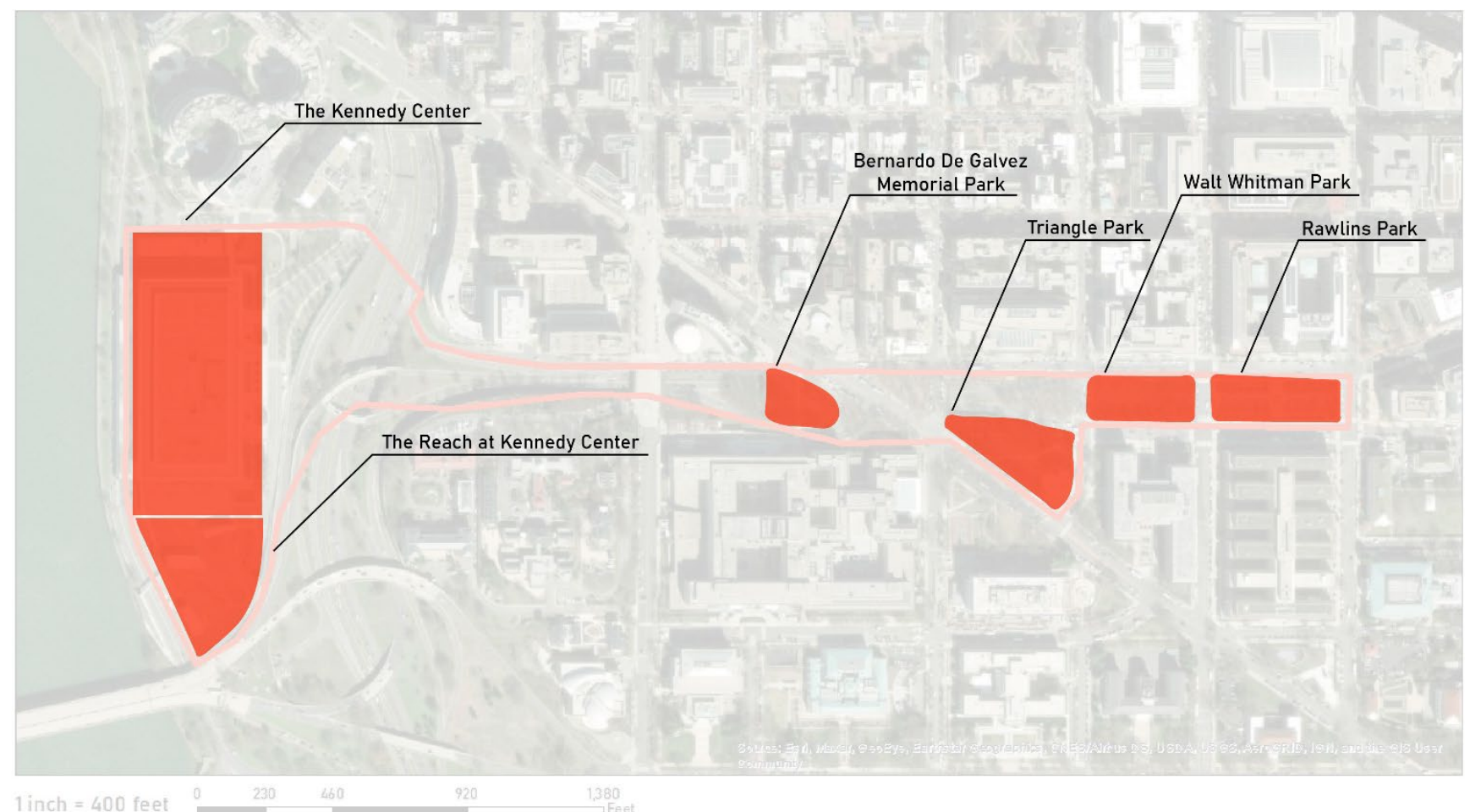

Figure 15: Site with Labeled Spaces (Gray) 


\subsection{Site Inventory and Analysis: Large Scale Thinking}

Location: This site of this thesis within District of Columbia is unique to the city that functions as the US capitol. Located 2 blocks north of the National Mall, and 2 blocks west of the White House, there is strong connection to the federal government with additional federal buildings edging the southern and eastern edges of the site (Figure 16). Other institutions such as George Washington University (GW), the headquarters of the American Institute of Architects (AIA) located in the Octagon House, and the National Park Service (NPS), all have land within the boundaries of the site or on the border of the site (Figure 17).

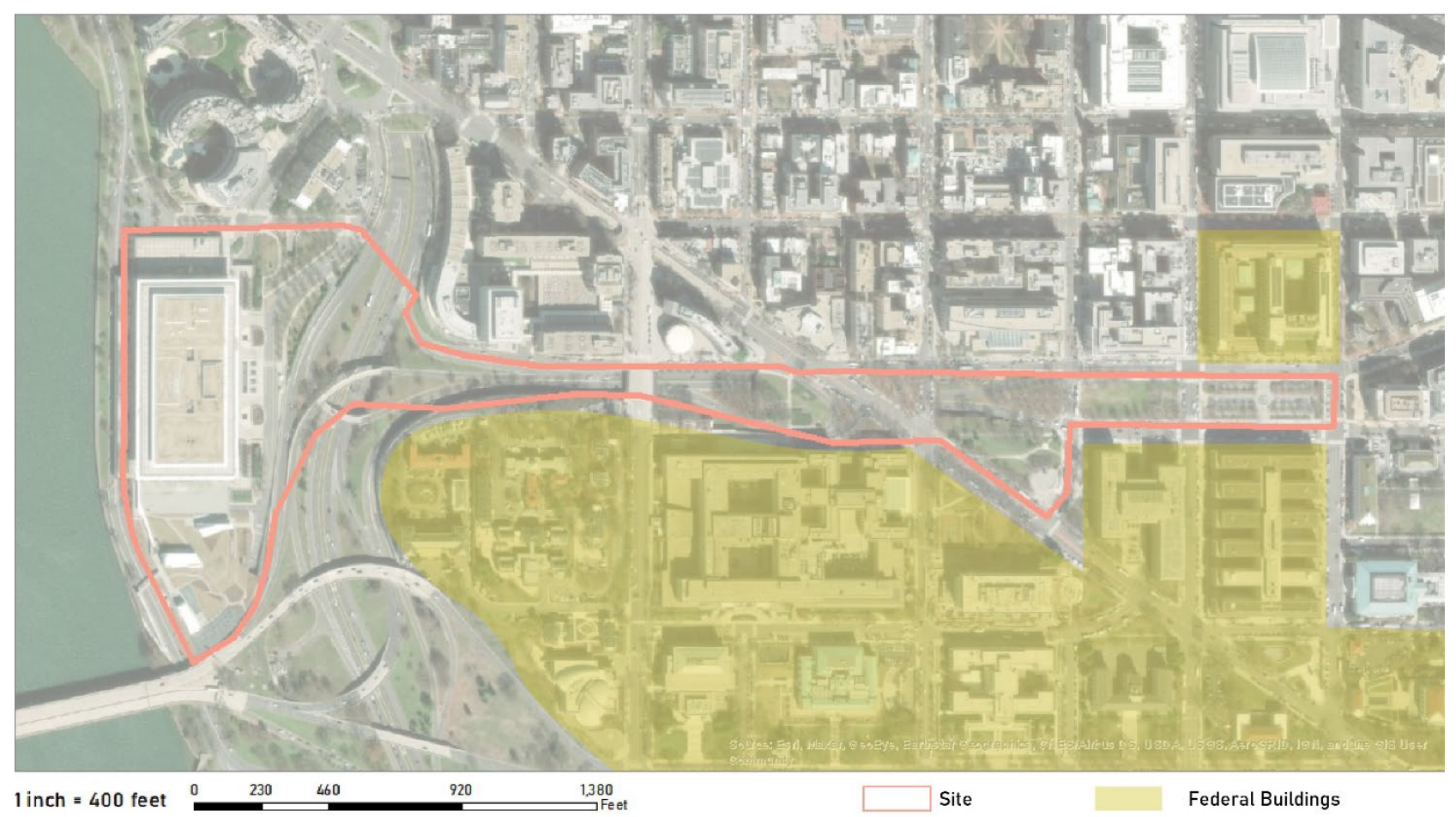

Figure 16: Map of Federal Buildings Near Site (Gray) 


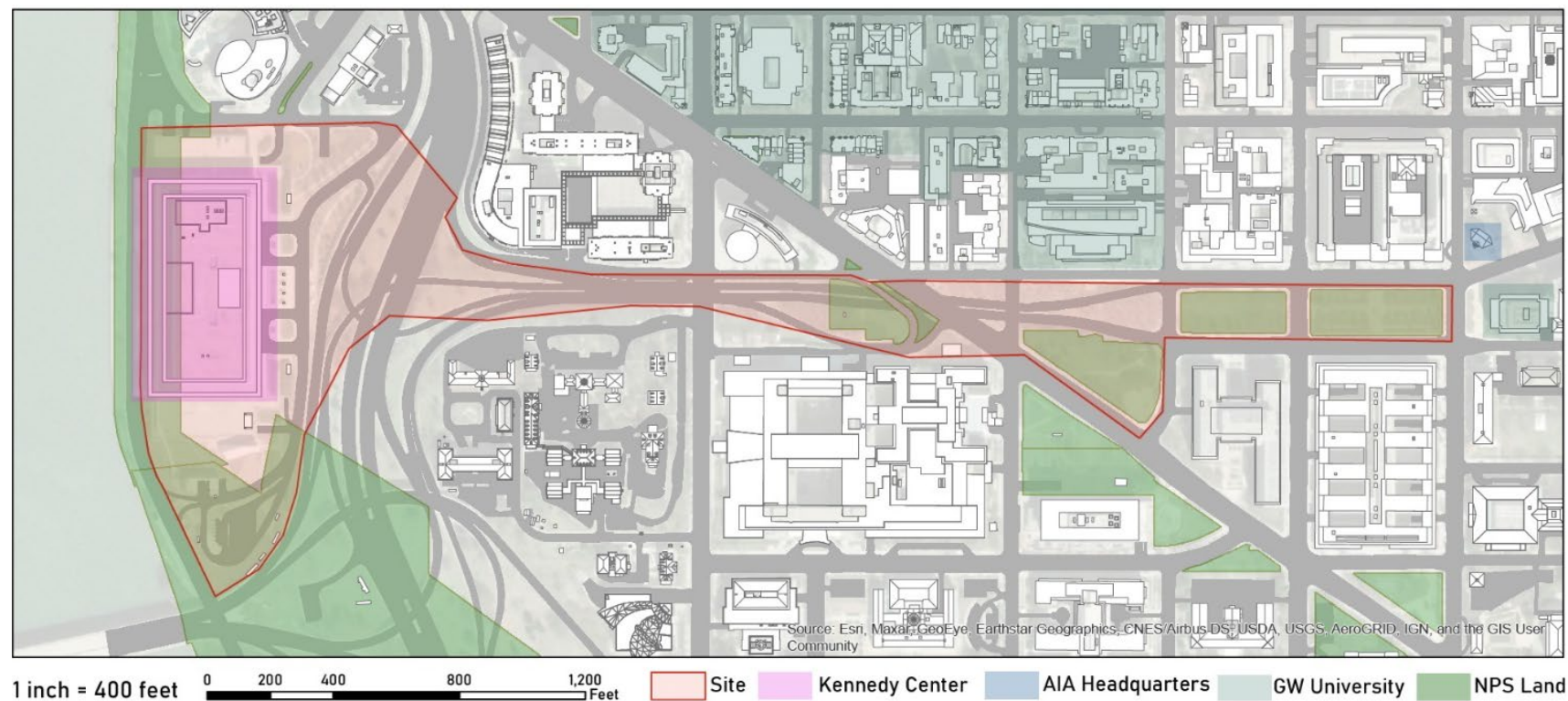

Figure 17: Institutions on and Near Site (Gray)

These institutions function as indicators of possible sound sources as well as user groups for the space. This information became particularly important for this thesis, as during the COVID-19 Pandemic the soundscape and users of the space had likely been altered from what had been prepandemic.

Connecting the Kennedy Center: Information gained from the knowledge of the site's location became essential when looking to professionals for information and guidance through this process. Through learning that Rawlins Park, Walt Whitman Park, Triangle Park, and Bernardo De Galvez Memorial Park, were a part of the National Park Service, more information was acquired with conversations from people from the National Park Service. One such conversation led to multiple discoveries about plans for the site, as well as plans regarding the Kennedy Center and the Reach at the Kennedy Center portions of the site. After the E Street Corridor and the Kennedy Center were marked as high priority in multiple reports from the National Capitol Planning Commission $(1997 ; 2001 ; 2009)$, and U.S. Department of 
Transportation in combination (2001) with other agencies completed a study that worked to better connect the Kennedy Center to the E Street Park system. As shown in figures 14-17, the E Street Park system and the Kennedy center suffer from separation due to the placement of Route 66. This multi-lane highway creates a depression in the land and an impassible barrier for pedestrians and potential users of either space. The previously stated reports and studies from governmental agencies took interest in this issue, and through this interest plans were created for the Kennedy Center. A design from Rafael Viñoly Architects was chosen to accomplish the goal of connecting the Kennedy Center (Figure 18). The main way Viñoly's plan connects the Kennedy Center to the E Street Park system is through a bridge built over Route 66, resulting in a viable pathway for pedestrians and vehicles from the Kennedy Center to the rest of Washington D.C. (Figure 19).

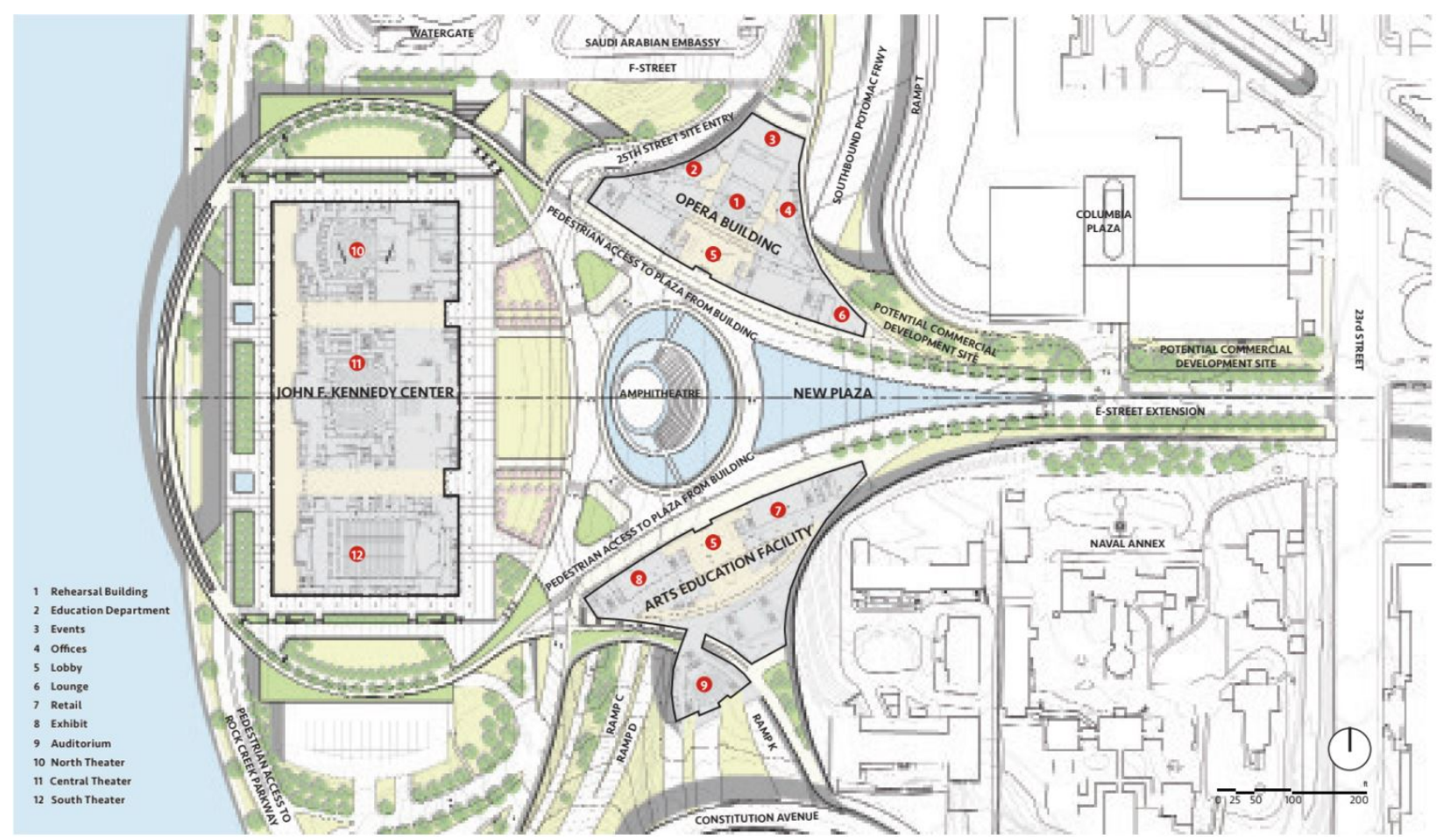

Figure 18: Viñoly Plan for the Kennedy Center (Reprinted with permission from Rafael Viñoly Architects) 


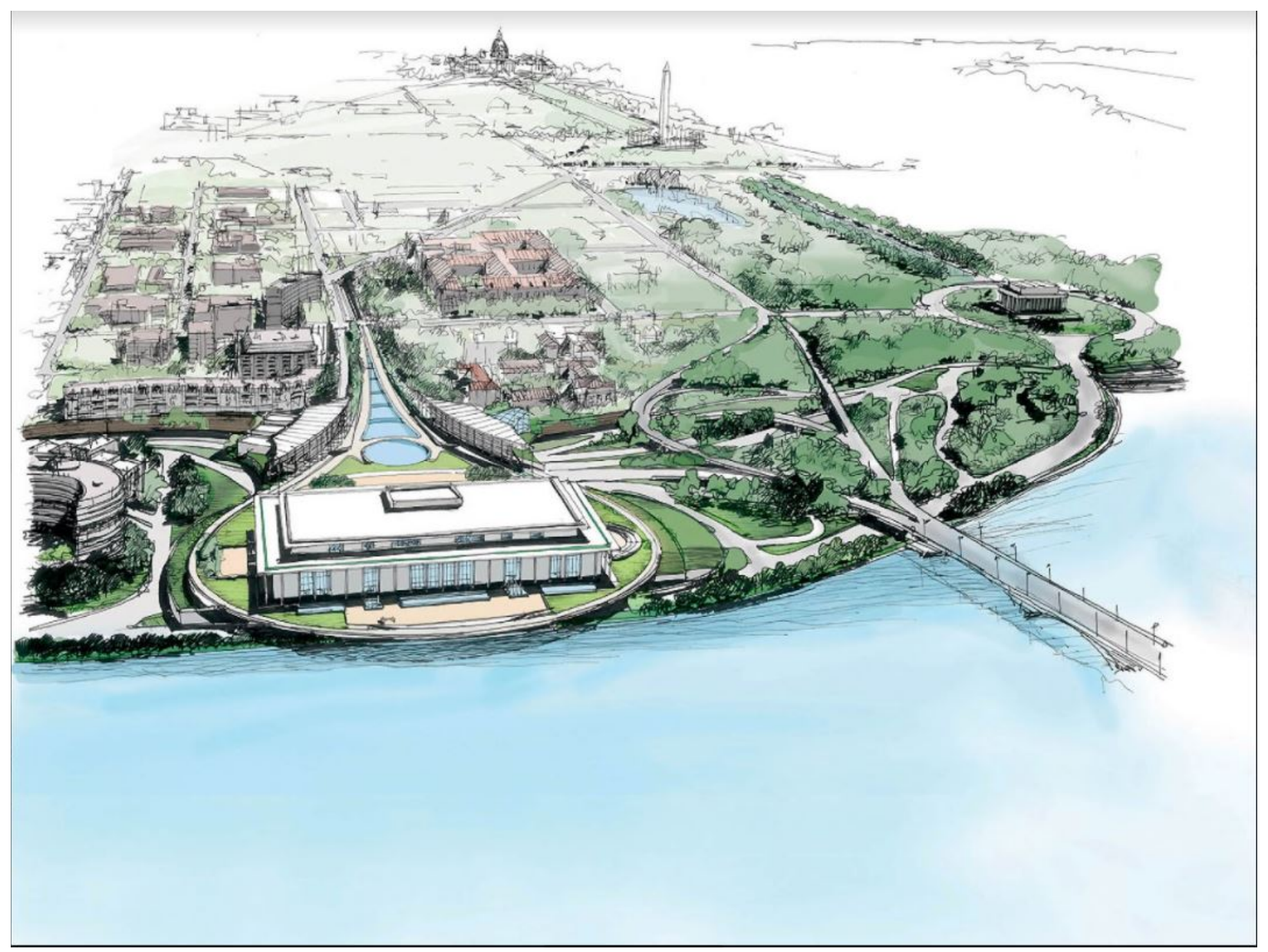

Figure 19: Aerial Perspective of Viñoly Plan for the Kennedy Center (Reprinted with permission from Rafael Viñoly Architects)

Ultimately the plan was stopped in 2005 after funding was cut (Pogrebin, 2013), but in 2013 a new plan to expand was created by Steven Holl Architects, resulting in the Reach at the Kennedy Center. The addition was finished in 2019 and extends performance spaces and outdoor spaces on the southern side of the Kennedy Center (Figure 20). While accomplishing that feat, The Reach at the Kennedy does not address the circulation issues that the plan from Rafael Viñoly Architects succeeds in doing.

Connecting the Kennedy to the E Street Park system also creates an interesting sound association for this thesis site. The Kennedy Center and the Reach at the Kennedy Center are places of performance, and frequently musical performance. The design implications of creating 
physical connections between two different types of space for showcasing sounds is something to further explore. Because of the level of detail available and time available for this thesis, the Viñoly plans for the western portion of the site will be combined with the Reach will be used, leaving the E Street Park System as the primary focus for further analysis and design (Figure 21).

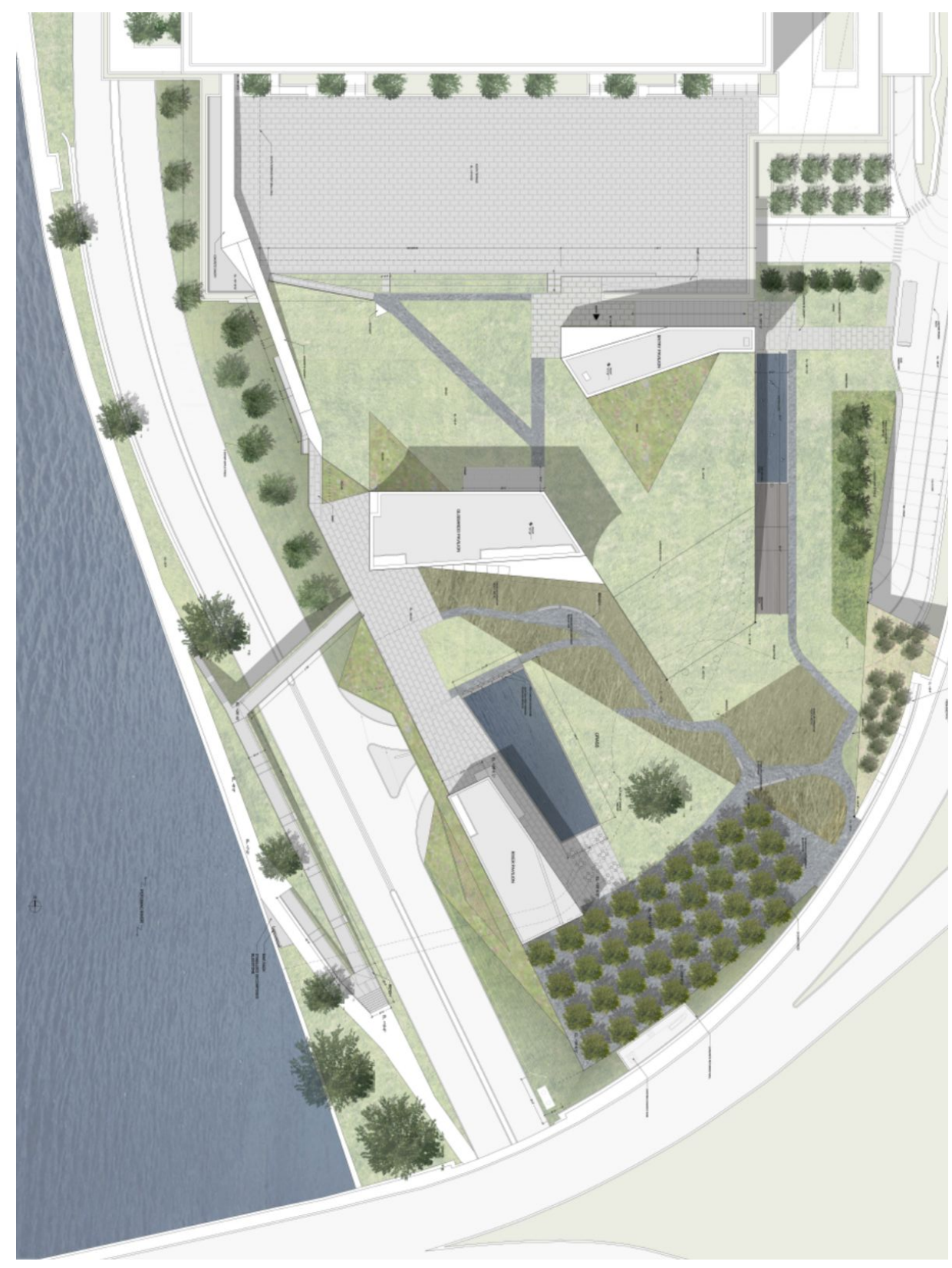

Figure 20: Plan for the Reach at the Kennedy Center (The REACH) 


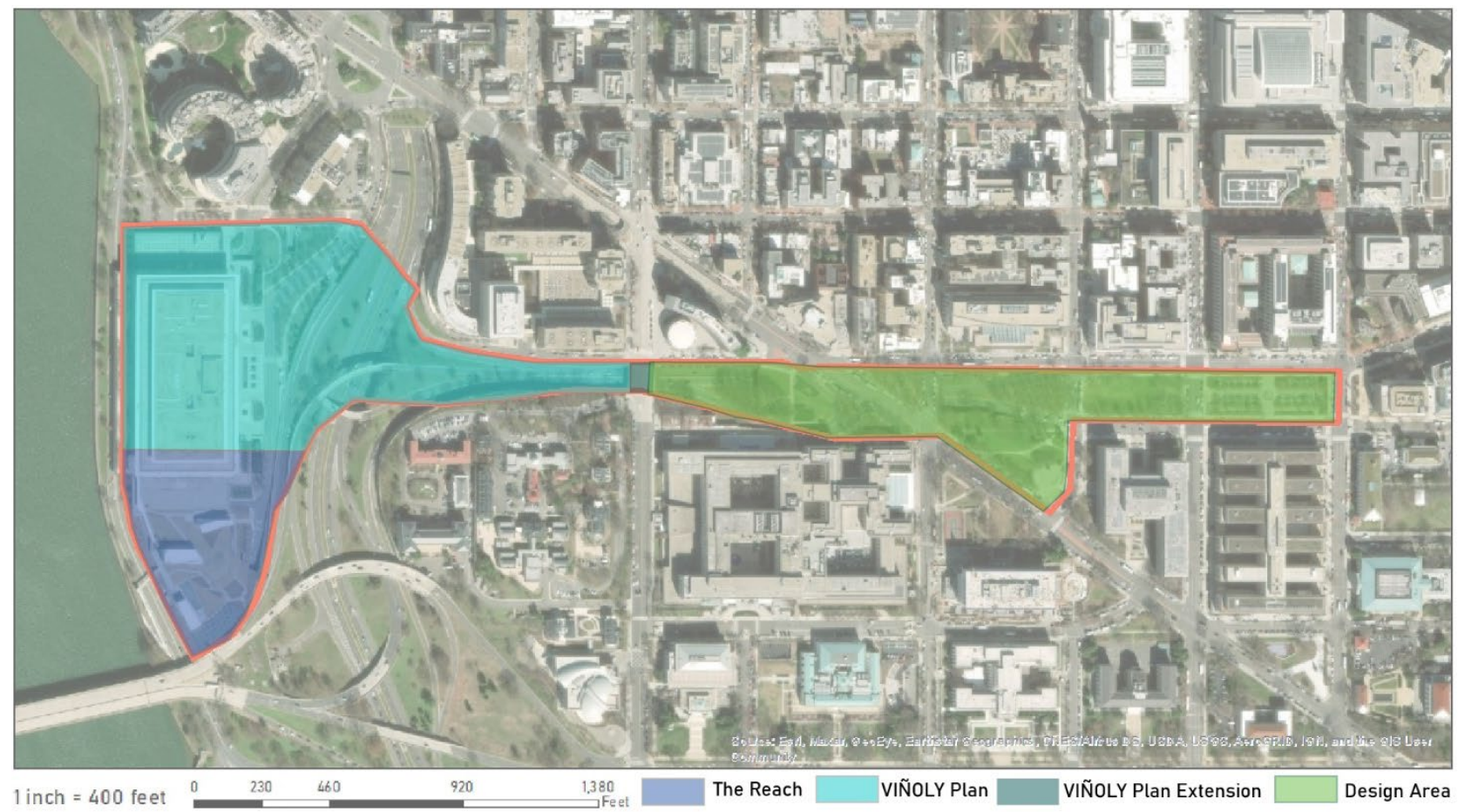

Figure 21: Map of Design Boundaries (Gray)

Roadways: Roadways divide all portions of the site (Figure 24), turning the space into a series of city blocks. E Street runs along either side of the E Street Park System. The park system divides E street into two, with westbound traffic north of the parks and eastbound traffic south of the parks, cutting off the parks from nearby buildings by as much as 5 traffic lanes at its widest, or as little as 2 lanes at its narrowest. Substantial roadways occur in the western portion of the site. Route 66 being the largest roadway and causing the most separation, cutting the Kennedy Center off from the E Street Park System. In the central portion of the site, the E Street Expressway begins, just west of Walt Whitman Park, heading west as it descends below street level and merging onto Route 66. On grade and above the E Street Expressway, Virginia Avenue 
cuts diagonally across the site creating an important connect to the National Mall, and a visual connection with the Washington Monument. The urban planning challenges include addressing connectivity and pedestrian safety. While the soundscape challenges will need to address the sounds from vehicular traffic.

Topography: Topography and enclosure are important to inventory as the shapes formed by the topography of the spaces will guide effect the direction and volumes of the sounds in the soundscape. The topography of the site features a complicated relationship between street level roadways and parks, and depressions for roadways such as the E Street Expressway and Route 66 (Figure 22). The highest elevation for the site is in the central portion, right before the E Street Park System ends, and the elevation drops for the meeting of the E Street Expressway and Route 66. From east to west, barring the depressions for the roadways, the slopes of the site are mild with movement through the space being relatively easy. On the eastern portion of the site, in Rawlins Park and in Walt Whitman Park, the northern sides of the parks are about 10' higher elevation than the southern sides of the same parks.

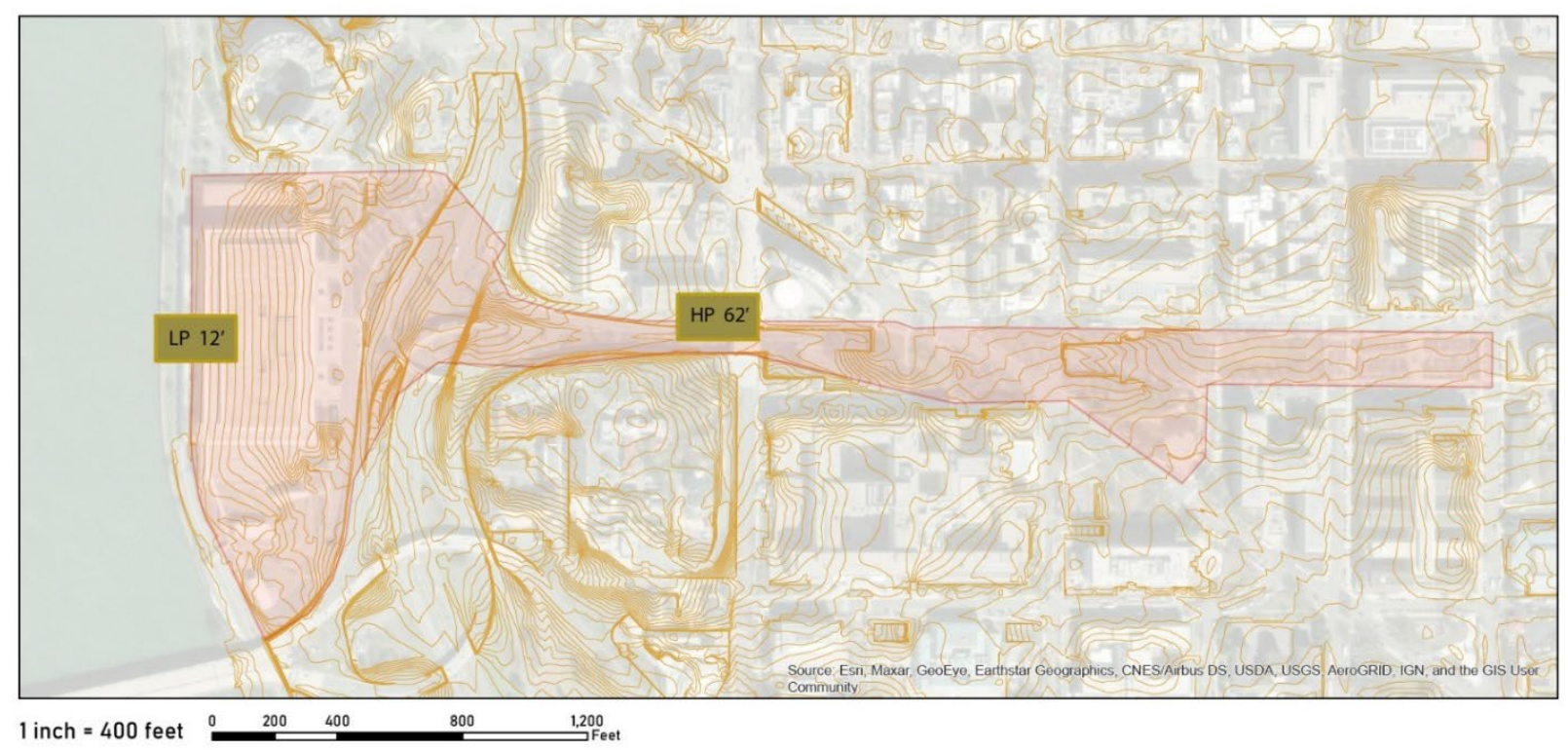

Figure 22: Topographic Map of Site (Gray) 
Enclosure: The distance of buildings between the north and south sides of the site are over 300 ' feet apart. Building heights surrounding the site do not exceed 10 stories, with most of the surrounding buildings topping off at 8 stories high (Figure 23). In the central portions of the site, in Walt Whitman Park, Triangle Park, the entrance to the E Street Expressway, and near the bus stations off Virginia Avenue, mature trees stand tall with wide spreading crowns (Figure 24). These trees are primarily Quercus $s p$. and create dense canopy coverage. While not severe, these factors will work to enclose the sounds from nearby roadways and overhead air traffic amplifying the noise.
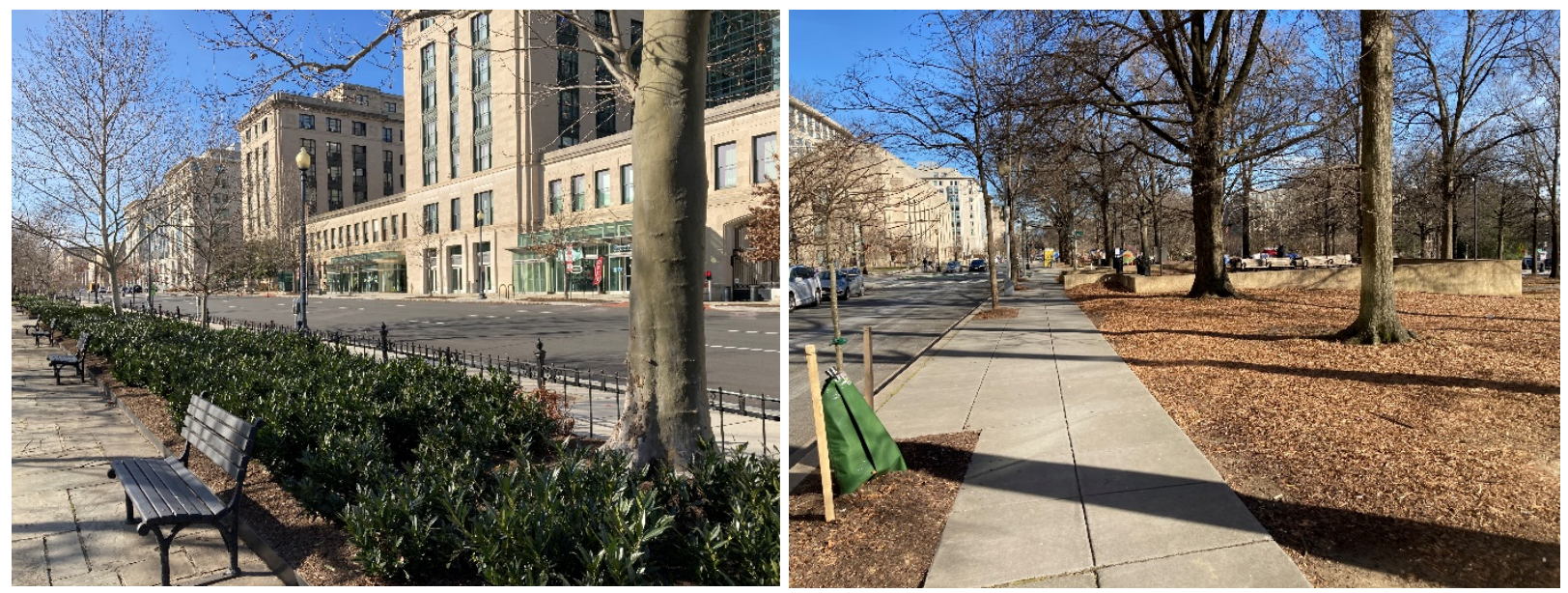

Left: Figure 23: Image of Building North of Rawlins Park (Gray) Right: Figure 24: Image of Existing Trees Near Bus Stations off Virginia Avenue (Gray)

Public Transportation: Public transportation access to the site is fair, but not ideal for a city (Figure 25). Three Metro lines run north of site, with only one Metro Station in a four-block radius from the site. Bus stops line eastbound E Street, with a substantial number of stops located at the intersection of E Street and Virginia Avenue creating a hub. Given this information, 
sounds from buses will primarily occur in the areas around Virginia Avenue, and to a lesser extent from the southern boundaries of the site.

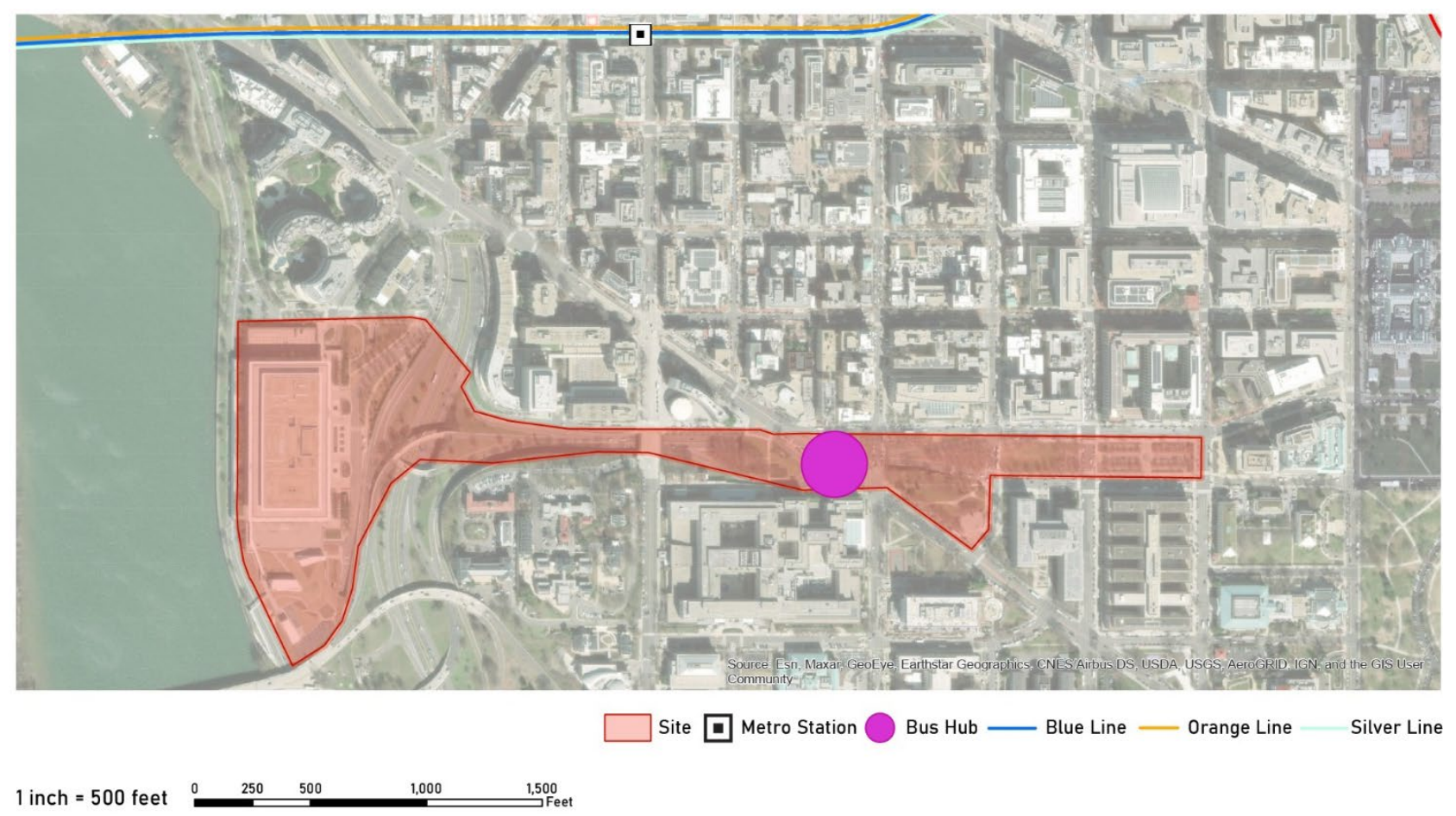

Figure 25: Map of Public Transportation (Gray)

\subsection{Site Inventory and Analysis: Establishing a Method to Document Existing Soundscape}

With the western portion of the site's design settled through the Viñoly plans, the E Street Park System was the focus for soundscape inventory and analysis. To successfully complete this task, it was decided that personal site visits, visual graphics of the soundscape, and audio recordings, would be required.

Site Visits: Initially this process began by making multiple in-person trips to the E Street Parks System. Clairaudience was used to gain an idea of the types of sounds that occurred in those soundscapes so research could be done to find the best way to visually document the soundscape. This resulted in the decision to visually document the soundscape in two ways. One 
showcasing the soundscape for a moment on the borders of the parks, and the other documenting the soundscape for an extended period in the centers of the parks. Additionally, these visits inspired the urge to create audio recordings of the parks for posterity of the current soundscape.

Graphic Notation: To visually express the soundscape as it currently exists in the site, a hybrid method of existing and newly created graphic styles was used. In researching ways to display sound, four sources became integral in deciding the method to use. The first source was the standard notation used in Western Classical Music (Figure 26). The benefits from this style notation are the flexibility to allow multiple sound sources to be notated, while using descriptive and simple symbology spread arranged in a manner that indicates the passage of time. The problem with this notation lies with the limited meanings of the symbology that would not be able to fully describe sounds outside of a purely musical vocabulary.

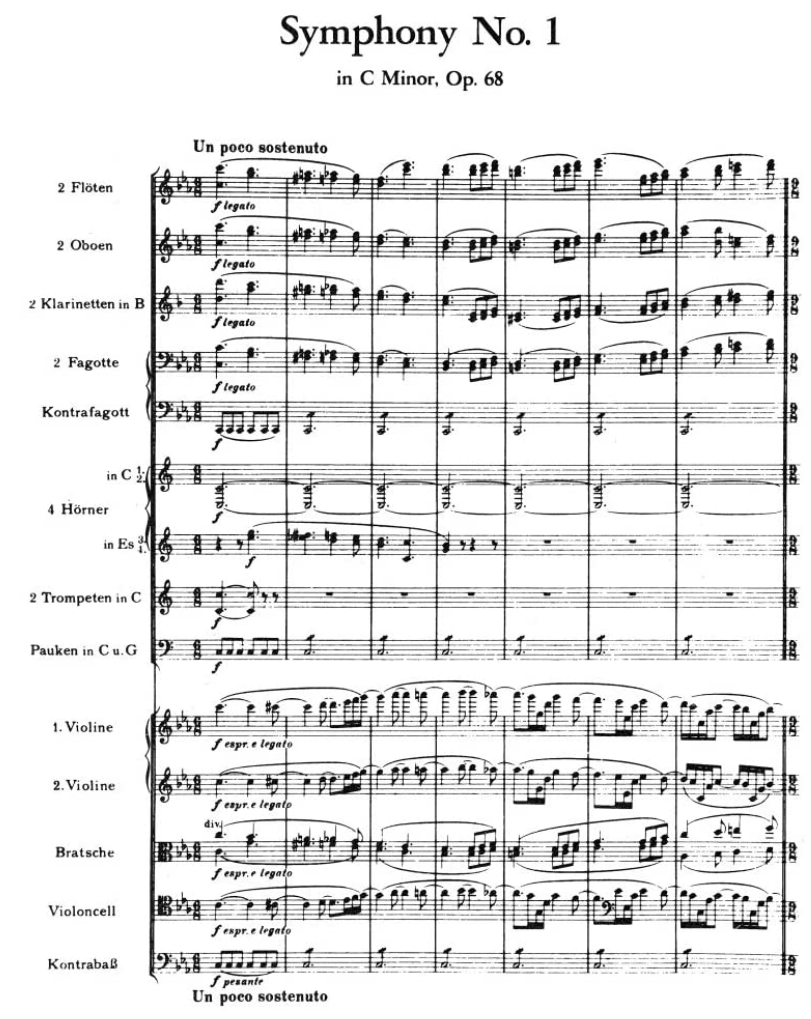

Figure 26: Brahms Symphony No. 1. (Brahms, 1876) 
The second source that was analyzed were the graphic scores of John Cage. Cage's work as an experimental composer pushed the graphic representation of sound in western music as Cage pushed the definitions of music itself. Because of this process, his scores range greatly in terms of visuals, depending heavily on when they were composed and the intent of the composition. While the scores helped to expand the visual and aural vocabularies, his style would not be appropriate for soundscape documentation for two main reasons. The style first represented looks like that of Western Classical Music notation (Figure 27) and suffers from similar issues. While the style of notation that would be considered a graphic music score (Figure 28 ), is too complex and illegible to the common reader.

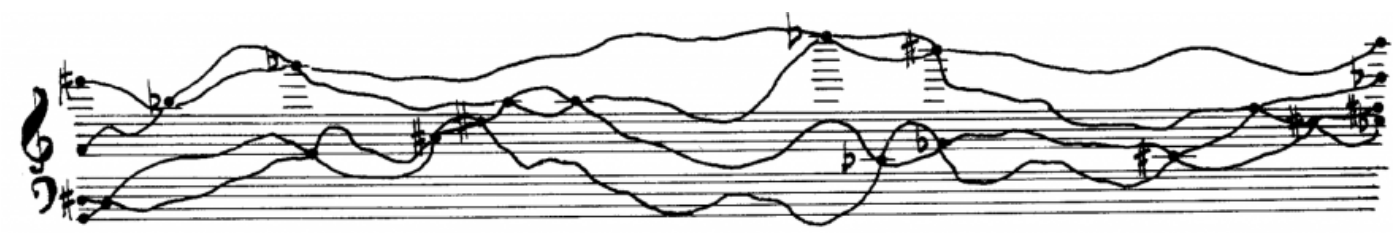

Figure 27: Score of Solo for Piano (Cage, 1958b)

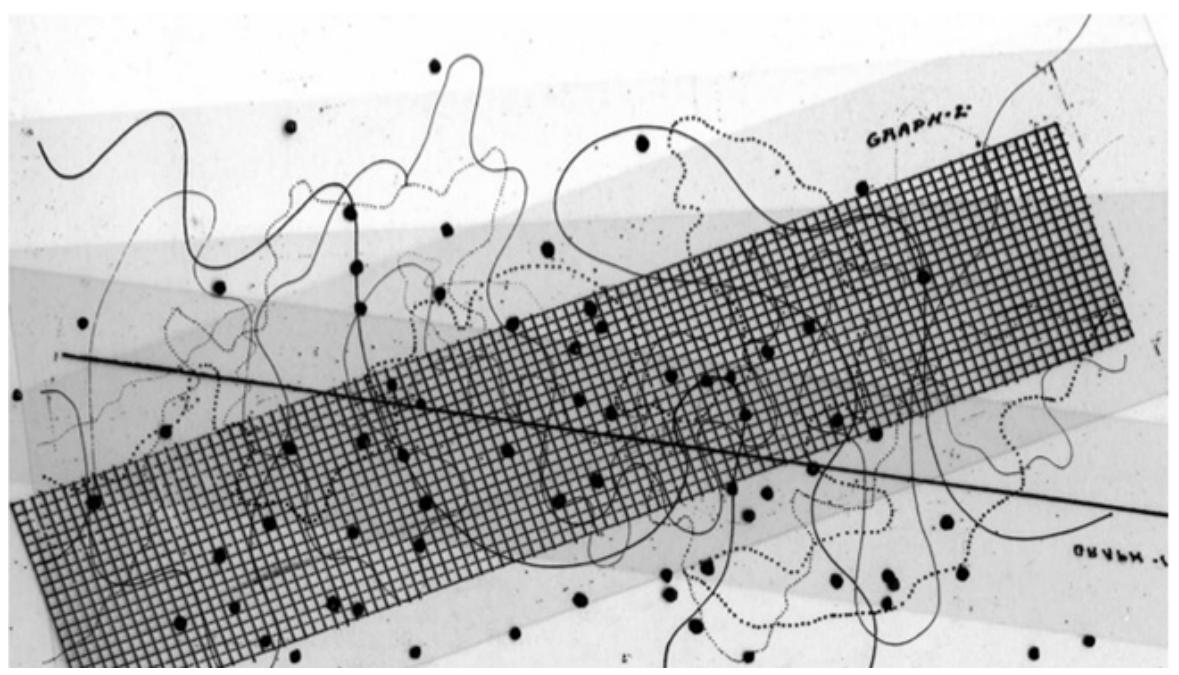

Figure 28: Score of Fontana Mix (Cage, 1958a) 
R. Murray Schafer was the third source for graphic representation. While establishing vocabulary and cornerstone theories in the soundscape field, he also created methods to visually explain sounds in several ways. One of his methods created a symbology that clearly showcases a way to visually describe all features of a sound (Figure 29). This symbology while exceedingly clear and descriptive, becomes too complicated when factoring in multiple sound sources possibly occurring at the same time. Another method Schafer created documents the relative volumes of sound sources around the perimeter of a site (Figure 30). The example shown legibly states the sound sources and their relative volumes, some of which are shown to be lumped together in groupings like that of his 6 sound categories.

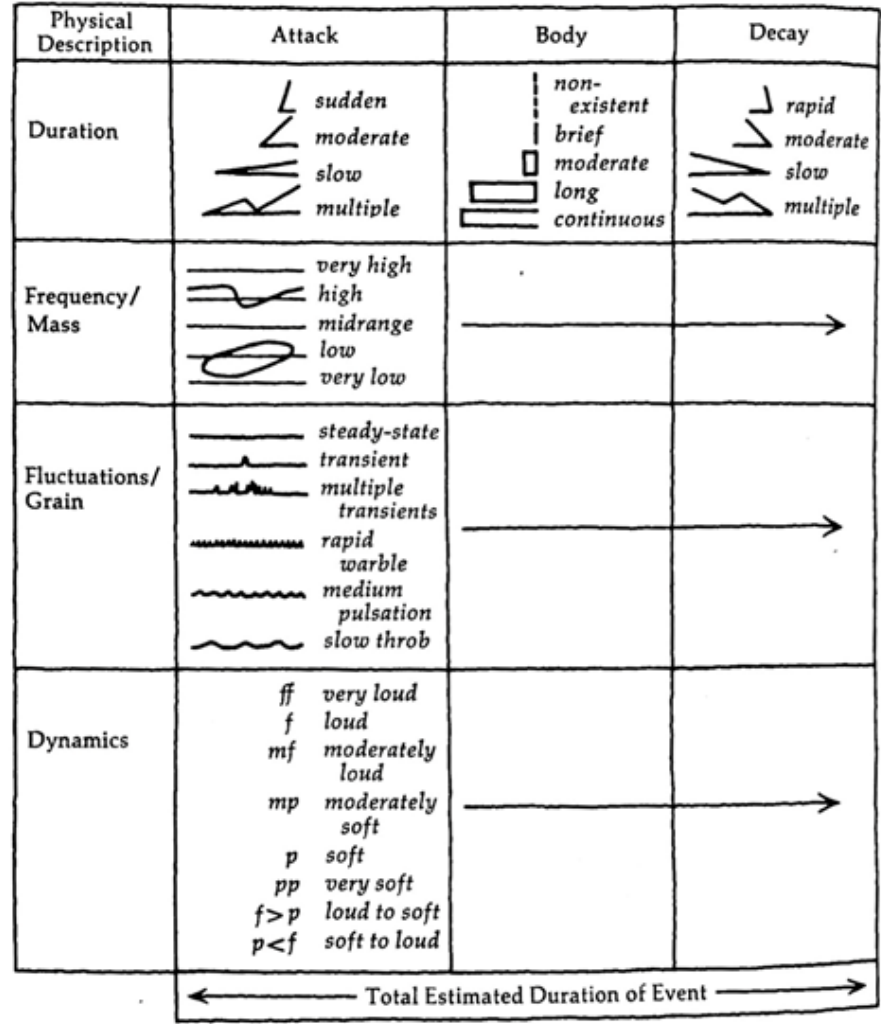

Description of a sound event.

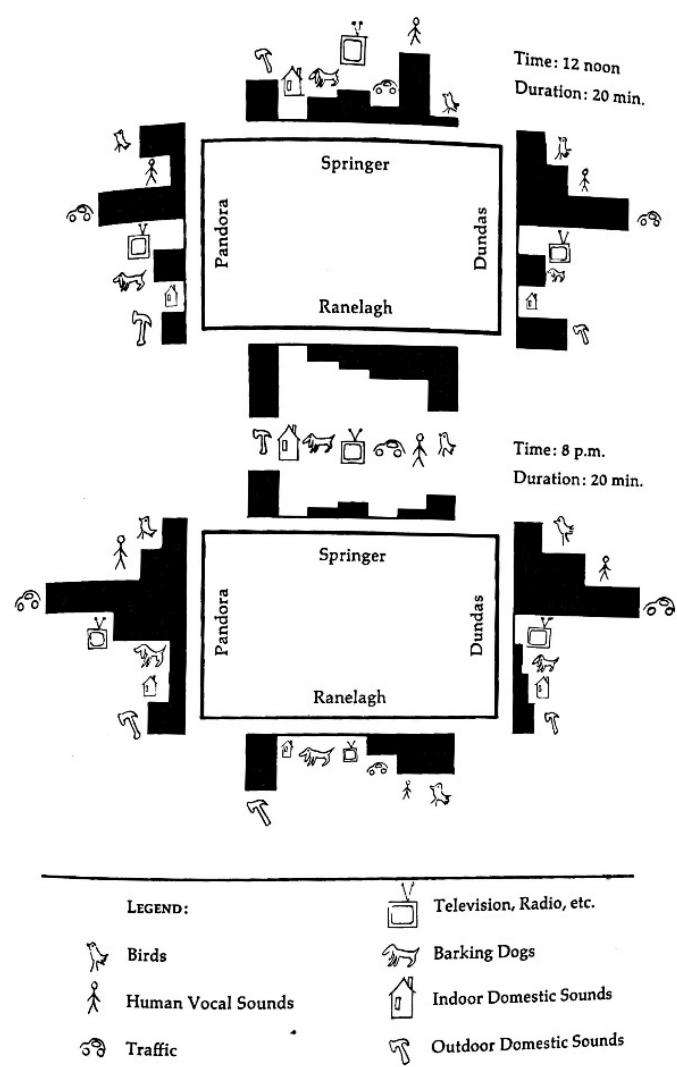

Left Figure 29: Schafer's Visual Descriptions of Sounds (Schafer, 1977)

Right Figure 30: Schafer Sound Map (Schafer, 1977) 
The final source of graphic representation for the soundscape is Landscape Architect, Lawrence Halprin. Halprin was a master in both Landscape Architecture and graphic communication, focusing much of his design work on theories associated with dance and movement. As theories in movement and dance were not commonly associated with the field of Landscape Architecture, Halprin created his own graphic system. An example of his work (Figure 31) shows the movement of water in a fountain. This example successfully shows movement and time in a legible manner and is simple enough to be done in the field. Had Halprin used his graphics to communicate sound, his would likely have been chosen for documenting the thesis site.

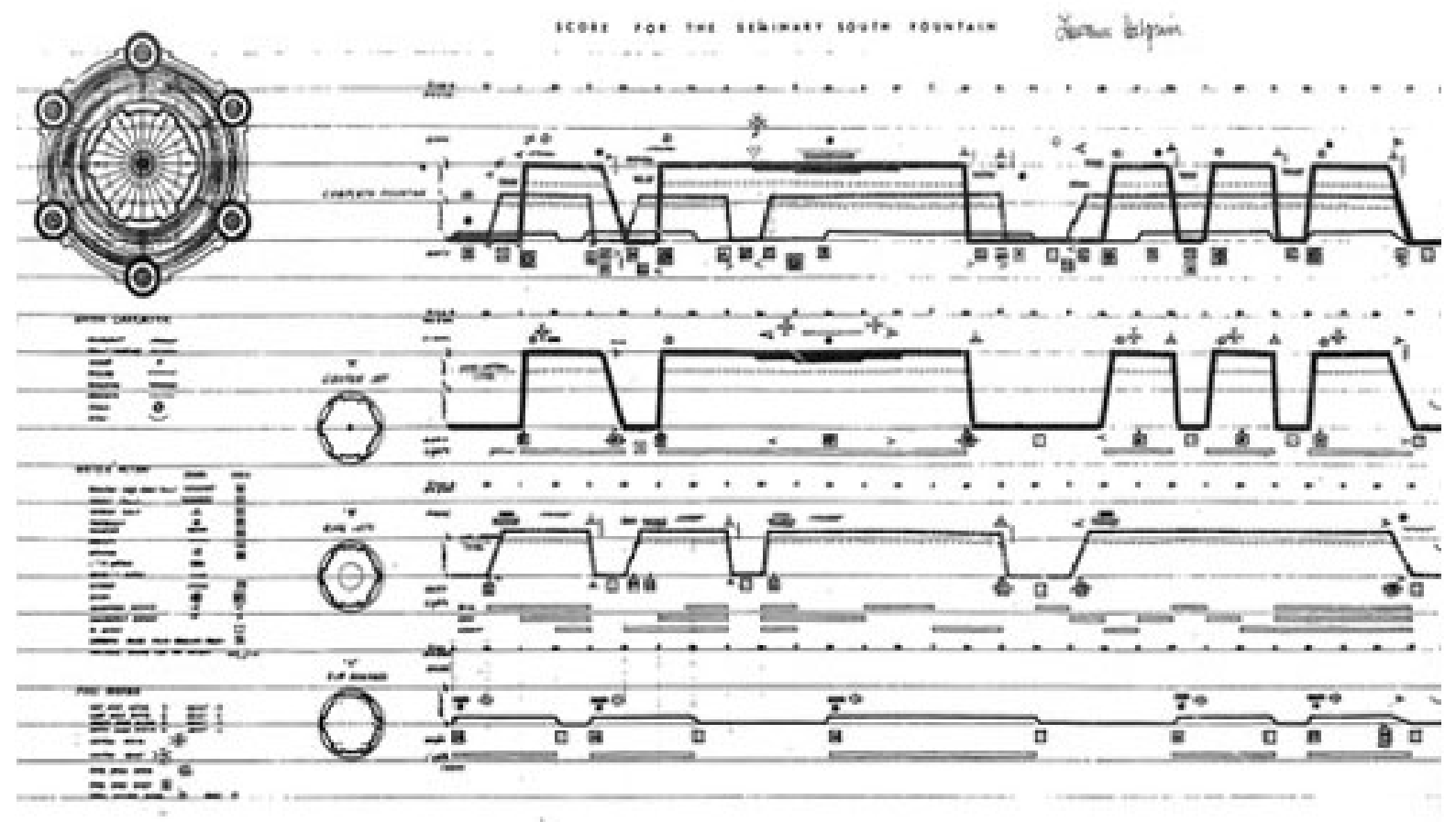

Figure 31: Score of Fountain Movement (Halprin, n.d.)

Ultimately, for graphic documentation showcasing the soundscape for a moment on the borders of the parks, a version of Schafer's graphic score was selected. To document the 
soundscape for an extended period in the centers of the parks, a new form of graphic communication was created using inspiration for Western Classical Music, Cage, Schafer, and Halprin. From Western Classical Music, the overall organizational system and visual forms used in orchestral works that feature of multiple staves for clarity of information with markers of time placed at 30 second intervals. From Cage, translating sounds into different graphic expressions that better represent the intent and feel of a sound. From Schafer, organization of sounds into the six sound categories for clear organization and legibility. From Halprin, a system that is visually engaging and simple enough to be done in the field.

Audio Recordings: To create audio recordings of the site, a digital recorder that would be able to make high quality binaural audio recordings was selected. Permission from the National Park Service to record in Rawlins Park, Walt Whitman Park, Triangle Park, and Bernardo De Galvez Memorial Park, was acquired in April 2021, through the receival of a Scientific Research and Collecting Permit.

\section{$\underline{3.3 \text { Site Inventory and Analysis: Existing Soundscape }}$}

Block Perimeter Soundscapes: To create Schaferian notation of the soundscapes at the perimeter of the parks, outlines of the blocks were drawn on sheets of paper. Then the perimeter of each block was walked while writing down the sounds that were heard beyond the site and ranking them from loudest to quietest in volume. From then, the sounds were compiled into Schafer's sound categories and graphed against each other on maps of the site. This method was done one time, on the afternoon of Tuesday April 13 $3^{\text {th }}, 2021$.

Unsurprisingly, mechanical sounds were the dominant sound category across the site with vehicular traffic being the primary sound source. In any given block, no more than 3 sound 
categories were sounding during the walk along the blocks. In Rawlins Park (Figure 32), mechanical sounds were most prominent along the northern, eastern, and southern borders, of the park. The second prominent sounds along the northern and southern boarders were natural sounds, primarily composed of bird song. And along the eastern border, the second most prominent sound category was the sounds as indicators, featuring sounds from a crosswalk. Walt Whitman Park (Figure 33) had mechanical sounds as the most prominent along the northern, and southern, borders of the park. The norther boarder featured natural and human sounds as second and third respectively, most prominent sounds, while the southern boarder featured no additional sound categories beyond mechanical sounds.

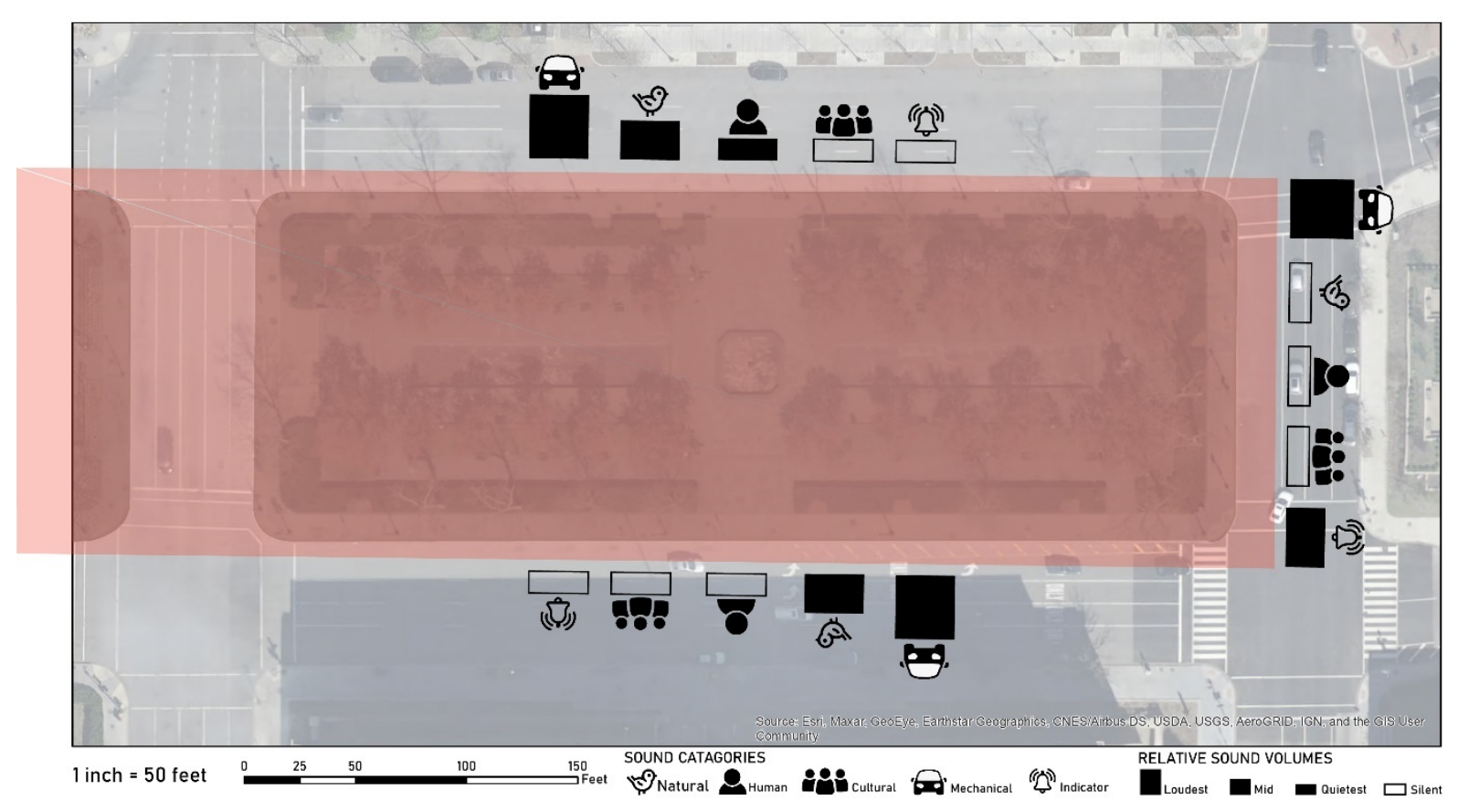

Figure 32: Perimeter Soundscape of Rawlins Park (Gray) 


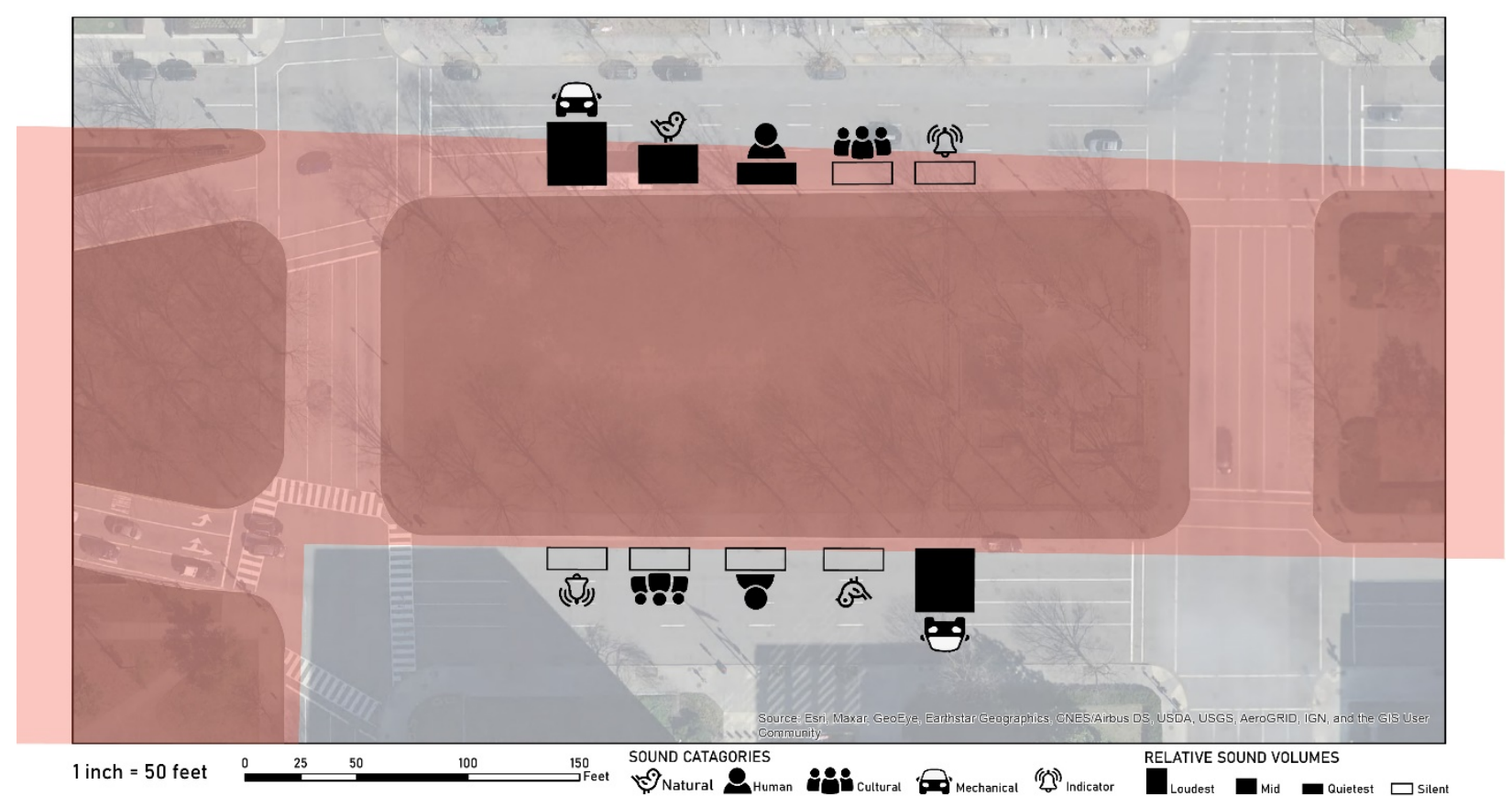

Figure 33: Perimeter Soundscape of Walt Whitman Park (Gray)

The northern side of the E Street Expressway Under Pass (Figure 34) features mechanical, natural, and human sounds as the most prominent, second prominent, and least prominent, respectively. Triangle Park (Figure 35) has mechanical sounds as its primary sound source along the southwestern, and eastern, borders of the park. The mechanical sounds on the southwestern border are mostly made from sounds of a ventilation system in a nearby building. The eastern boarder has no secondary or tertiary sound category. While the southwestern border's secondary sound category are cultural sounds, resulting from the nearby construction off site. Virginiana Avenue Bus Hub and Bernardo De Galvez Memorial Park (Figure 36) have mechanical sounds as their primary sound source and natural sounds as their secondary sound source. While not a sound source coming from outide the perimeter of the site, a vent on the northwest tip of the Virginia Avenue Bus Hub dominates the soundscape along the boarders of those blocks covering all else. 


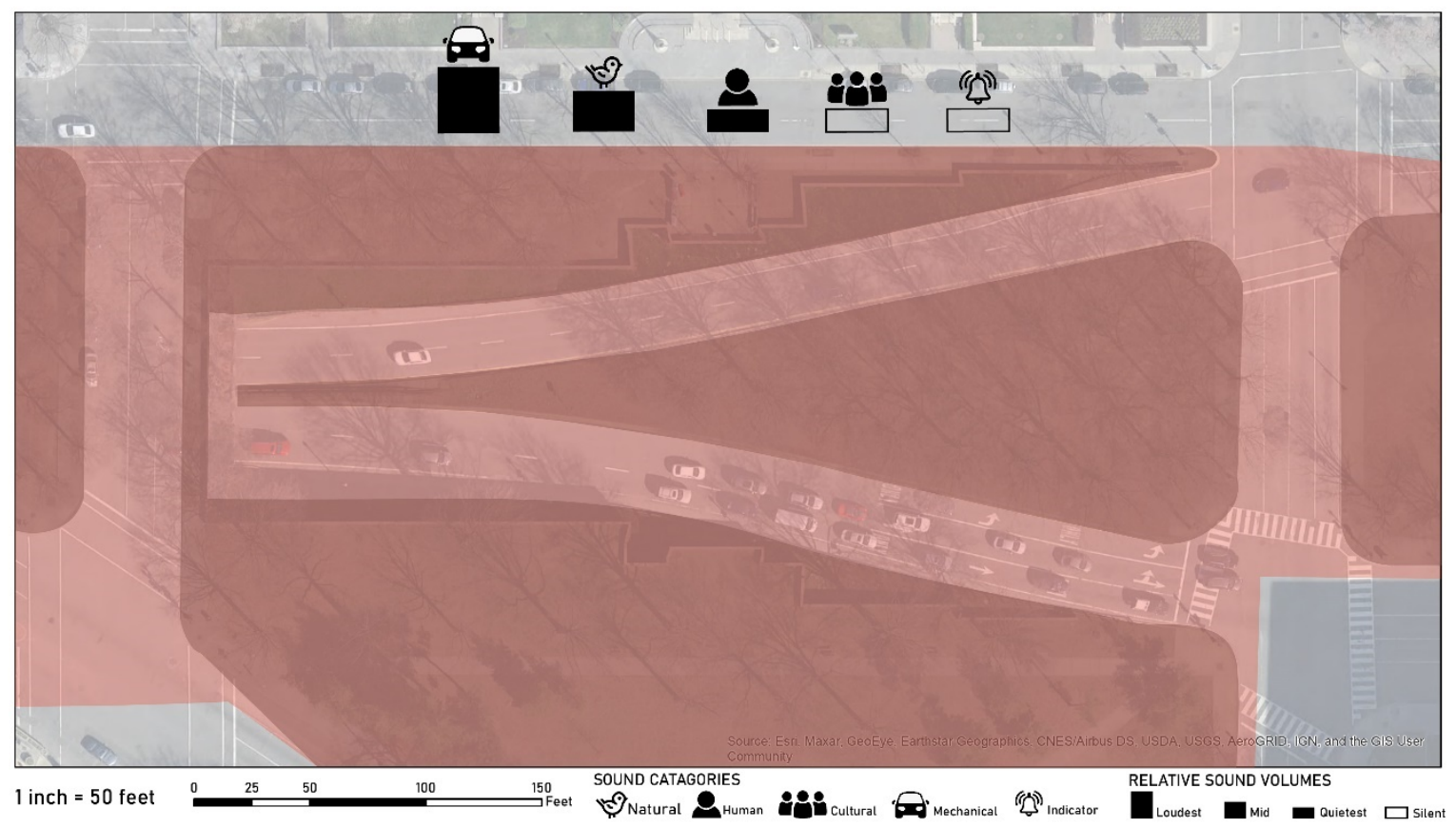

Figure 34: Perimeter Soundscape of E Street Expressway Under Pass (Gray)

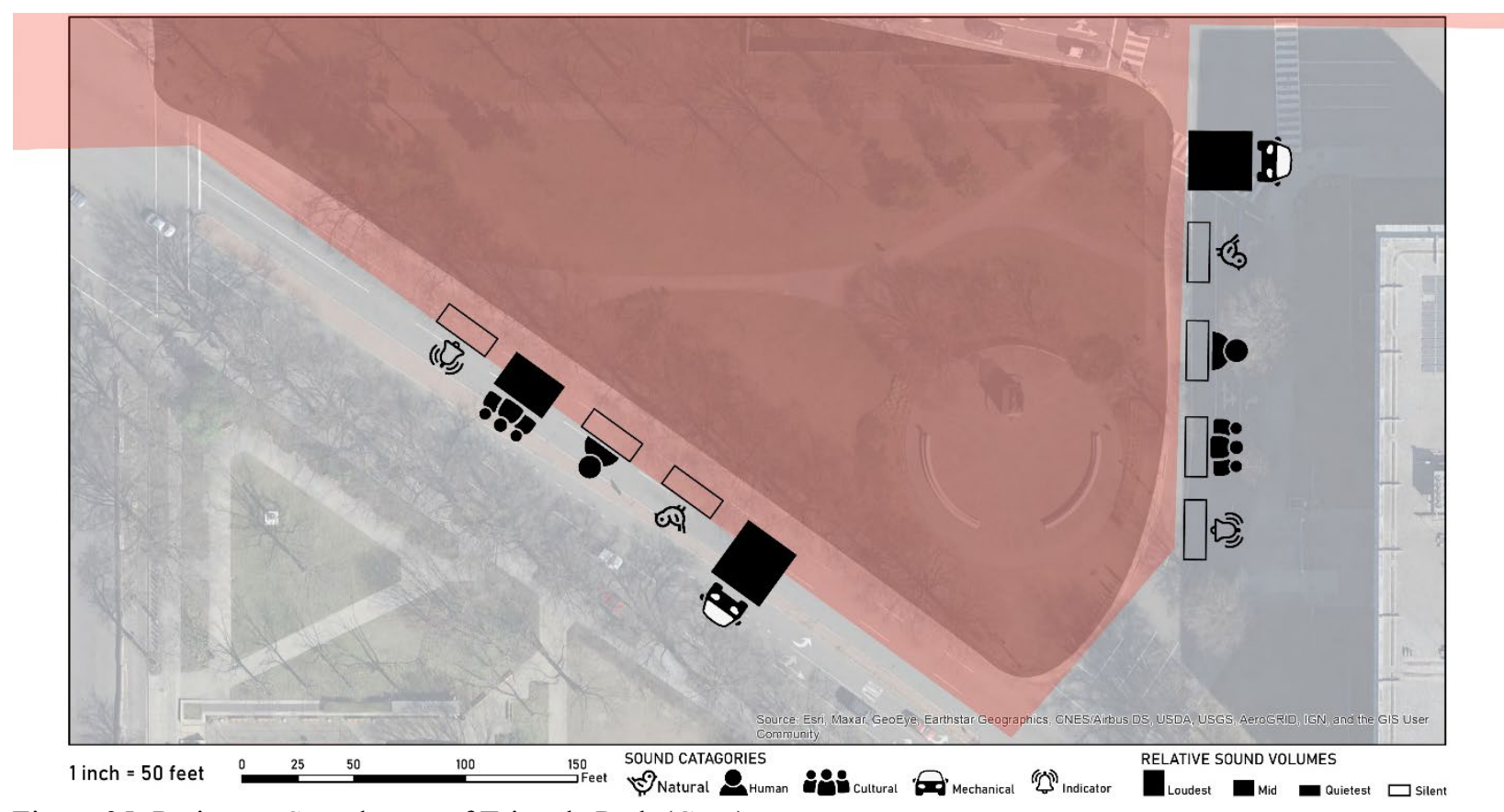

Figure 35: Perimeter Soundscape of Triangle Park (Gray) 


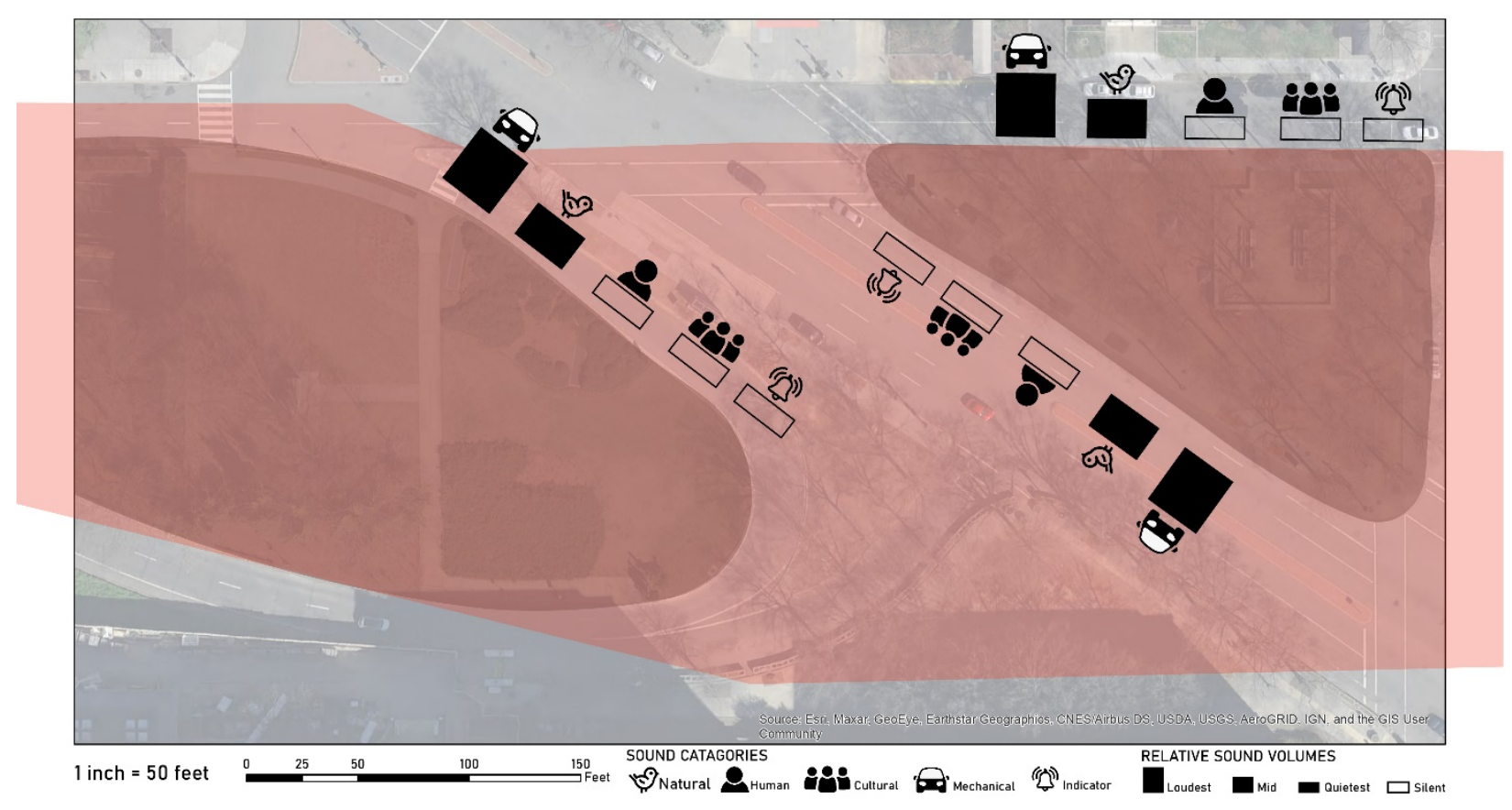

Figure 36: Perimeter Soundscapes of Virginiana Avenue Bus Hub \& Bernardo De Galvez Memorial Park (Gray)

Mid-Block Soundscapes: To graphically represent the soundscapes of the National Parks, a clean base score (Figure 37) would be used to write down the sounds heard in the park. Each base score has 6 staves, one for each of Schafer's sound categories. Above each system of staves are numbers to indicate minutes, lasting to 10 minutes, with vertical lines crossing the staves to mark the passage of 30 seconds. When a sound from any of the categories is heard, it is immediately marked on the stave its sound category at the approximate time indicated from the start of active listening. Sounds that are longer appear wider on the score, indicating length of sound. Location on the stave indicates relative pitch within a sound category, with sounds in the upper portion of the stave being higher than the sounds in the lower portion of the same stave. Markings to indicate relative volume of sounds are located below each stave (Figure 38). 

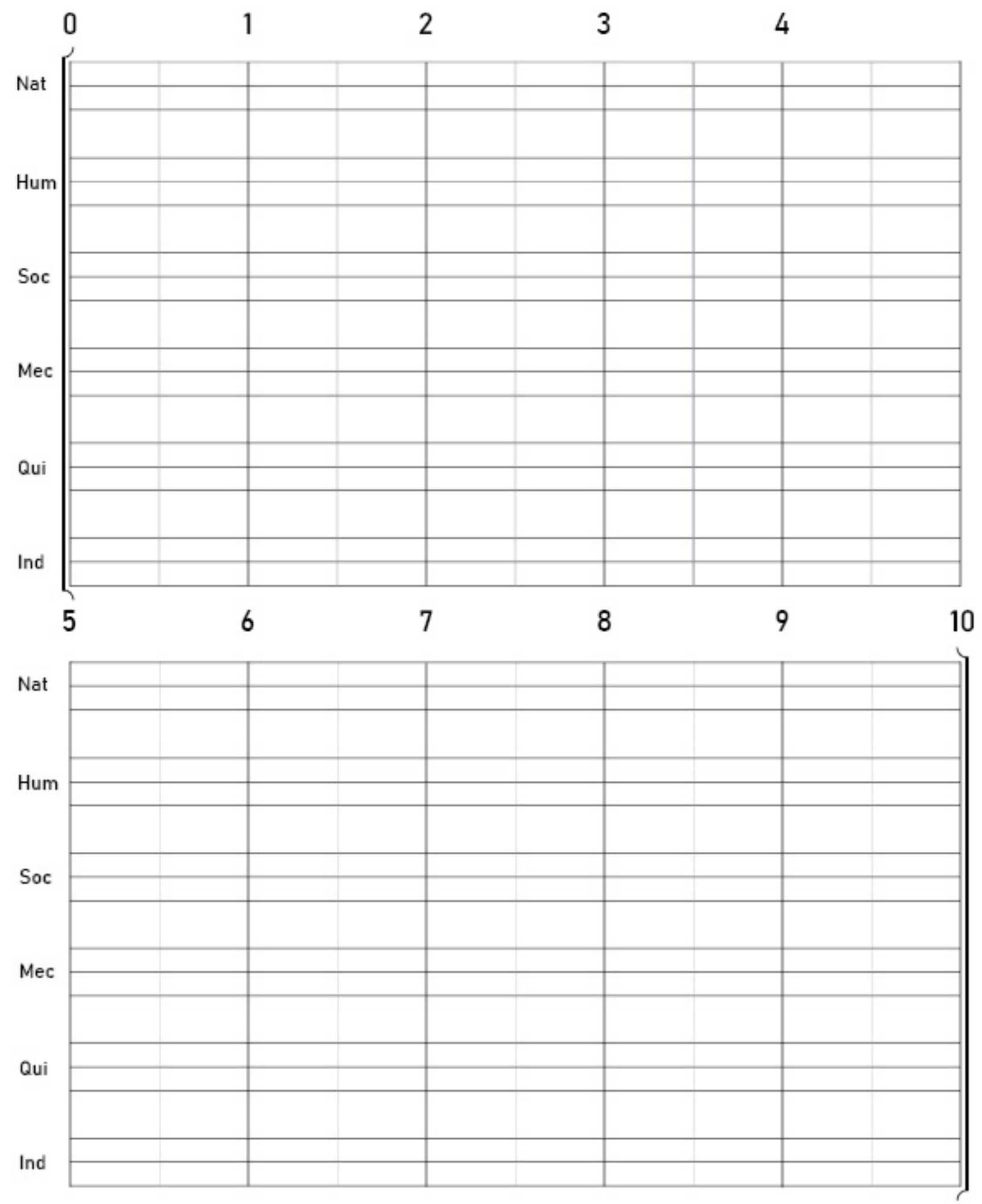

Figure 37: Base Score (Gray) 


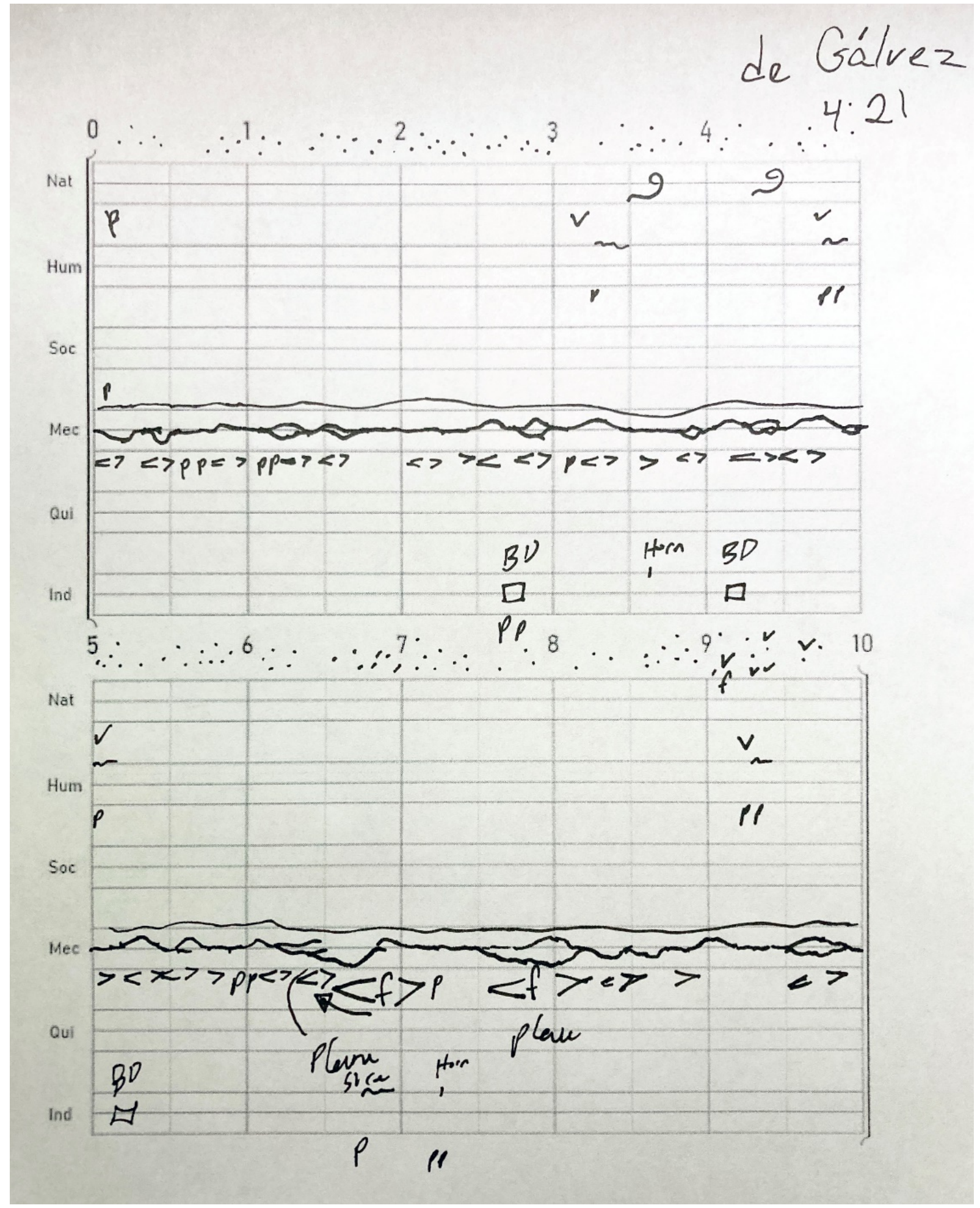

Figure 38: Filled Out Score of de Galvez Park on Saturday, in the Late Afternoon (Gray) 
After crafting the notation styling for longer term soundscape representation, the decision was made to create the graphic soundscape scores at the same time as the audio recording for each park. To get a sample of the different ways the soundscape would present itself in the $\mathrm{E}$ Street Park System, a weekday and a weekend day were selected for sampling. Recordings and the creation of sound scores occurred on Tuesday April $13^{\text {th }}, 2021$, and Saturday, April $17^{\text {th }}$, 2021 , between 8:30am and $5 \mathrm{pm}$. The weather on both days was partly cloudy with temperatures in the mid-60 and a slight breeze, making these days ideal for recording a wide variety of sounds across sound categories. Audio recordings of 10-minute intervals took place in Rawlins Park, Walt Whitman Park, Triangle Park, and Bernardo De Galvez Memorial Park (Figure 39), three times a day using a with one set of recordings being conducted in the morning, one set conducted in the afternoon, and one set conducted in the late afternoon/early evening. The manned recordings were created using a Roland R-07 High Resolution Audio Recorder with Roland CS10EM Binaural Microphones/Earphones. To protect the park users' security, signage indicating active audio recording was placed within 20 feet of the live recording device.

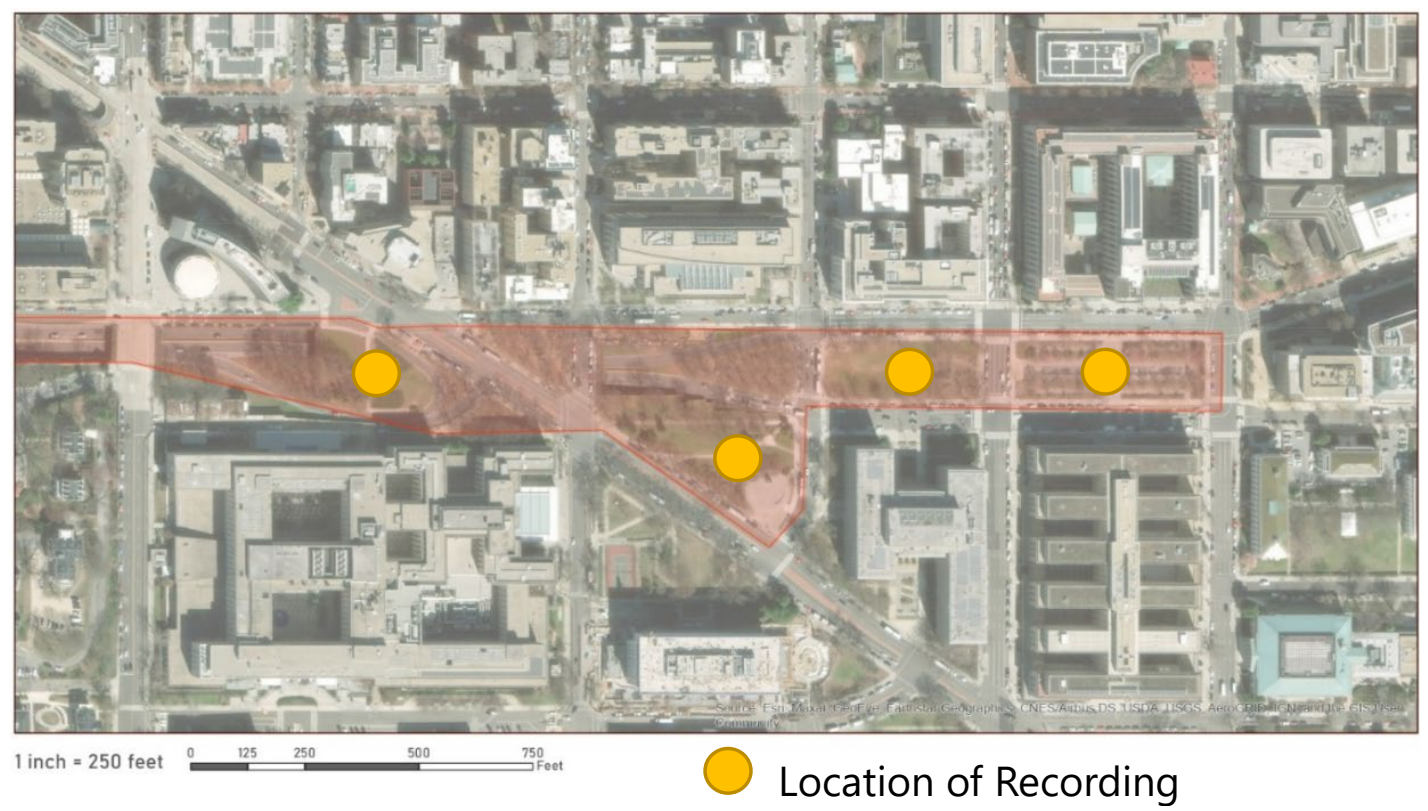

Figure 39: Recording Locations (Gray) 
The 24 audio recordings and graphic scores (See Appendix) that occurred because of these site visits helped to document the soundscape of the E Street Park System, painting a picture of the existing soundscape and its users.

Across the 24 recordings and graphic scores, all sounds from all 6 sound categories were heard with $23^{1}$ different ${ }^{2}$ sound sources were identified (including silence) across the parks. All parks notated all 6 sound categories throughout the recording process, but no one park notated all 23 identified sound sources. The natural sounds had the most variance with 6 different sound sources identified, while the sounds of silence and quiet had least with only 1 being identified. The other sound categories featured 3,4,4, and 5, different sounds, in the human, cultural, societal, and sounds as indicators, respectively. Sounds from the mechanical category were identified most frequently throughout the parks, with sounds of vehicular traffic or ventilation systems identified as the keynote sound for all the parks. Air traffic was another substantial sound source across all parks but may not be considered a keynote sounds due to the inconsistent flights passing by and at their loudest, becoming one of the most disruptive sounds sampled from the site. Bird song was surprisingly present, consistent, and noticeable in the parks, almost being heard for the same amounts of time as vehicular traffic. though not as sounds of air traffic were frequent in the mornings and tapered off as the day progressed. Rawlins Park encountered $7-10$ different soundscape sources in a given period recorded by the sound scores. This park was the only park to notate all 6 of the natural sounds, and specifically have a soundmark in the sounds

\footnotetext{
${ }^{1}$ Two identified sounds were not included on the scores. One, was the sound of paper from my writing on the scores. The other was a piece of litter passing by. The second of the two was excluded due to it not fitting within Schafer's Sound Categories.

${ }^{2}$ Some sounds such as the sounds of different birds, or the sounds of different types of automobiles, were combined on the scores and titled as a more general sound source.
} 
of water. Walt Whitman Park encountered 7 - 10 different soundscape sources in a given period recorded by the sound scores. Triangle Park encountered $8-12$ different soundscape sources in a given period recorded by the sound scores. Bernardo de Galvez Memorial Park encountered 6 9 different soundscape sources in a given period recorded by the sound scores.

A Note Regarding Graphic Scores: For the two types of graphic scores to document the soundscapes of the E Street Park System, it is important to state that all sounds that were identified and who duration and volume noted, were done so on site while using clairaudience. This in turn means that it is biased to what the surveyor was accustomed to hearing at the time, and the visual documentation would be different than if the surveyor were to create the scores from recordings of the sites. This does not change the validity of the information recorded on the soundscape scores, only that it is in part a perception-based inventory. 


\title{
Chapter 4: Composing the Soundscape
}

\author{
4.0 Soundscape Design Goal and Objectives
}

Design Goal. Advance the Field of Soundscape Design in the Landscape

Objective 1. Fully design and shape the soundscape through Landscape Architecture.

Objective 2. Design the soundscape based on existing sounds and create an appropriate response for both the site and the surrounding area.

Objective 3. Design large scale soundscapes at the urban planning level.

Objective 4. Increase awareness of soundscape and listening through creating different soundscapes.

\subsection{Large Scale Thematic Design}

After multiple trips to the site and experiencing while focusing on clairaudience, the existing soundscape inspired the idea of the symphonic form in Western Classical Music. Developed in the 1700s largely by the composer Joseph Haydn (Vialma, n.d.), the symphony has a simple and clear structure. This form manifests in 4 distinct movements, the Allegro, the Adagio, the Minuet/Scherzo, and the Finale (Bratman, 2002). The Allegro movement is often a strong, introducing themes or motifs that appear throughout all the symphony, and are typically fast in tempo (Bratman, 2002). The Adagio movement is often smooth and lyrical, and is usually slow in tempo (Bratman, 2002). The Minuet/Scherzo movement is inspired by dances and is often lighthearted and medium to fast in tempo (Bratman, 2002). The Finale movement recapitulates themes and ideas from previous movements often in a dramatic manner, and is also fast in tempo (Bratman, 2002). 
The initial soundscape experiences on site recalled memories of the symphony, and characteristics that matched those of symphonic movements. The soundscape experience in Rawlins Park gives a strong introduction to all the sound types that would be heard as one continued west through the site (Figure 40). The soundscape experience in Walt Whitman Park and Triangle Park creates a sense of separation from the busy urban surrounding, creating a greater sense of tranquility and a slower pace. Listening to the soundscape in central portion of the site near the E Street Expressway Underpass and the intersection at E Street and Virginia Avenue, the heavy sounds of vehicular traffic led to a feeling of unbalance act between the need to hear traffic for human safety and aural discomfort from noise. The soundscape of the Kennedy Center is heavily littered with the sounds of air traffic, the same sounds experienced throughout the rest of the site, but intensified.

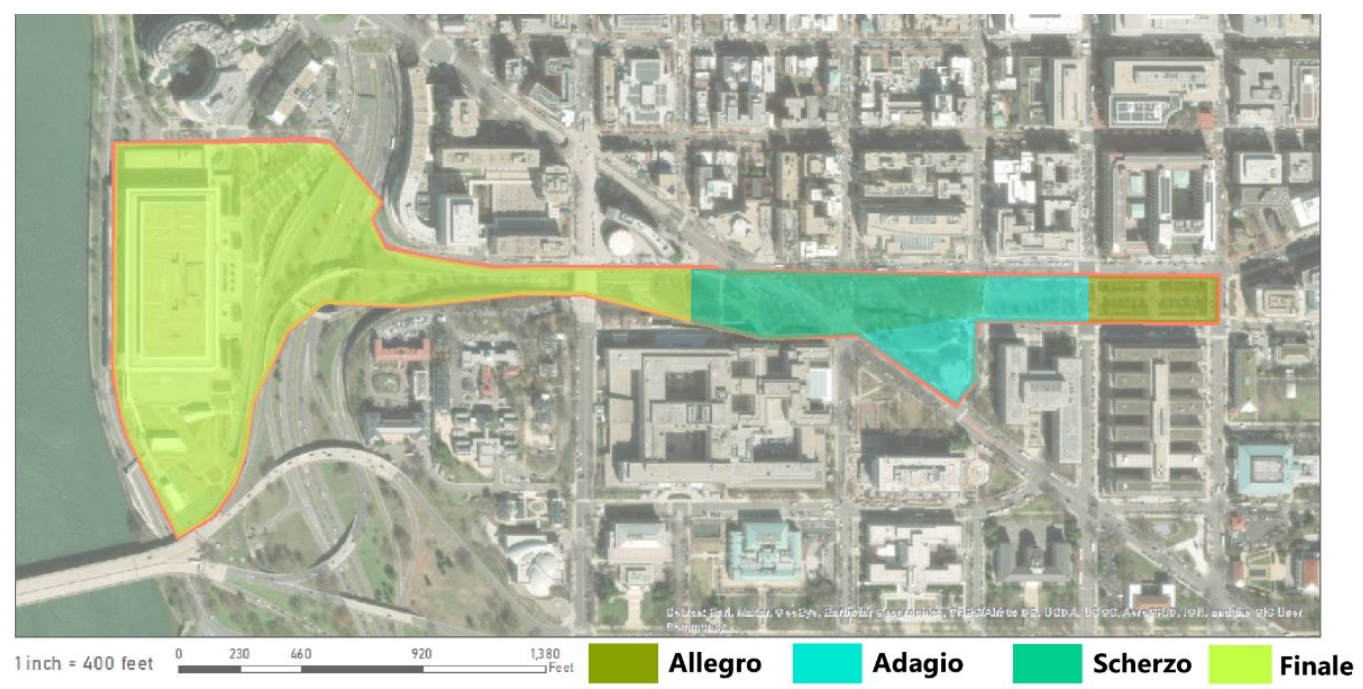

Figure 40: Symphonic Form Diagram (Gray)

The sound-based form creates a strong yet subtle structure and can help to design, building off of the existing soundscape of the site. 


\subsection{E Street Park System Soundscape Design Using System Schafer's Sound Categories}

Scaling down to the E Street Park System, a different soundscape design system is used. As with the larger scale plan the smaller scale soundscape plan is built off the existing soundscape, encouraging and exaggerating existing sound features. The perception of the existing soundscapes supported by the soundscape scores and audio recordings (See Appendix) led to the E Street Park System to be divided into 6 soundscapes featuring Schaferian sound categories (Figure 41).

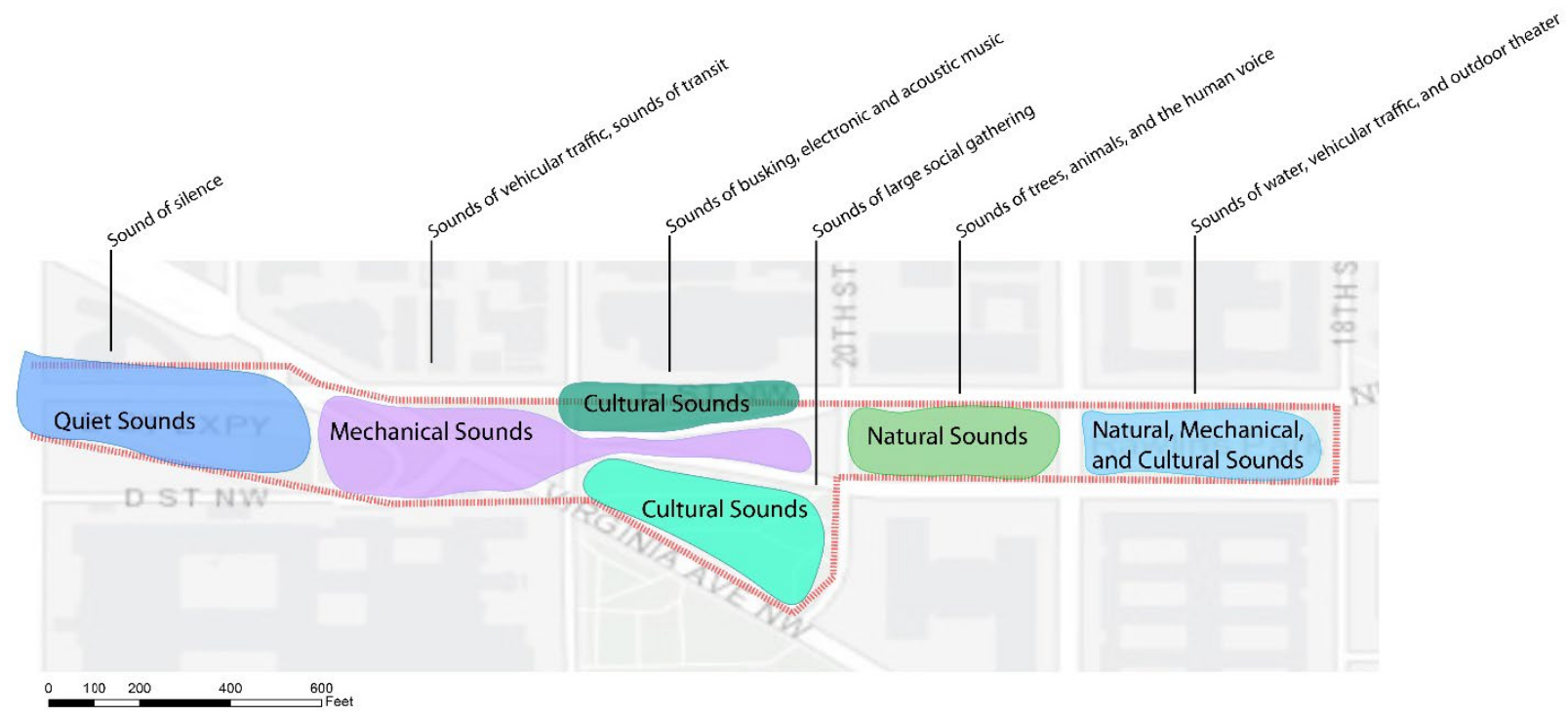

Figure 41: E Street Park System Schafer's Sound Category Diagram (Gray)

The eastern most soundscape, that of Rawlins Park, will foster the sounds of water, vehicular traffic, and performance. The soundscape of Walt Whitman Park puts the sounds of trees and animals into focus. Central soundscapes work to highlight societal sounds with sounds of social gathering in Triangle Park, and music to the north of the E Street Expressway Entrance. Mechanical sounds of vehicular traffic and forms of public transportation will be the centerpiece soundscape at the Virginia Avenue Intersection and the entrance to the E Street Expressway. Sounds of silence will be created in Bernardo de Galvez Park and continuing to the beginning of 
the Viñoly plan, creating a threshold for the Kennedy Center and the Reach and a departure from E Street. Finally, by encouraging human engagement within the soundscapes, an increase of human would be anticipated throughout all the soundscapes. This will help to increase human comfort levels (Jo et al, 2020) creating the opportunity for exposure to soundscape design and education. 


\section{Chapter 5: Composition Through Landscape}

\subsection{Landscape Design Goals and Objectives}

\section{Goal 1. Support and Design the Soundscape Through Landscape}

Objective 1: Shape landscape to foster sound experiences.

Objective 2: Create visual differences in space that indicate sound change.

Objective 3: Increase soundscape education through signage.

\section{Goal 2. Create a Continuous Gesture Across the Site Connecting Sound and Space}

Objective 1. Create overpass over Route 66 and more pedestrian friendly crosses on E Street.

Objective 2. Create environments that would look visually related and foster similar sound categories.

Objective 3. Create spaces that signify visual and aural thresholds.

\subsection{E Street Park System Landscape Design}

The site plan of the E Street Park System features four distinctive spaces (Figures 42 and 43). The first is Rawlins Park, the second is Walt Whitman Park, the third is Cage Bridge with Triangle Park, and the fourth is the Virginia Ave Bus Hub with Bernardo De Galvez Memorial Park. 


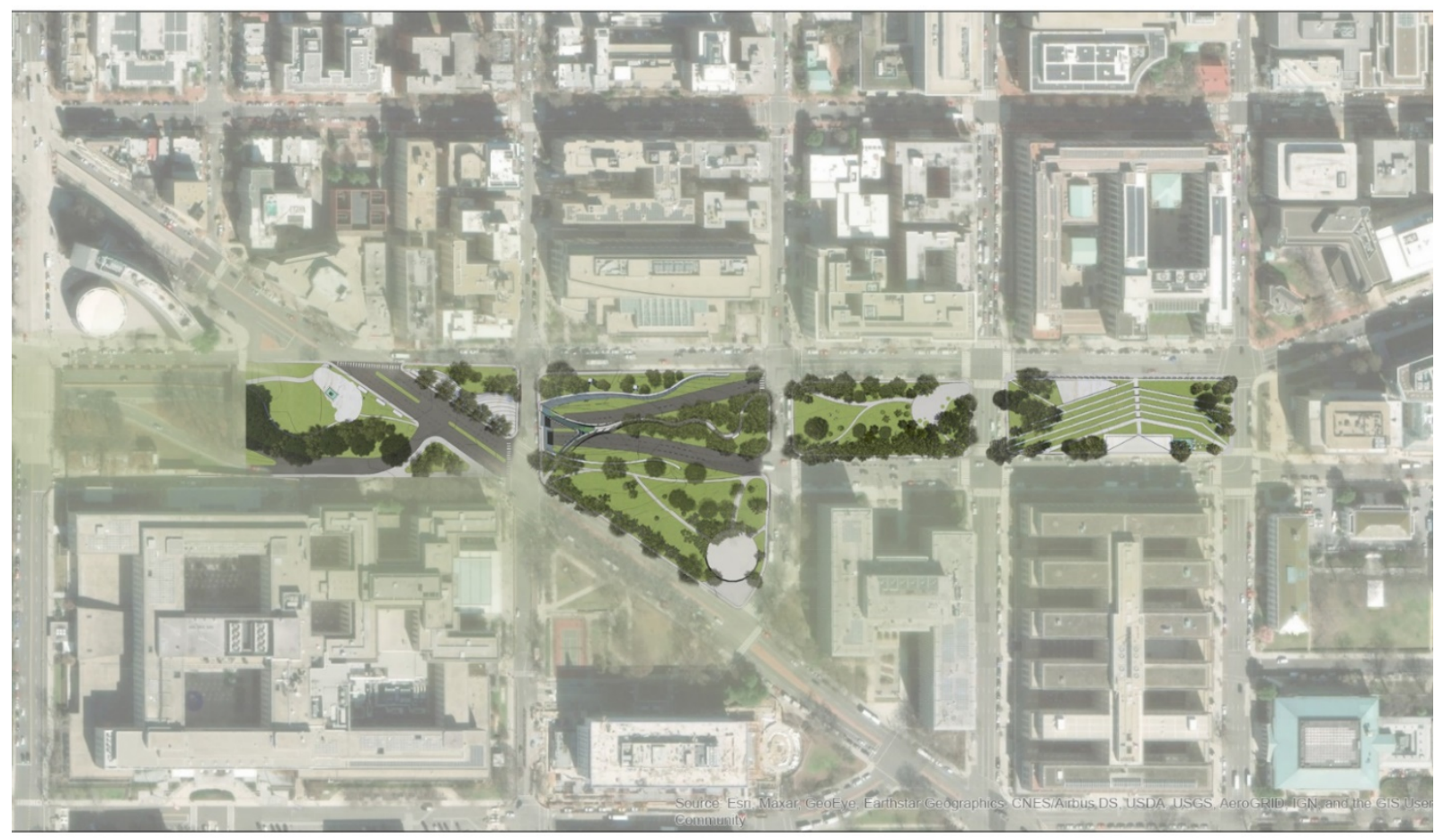

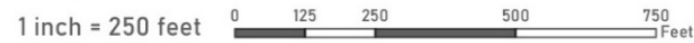

Figure 42: E Street Park System Site Plan (Gray)

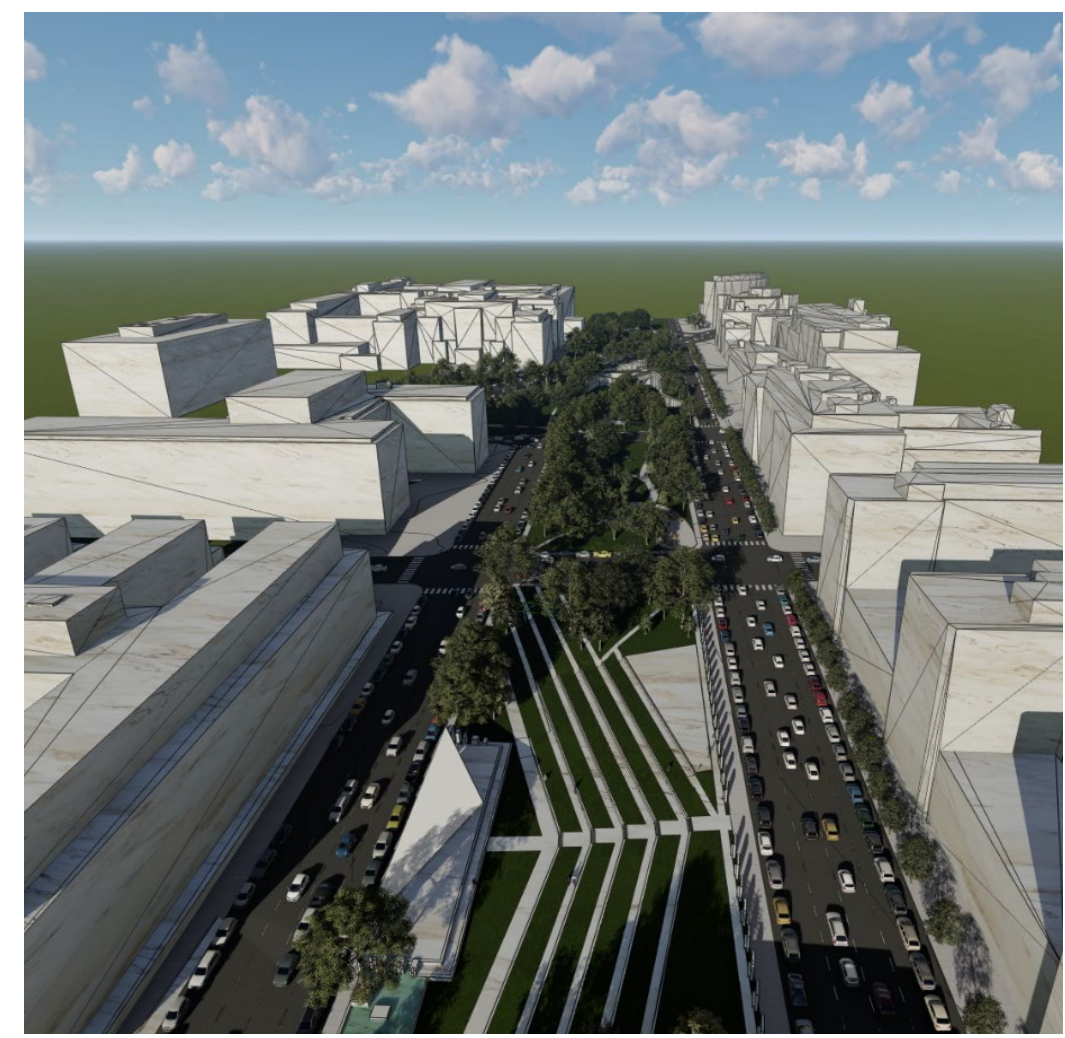

Figure 43: Aerial View of E Street Park System Site Plan Over Rawlins Park Looking West (Gray) 


\section{$\underline{5.2 \text { Rawlins Park Design }}$}

The design of Rawlins Park cultivates sounds of nature, society, and the mechanized, while creating a space that introduces thematic ideas across the thesis site. Already present on site are the sounds of water, bird song, and vehicular traffic, leaving societal sounds to be introduced. Vehicular traffic is currently the keynote sound, with water being the soundmark of this soundscape. To address the design needs of the soundscape in Rawlins Park, defensive and creative soundscape management strategies should be used. The defensive strategy was used to lower the levels of sound of vehicular traffic from the surrounding roadways to decrease decibel levels and competition among sounds. While creative soundscape management strategies should be used to increase the sounds of society, introducing a generally welcoming sound source to listeners. Establishing this soundscape as an introductory soundscape to the remainder of the park system.

The resulting design of Rawlins Park addresses these challenges (Figure 44), as well as creating a hospitable space for students at nearby George Washington University, employees of nearby Federal employees, and possible tourists visiting the area. 


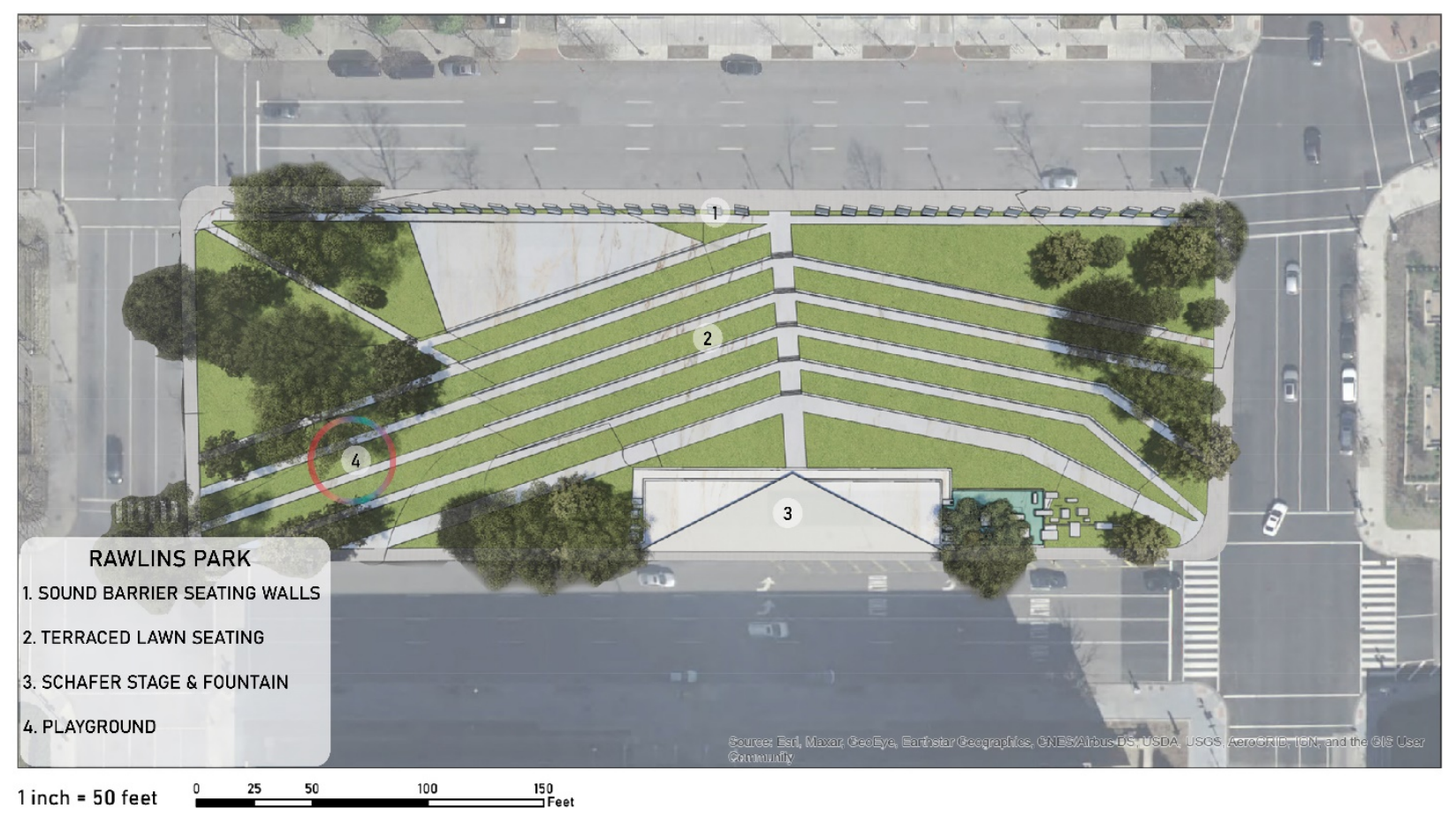

Figure 44: Site Plan for Rawlins Park (Gray)

To defensively manage the sounds of vehicular traffic from roadways on the northern side of the site, sound barrier seating walls were designed (Figure 45). These eight foot tall structures are angled slightly, to block the sounds from westbound traffic on E Street. The seating walls are broken up, creating ways for reduced amounts of sound from vehcular traffic as well as visitors to enter the space at points along the park block. 


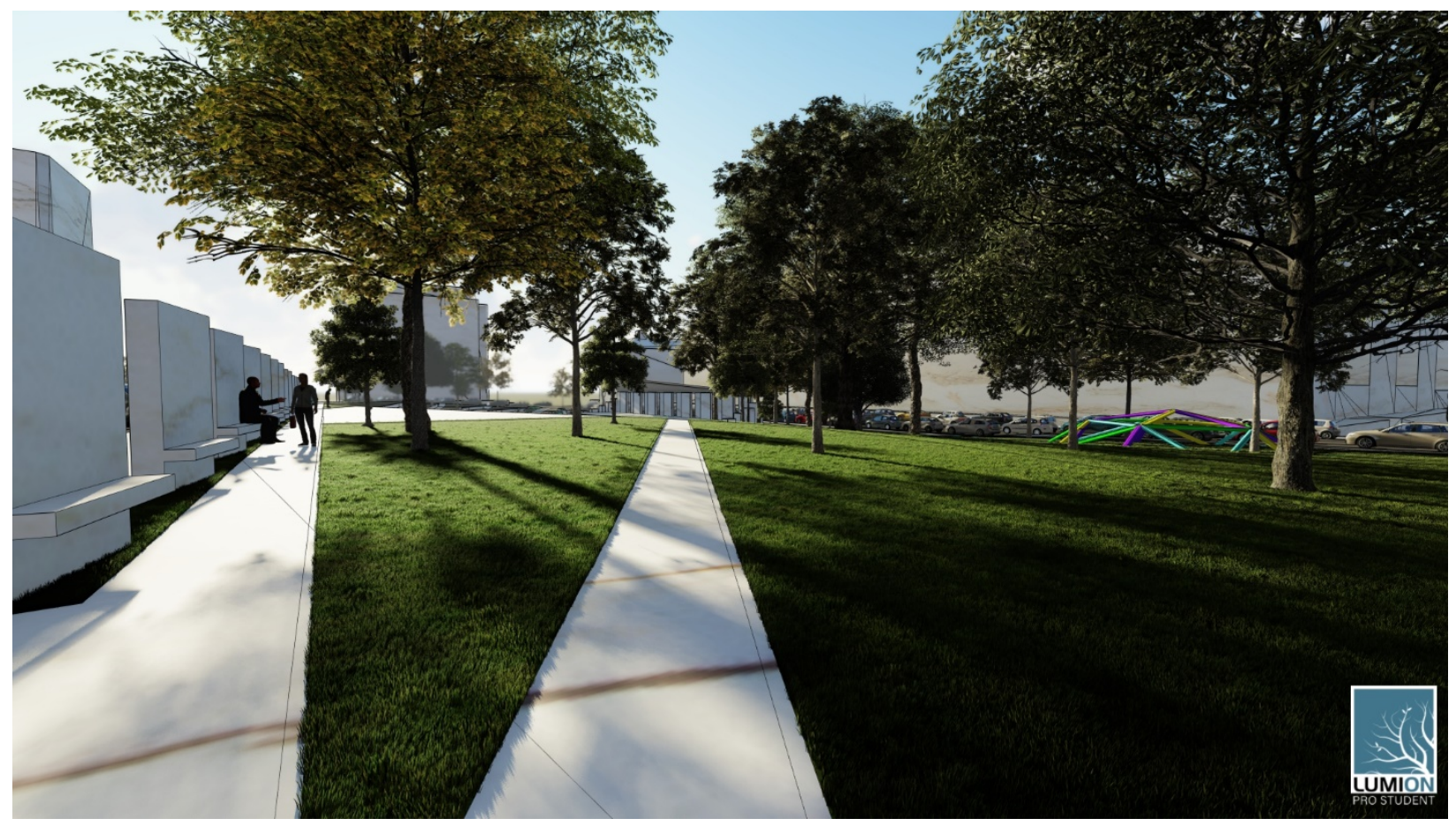

Figure 45: Perspective of Sound Barrier Seating Walls in Rawlins Park (Gray)

In the process of considering possible creative management solutions, the existing drop in elevation from the north side of Rawlins Park to the south side (Figure 46) was flagged as a possible solution. This elevation change could support the addition of societal sounds by functioning as terraced seating for an outdoor theater on the southside of the park. A section (Figure 47) and perspective (Figure 48) were created to showcase the terraced seating and stage.

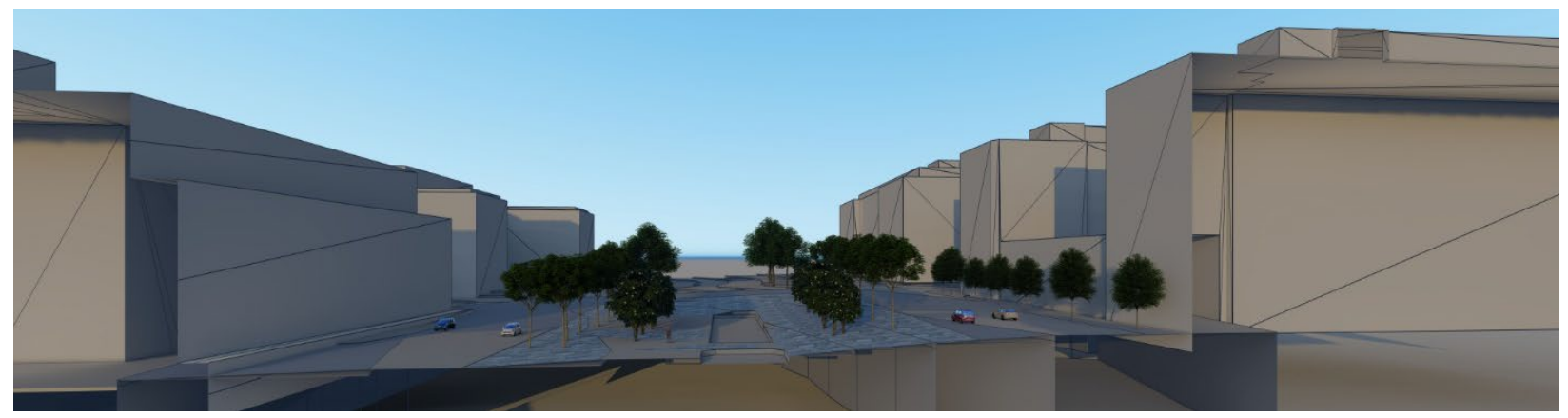

Figure 46: North-South Section of Existing Rawlins Park (Gray) 


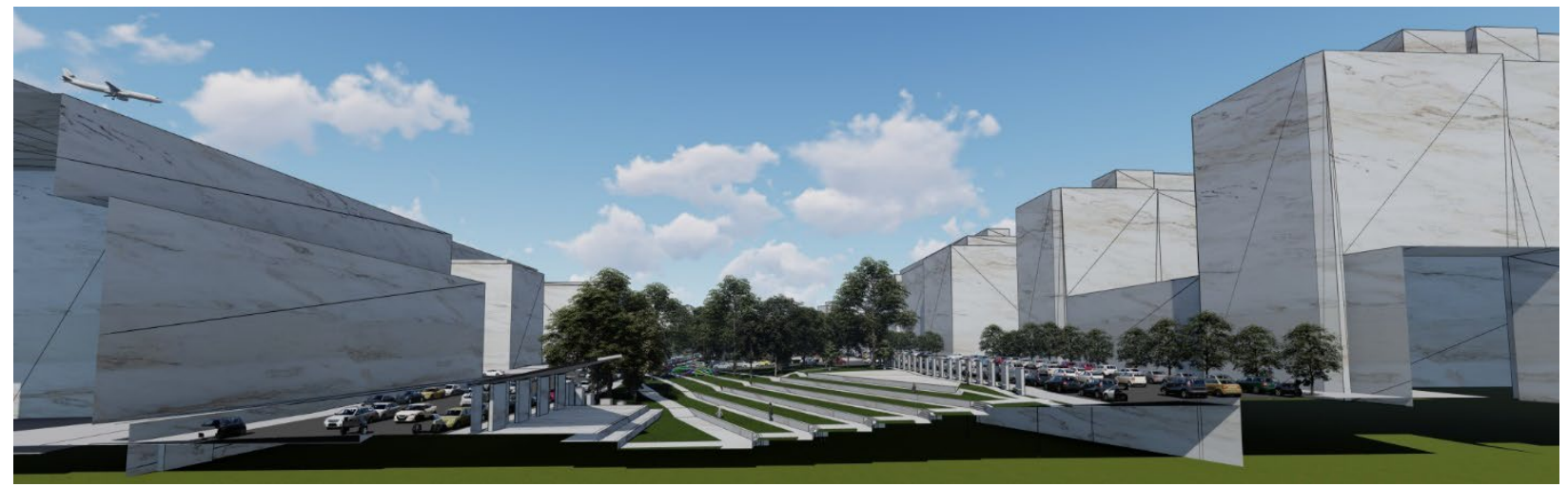

Figure 47: North-South Section of Proposed Soundscape and Landscape Interventions Rawlins Park (Gray)

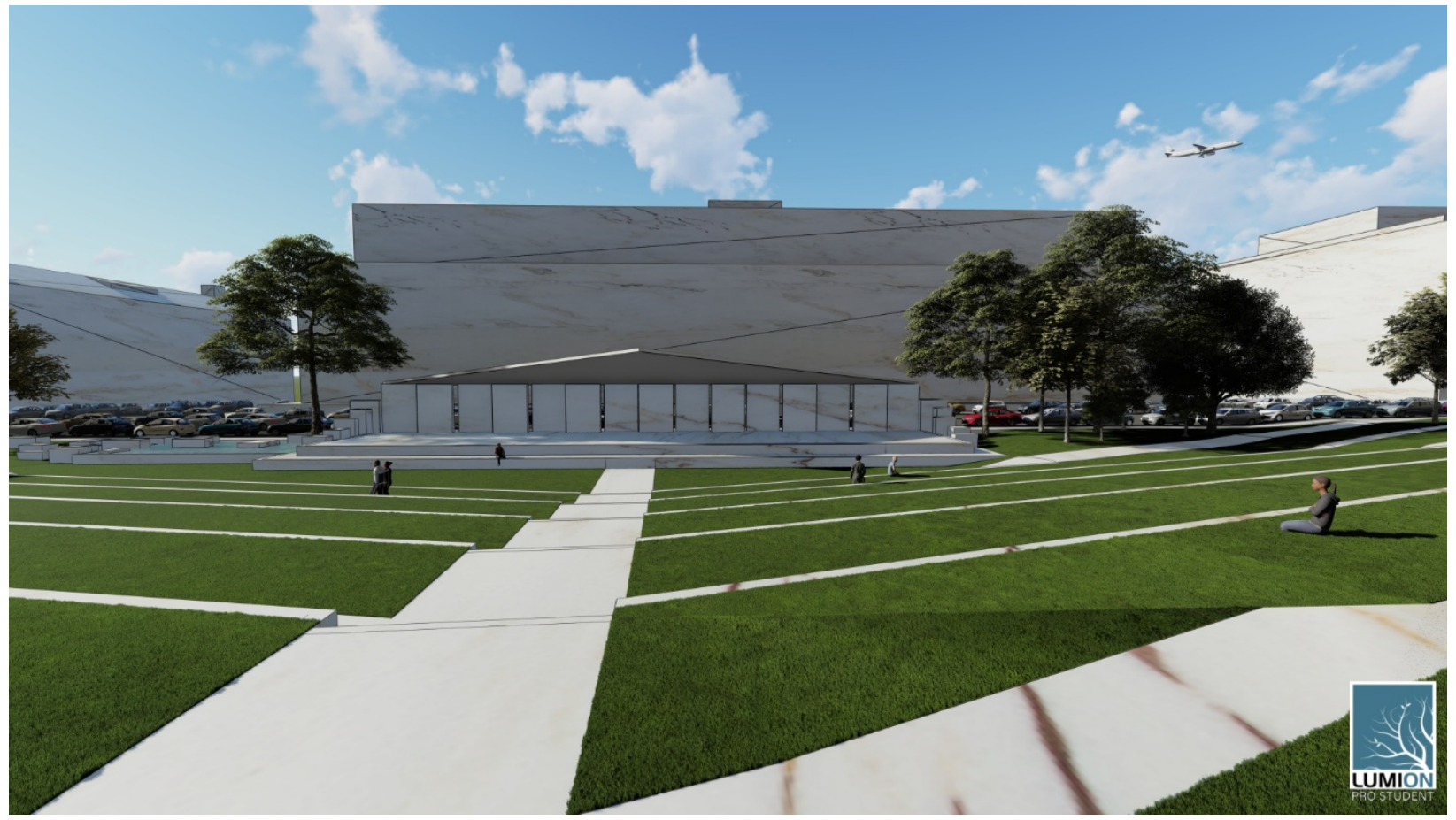

Figure 48: Perspective of Terraced Seating and Schafer Stage (Gray)

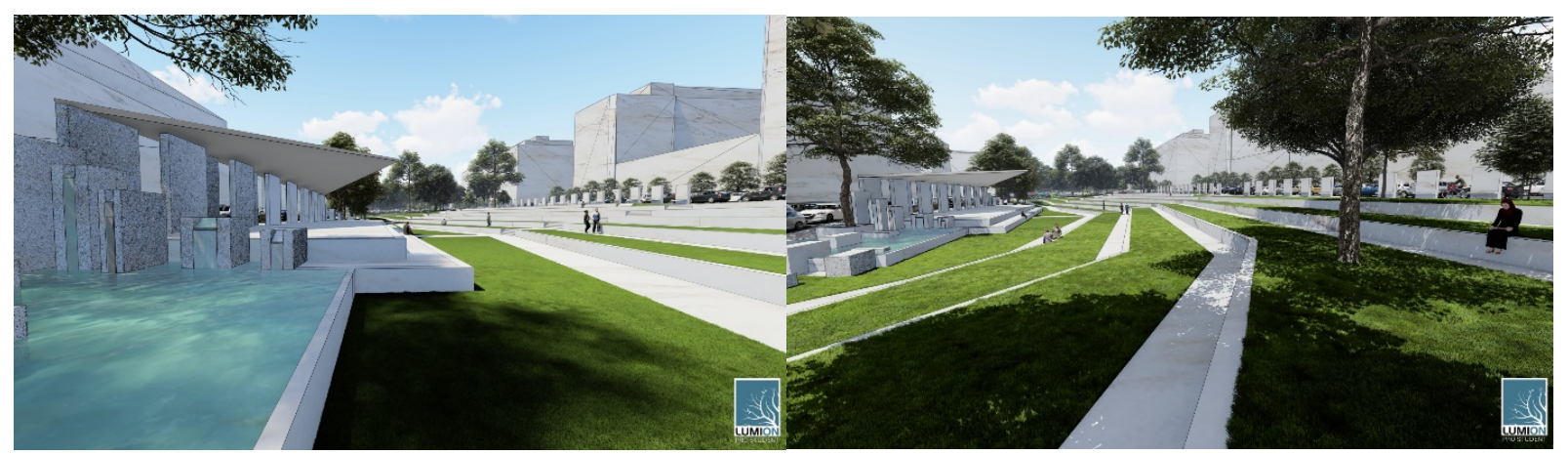

Left: Figure 49: Perspective of Schafer Stage and Fountain (Gray)

Right: Figure 50: Perspective Linear and Clear Pathways (Gray) 
Additional interventions were made using creative management stratagies, including a play structure to encourage human sounds while creating a source another source of entertainment for children during performances. A water fountain was introduced to cover sounds of trafffic near the theater (Figure 49), increasing the the presence of the soundmark of Rawlins Park. To encourage a faster pace of movement along the sides of he park that are more likely to be used as thriughways, linear pathways were designed with lower amounts of natural sound (Figure 50) sources to decrease the likelihood of users slowing down due to said sounds (Maculewicz et al, 2016).

\subsection{Walt Whitman Park Design}

The design of Walt Whitman Park works to primarily encourage sounds of nature and encourage respite and relaxation from the surrounding hustle and bustle of the streetscape. The primary sound sources in the soundscape of Walt Whitman Park were bird song and vehicular traffic. To focus in on the sound design goal for this park, reducing sound from vehicular traffic through defensive soundscape management practices, while using creative strategies to encourage more bird song and other natural sounds that have been found on site will be essential.

To accomplish the goal to decrease mechanical sounds and increase natural sounds while growing a space intended for passive engagement and relaxation, the site plan for Walt Whitman Park will include topographic changes and increased plantings as the main courses of action (Figure 51). 


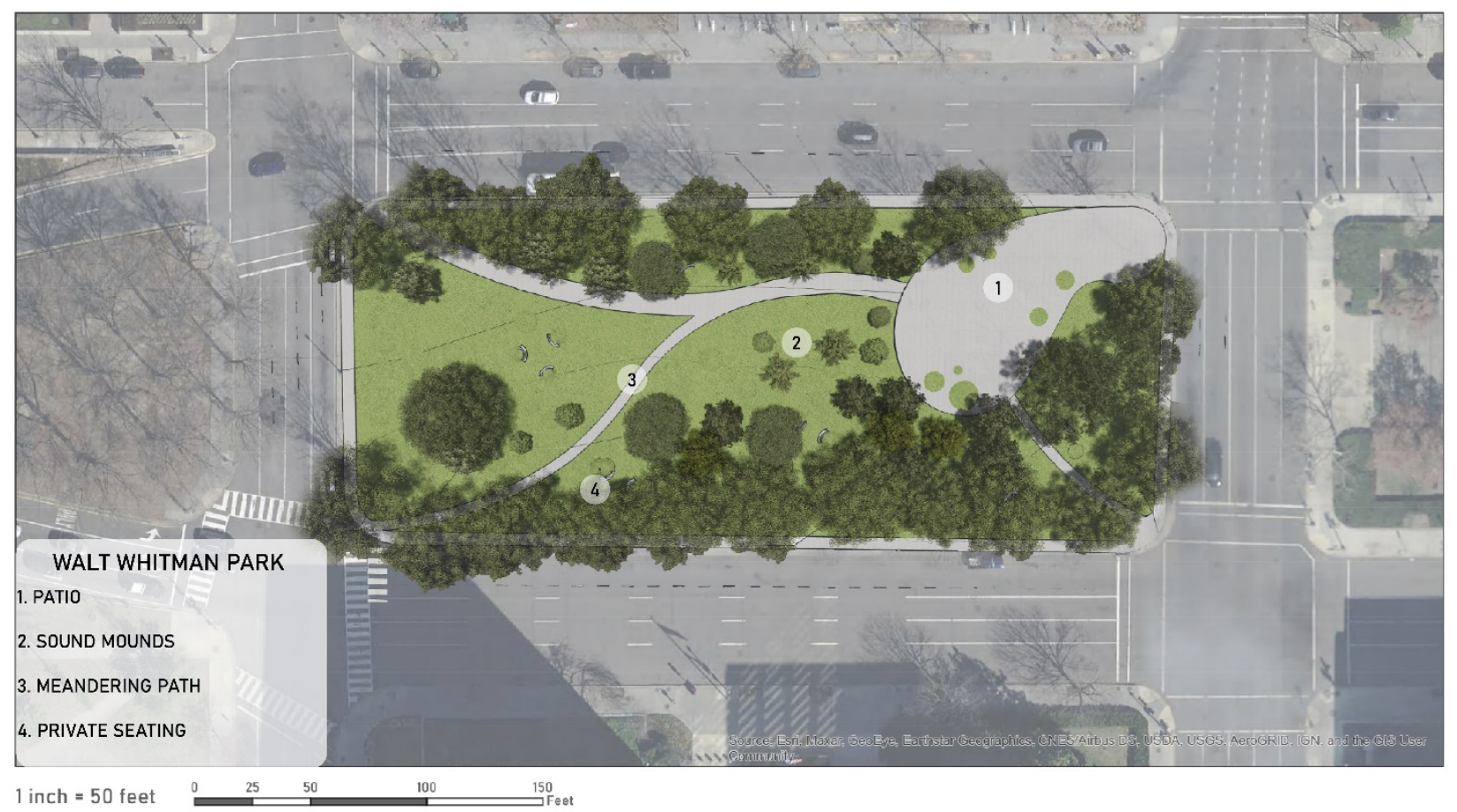

Figure 51: Site Plan for Walt Whitman Park (Gray)

In and around the patio, as well as throughout the park, sound mounds were placed to dampen roadways sounds. This was done to lower the amount of sound from vehicular traffic and to help create a sense of enclosure without distrupting eye level visibilty. The mounds range from 1'-4' tall and gently grow out of the existing topography (Figure 52 and 53). Among the mounds are seating walls inspired by the sound barrier seating in Rawlins Park (Figure 54). This seating represents a creative soundscape management coice that leads to the creation of more human sounds within the mounds.

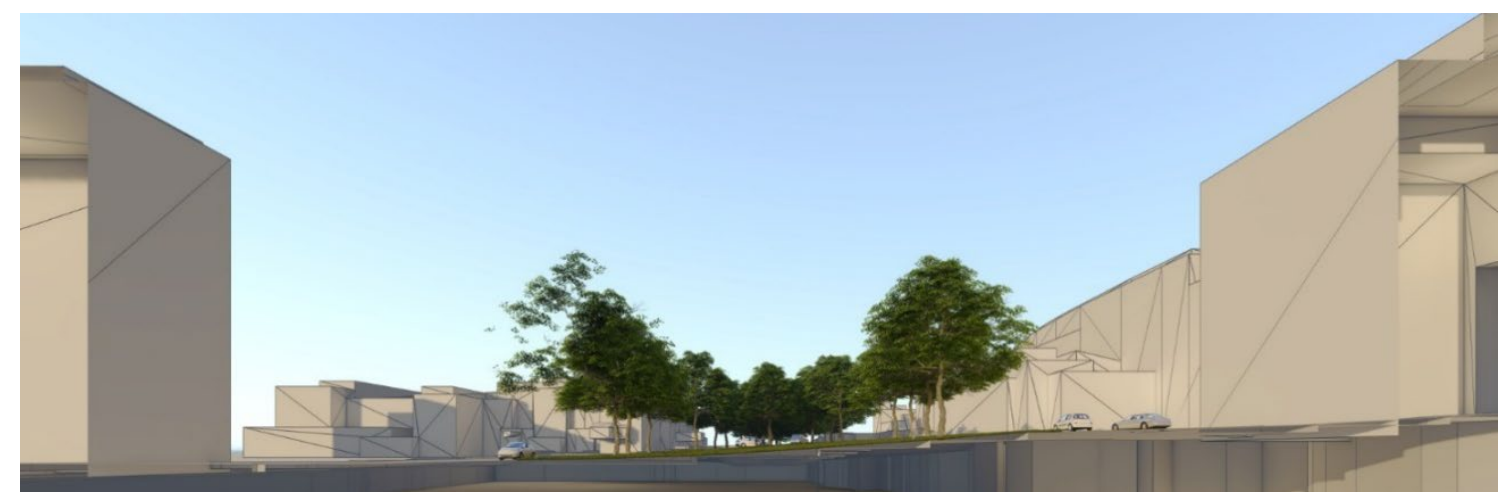


Figure 52: North-South Section of Existing Walt Whitman Park (Gray)

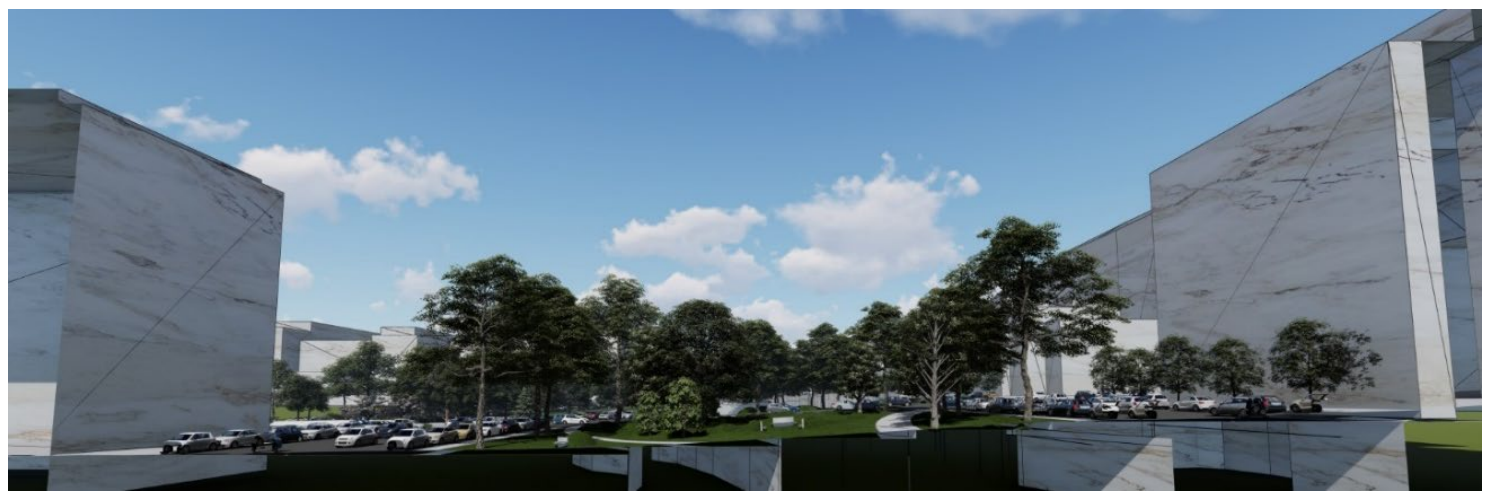

Figure 53: North-South Section of Proposed Soundscape and Landscape Interventions Walt Whitman Park (Gray)

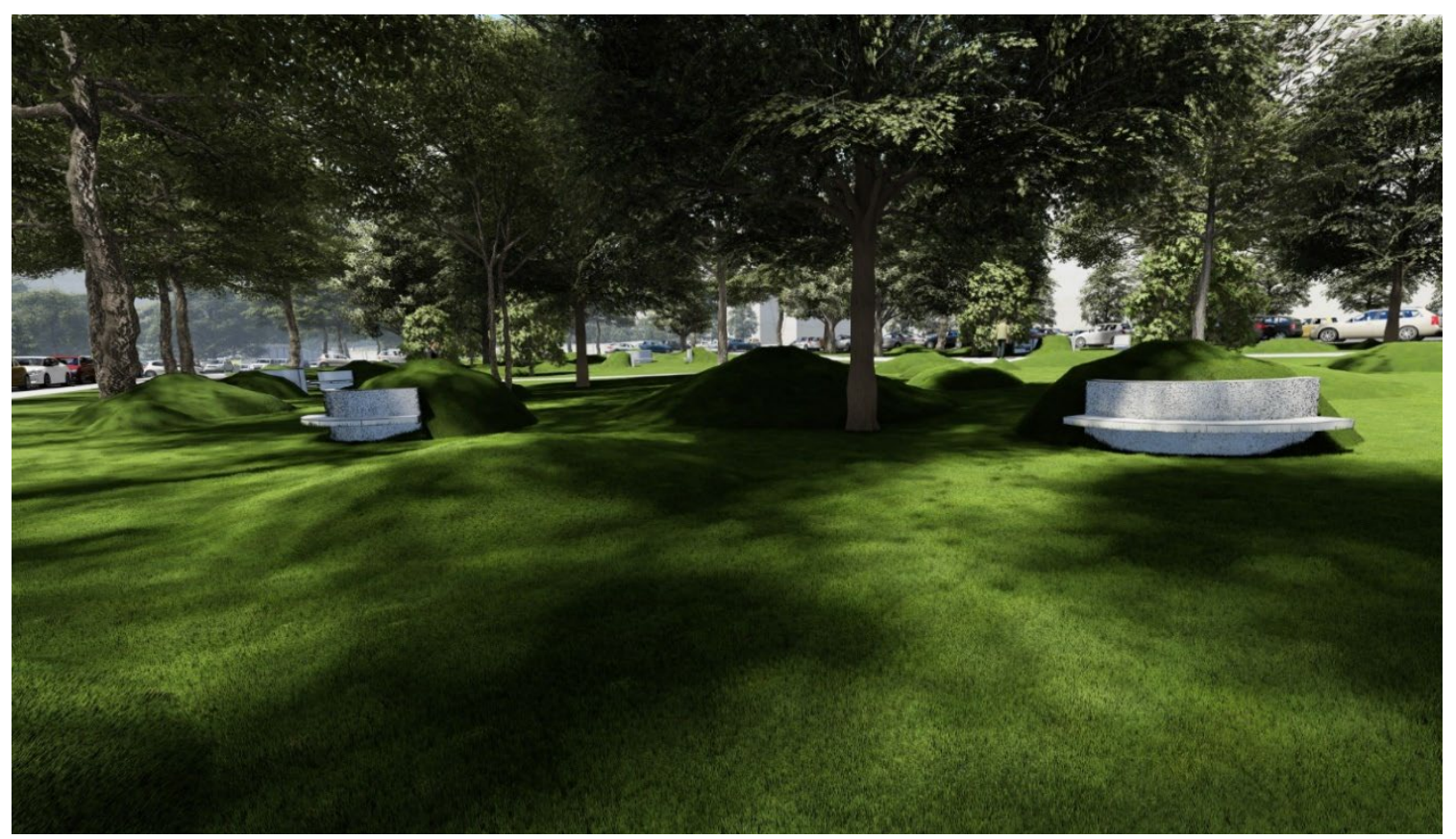

Figure 54: Perspective of Sounds Mounds with Seating in Walt Whitman Park (Gray)

Creative soundscape methods also led to more introductions of human sounds through the addition of a patio space and seating area on the northeast corner of the site, across from the campus of George Washington University. Tree plantings were also added near the patio (Figure 55) and around the boarders of the site creating habitats for wildlife to live within and around. 
These habitats will foster more nature-based sounds, helping to achieve one of the goals for this site.

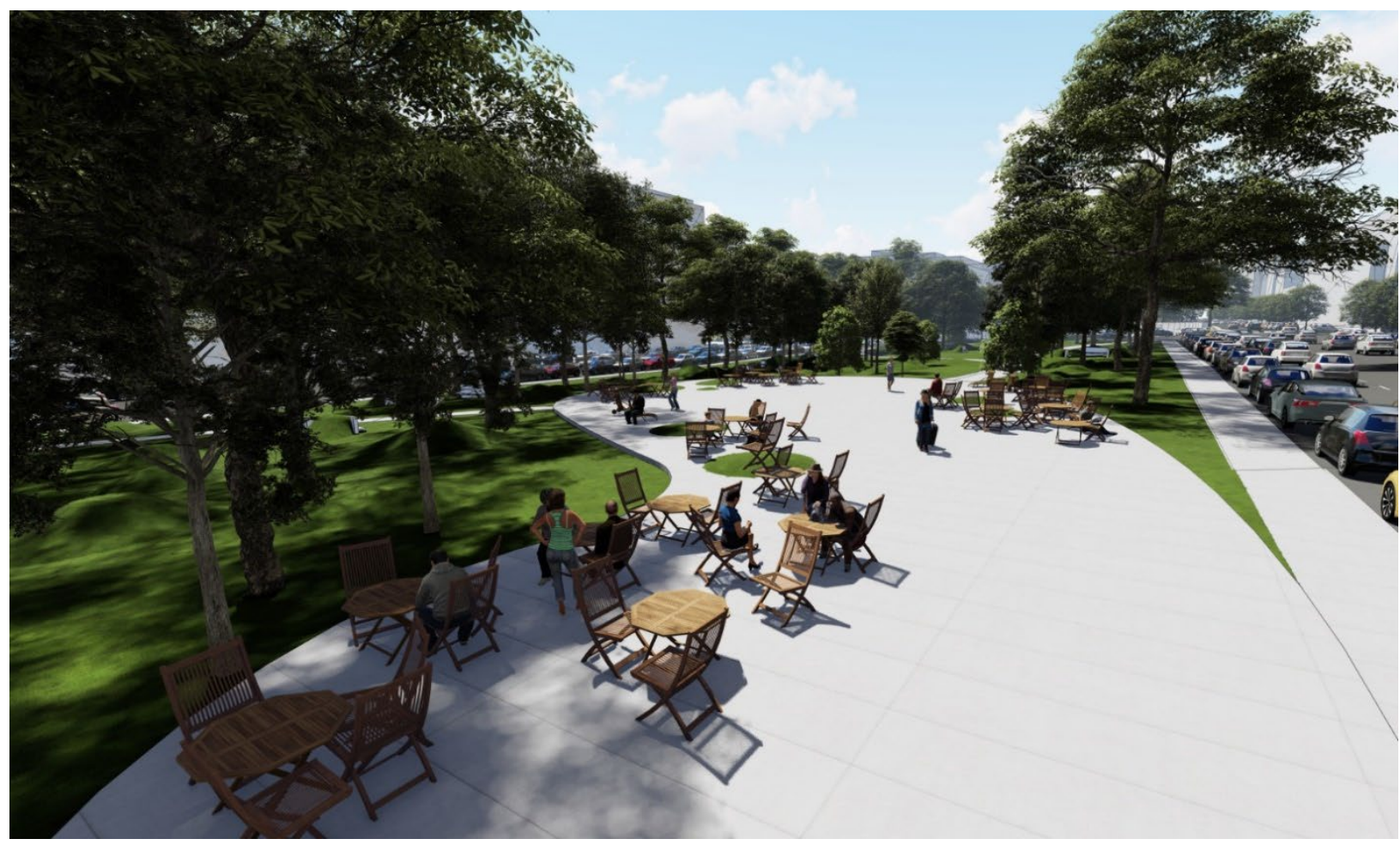

Figure 55: Perspective of Plaza and Vegetation Walt Whitman Park (Gray)

The final goal for the design of the site for Walt Whitman Park included the shaping of a meandering path through nature, helping to slow the walking pace of park visitors creating a more tranquil space and soundscape.

\subsection{Cage Bridge and Triangle Park Designs}

The designs of Cage Bridge and Triangle Park showcase mechanical sounds and societal sounds, respectively. Both spaces have a distinct soundscape intention that may initially seem counterproductive to one another, but ultimately best represent life in urbanized areas.

The existing sound sources for the green space at the dividing entrance and exit to the $\mathrm{E}$ Street Expressway (the proposed site of Cage Bridge) almost exclusively are comprised from 
motor vehicles with bird sounds and rustling leaves peeking through periodically. This existing soundscape plans to highlight the sounds that are already most prominent in that green space, vehicular traffic. To do so, the soundscape management strategy will be offensive.

In Triangle Park, a wide variety of sound sources already seem to pass through this space. Sounds from birds, passing vehicles, and a nearby ventilation system, create constant sounds in the soundscape of Triangle Park. Temporary sounds in Triangle Park have ranged from human footsteps and conversation to the hum of a radio for the full duration of an audio recording, this space has the most variety of sounds of the four parks recorded. The diversity of sound sources, Triangles Park's location within the E Street Park System, and the existing memorial plaza for General Jose De San Martin, lead the soundscape design intention to be that of a welcoming space featuring societal sounds. The soundscape for Triangle Park is close to the intended goal, but through creative soundscape management and landscape design, the space will feature additional greenery and different internal pathways, becoming more hospitable to social gatherings creating societal sounds.

In the site plan created for Cage Bridge and Triangle Park (Figure 56) both sites can emphasize the desired sound category while working to increase participation in their respective spaces through visual changes in the landscape. 


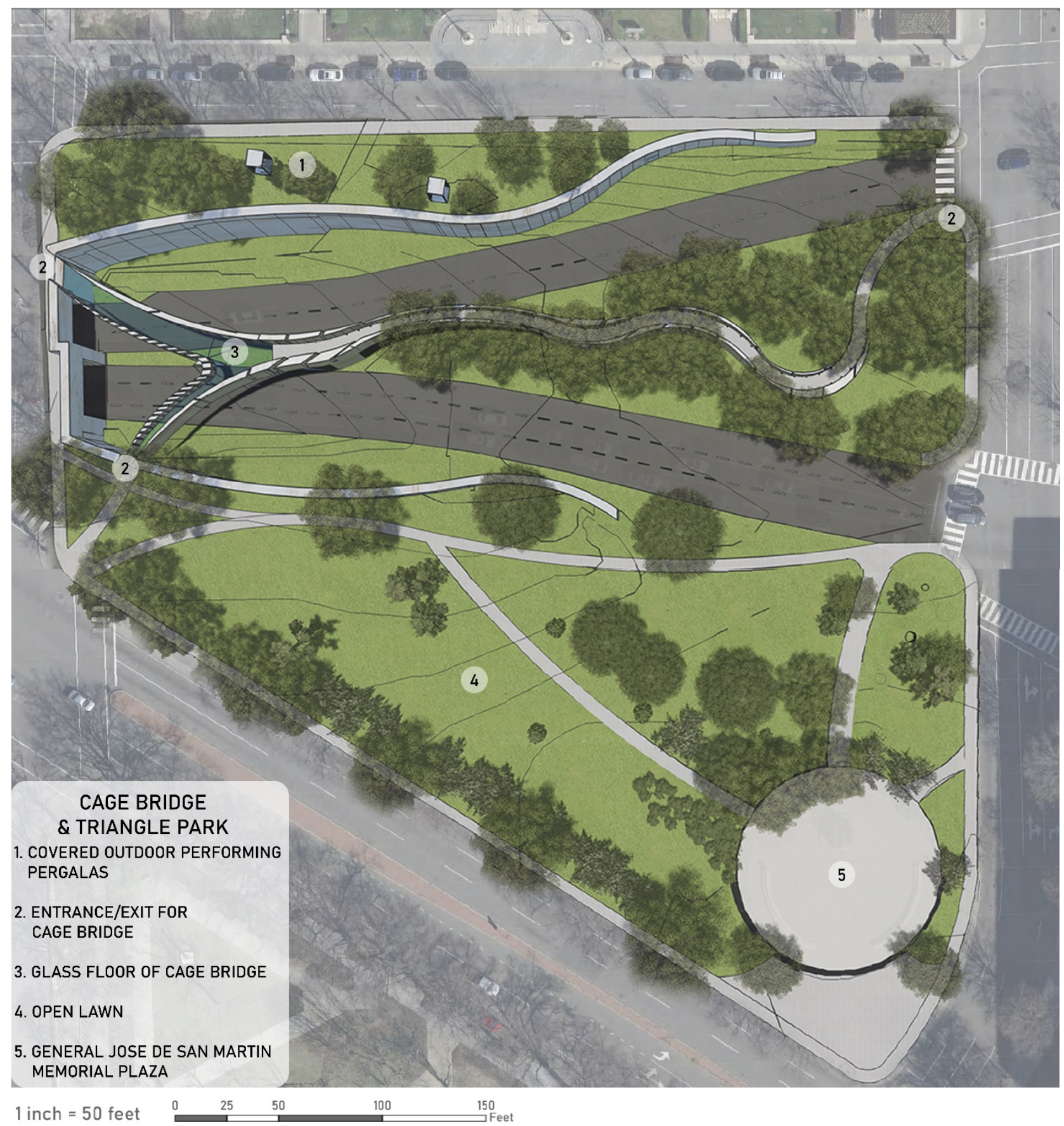

Figure 56: Site Plan for Cage Bridge and Triangle Park (Gray)

The proposed site of Cage bridge currently stands on a grassy triangle with 18 mature Quercus phellos (willow oaks), this green space tapers away as the topography descends into the vehicles only entrance and exit to the E Street Expressway (Figure 57). This grassy triangle 
offers both challenges and great opportunities for soundscape and landscape design. For the soundscape, this space could take listeners and immerse them in the one of the most important sounds of the city, traffic. For the landscape, this triangle offers a direct connection parallel to $\mathrm{E}$ Street, creating a direct path from east to west. The soundscape and landscape solution to these challenges, is a bridge that takes listeners through both soundscape and landscape (Figure 58). Cage Bridge, named after experimental composer John Cage, introduces listeners to different types of listening through the music of traffic. Starting at grade level on the northeast corner of the green triangle of the E Street Expressway Entrance, the bridge initially starts the descent along with the westbound traffic down towards the tunnel (Figure 59). Soon after, the bridge levels off and continues by weaving through the trees within the triangle of green space, alternating movements that guide the listener to hear the different directions of traffic.

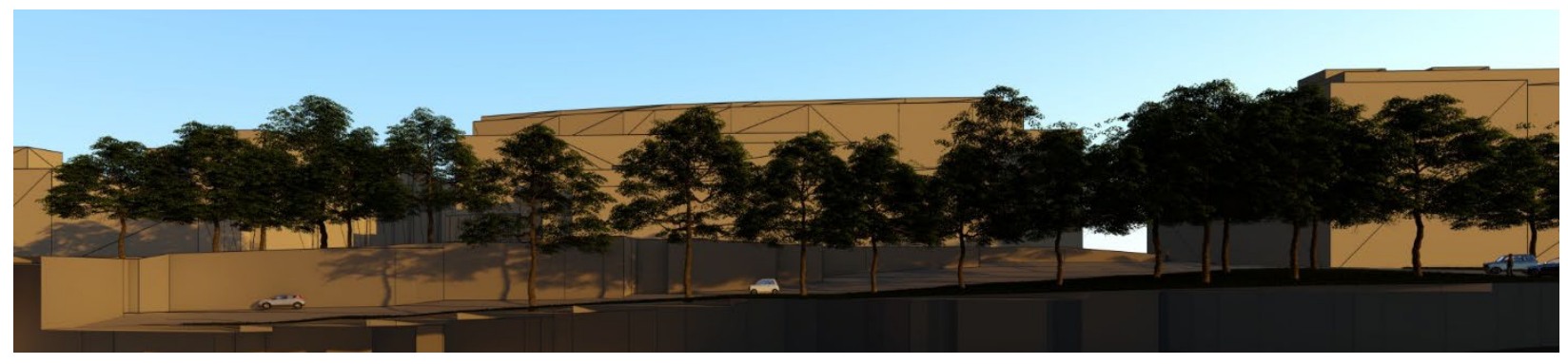

Figure 57: West East Section of Existing E Street Expressway Underpass (Gray)

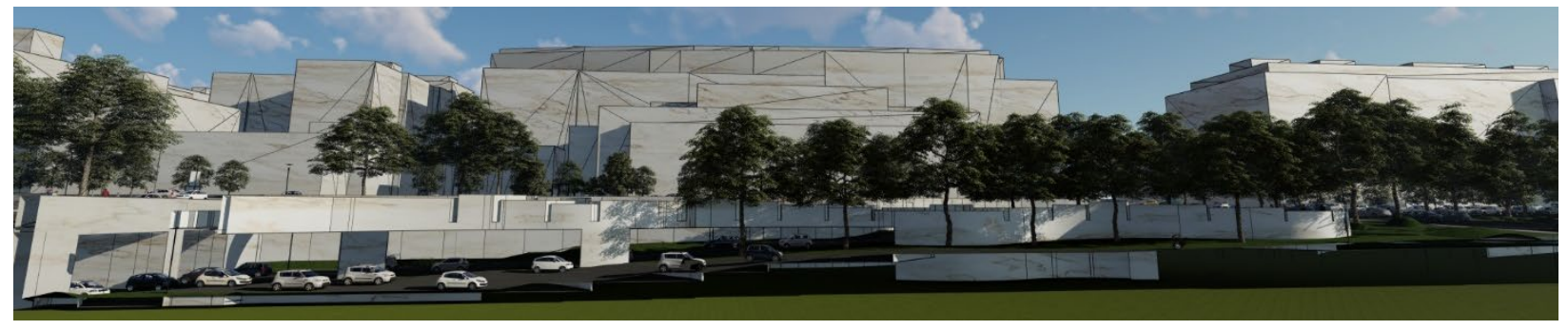

Figure 58: West East Section of Proposed Cage Bridge Ascending Through Existing E Street Expressway Underpass (Gray) 
As the bridge heads towards different sides of the expressway, the walls of the bridge begin to undulate heights (Figure 60) allowing for limited amounts of sound to travel over and the wall while blocking others. The walls also have periodic slits that let sound and light slip through the stone at an angle. The purposeful blocking and allowance in combination with proximity to the sound source challenge visitors to engage in a unique listening experience. Just as the bridge begins to fork, the walls in front of the tunnels become shorter with more space between, and the floor transitions from concrete to glass, opening both sonically and visually (Figure 61). This spot marks the climax of the soundscape and landscape on Cage Bridge, and the routes to exit either north or south appear.

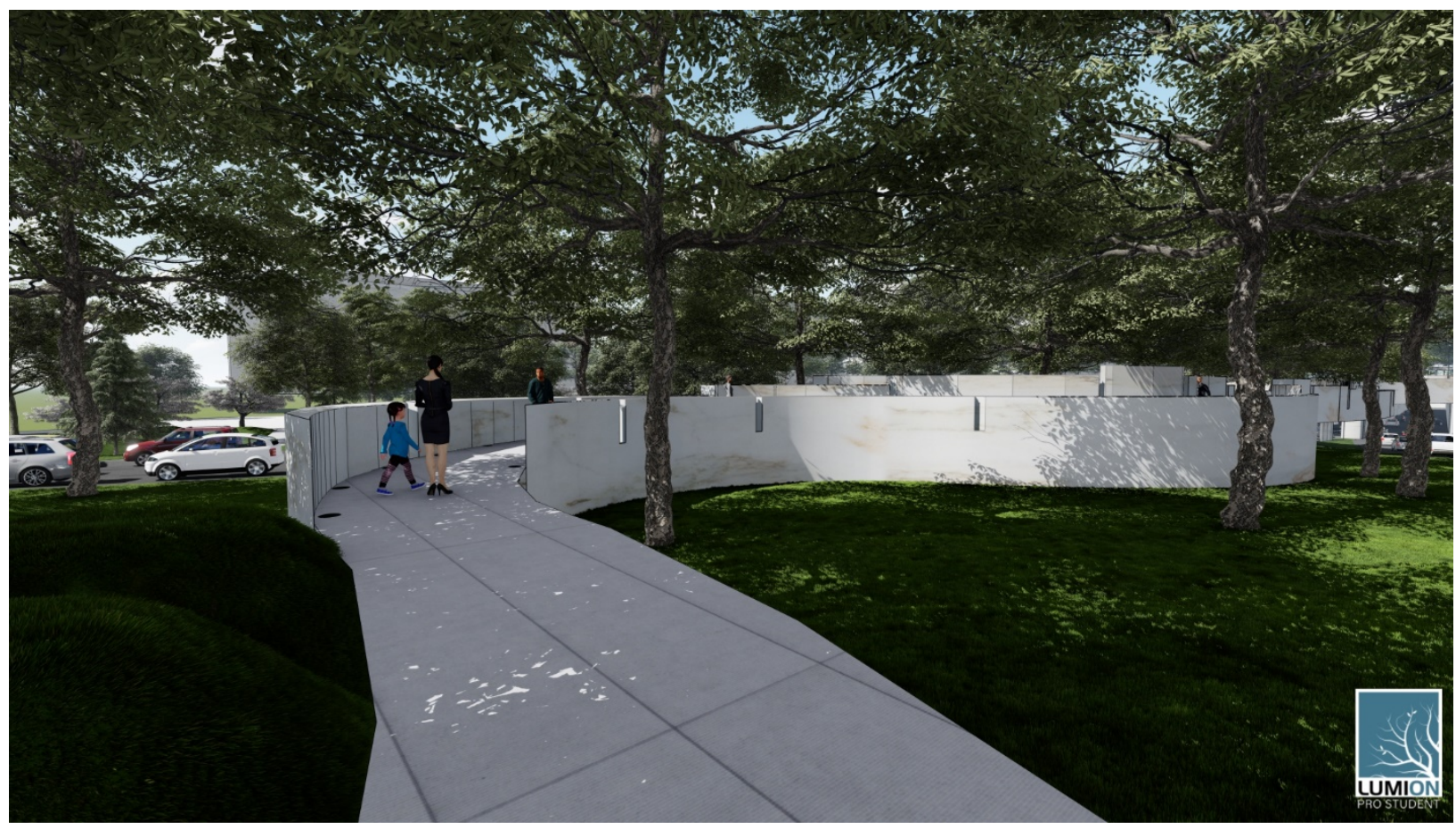

Figure 59: Eastern Entrance to Cage Bridge (Gray) 


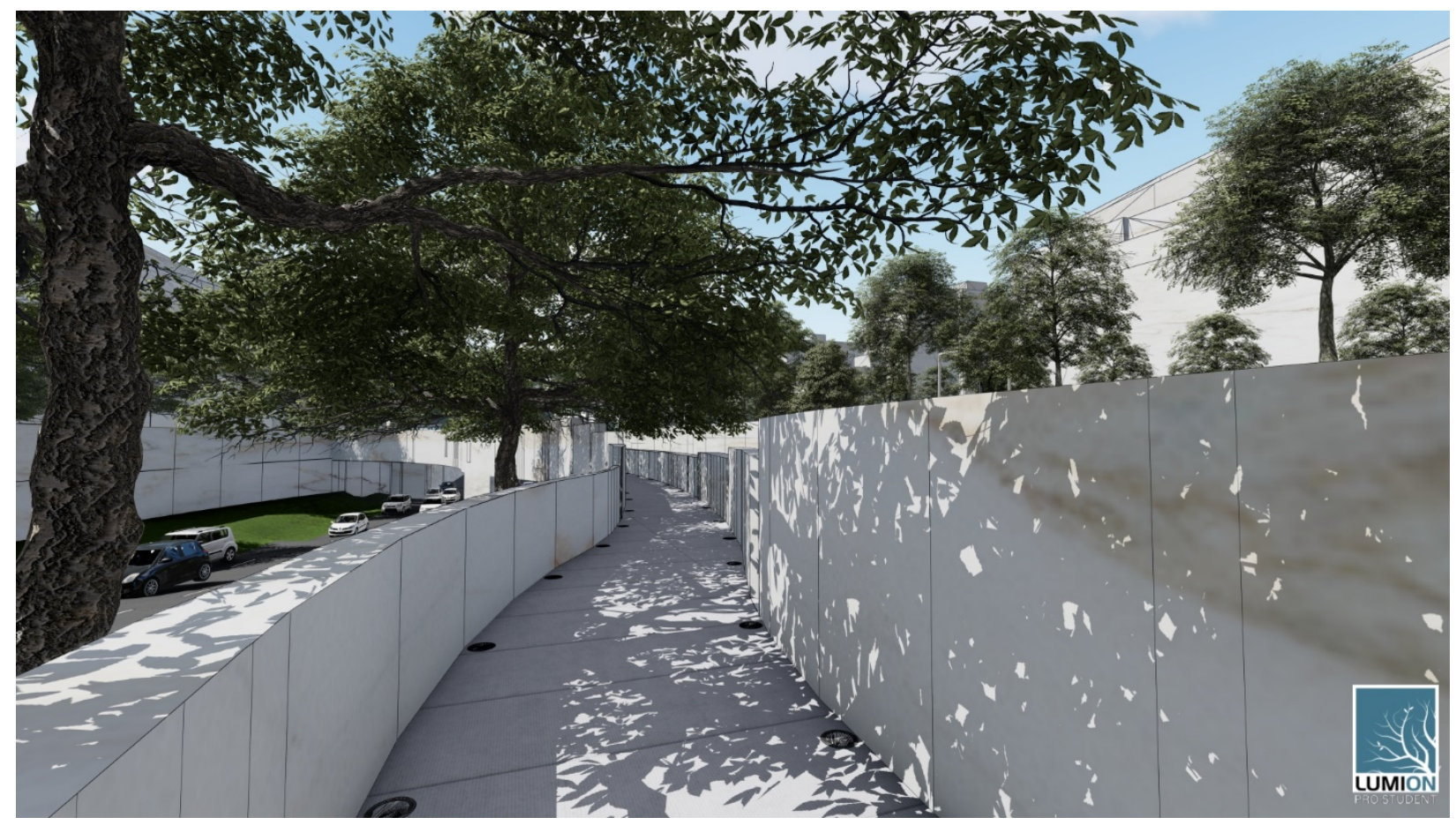

Figure 60: View of Different Wall Heights on Cage Bridge (Gray)

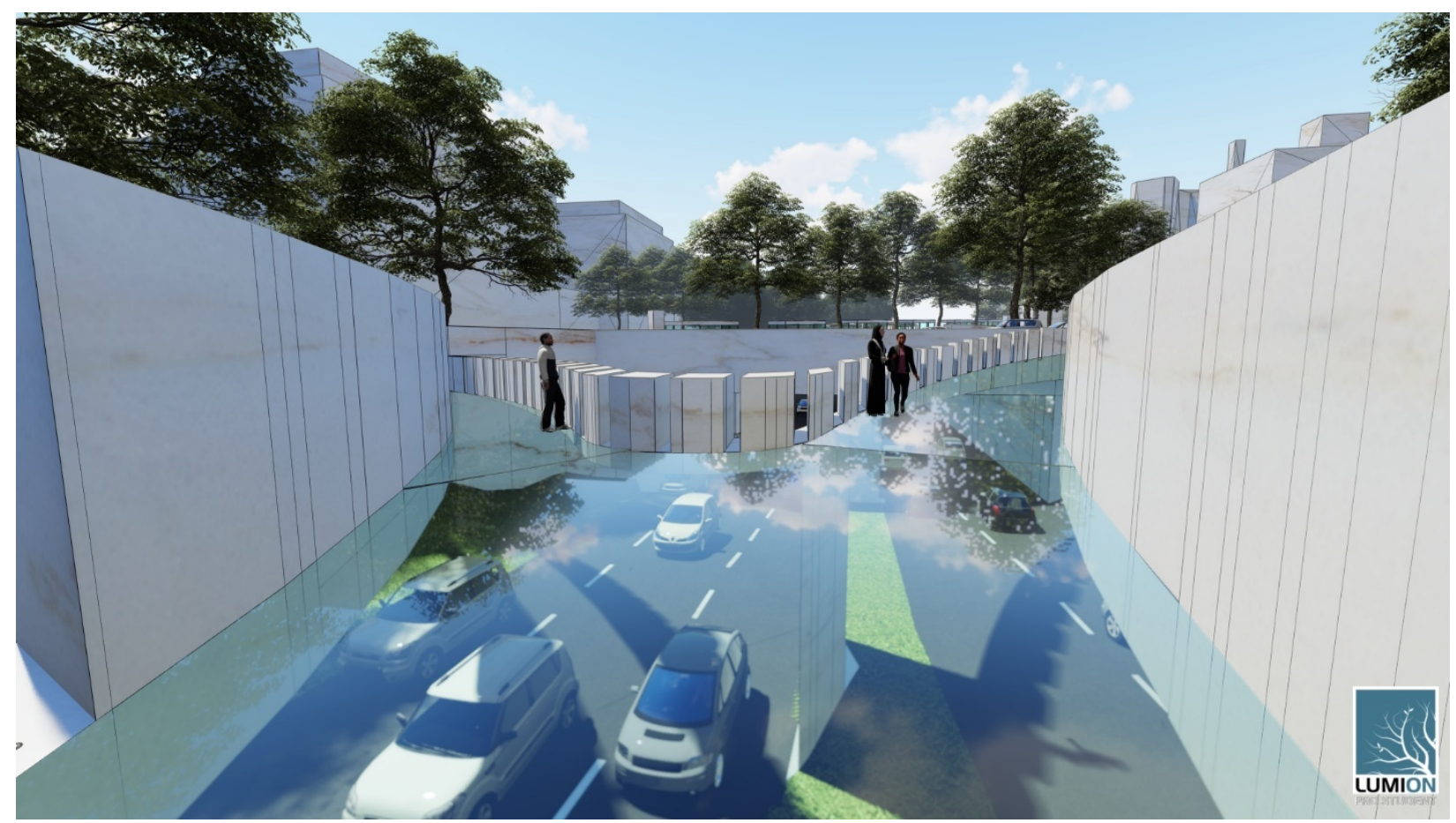

Figure 61: View over Y Intersection on Cage Bridge (Gray) 


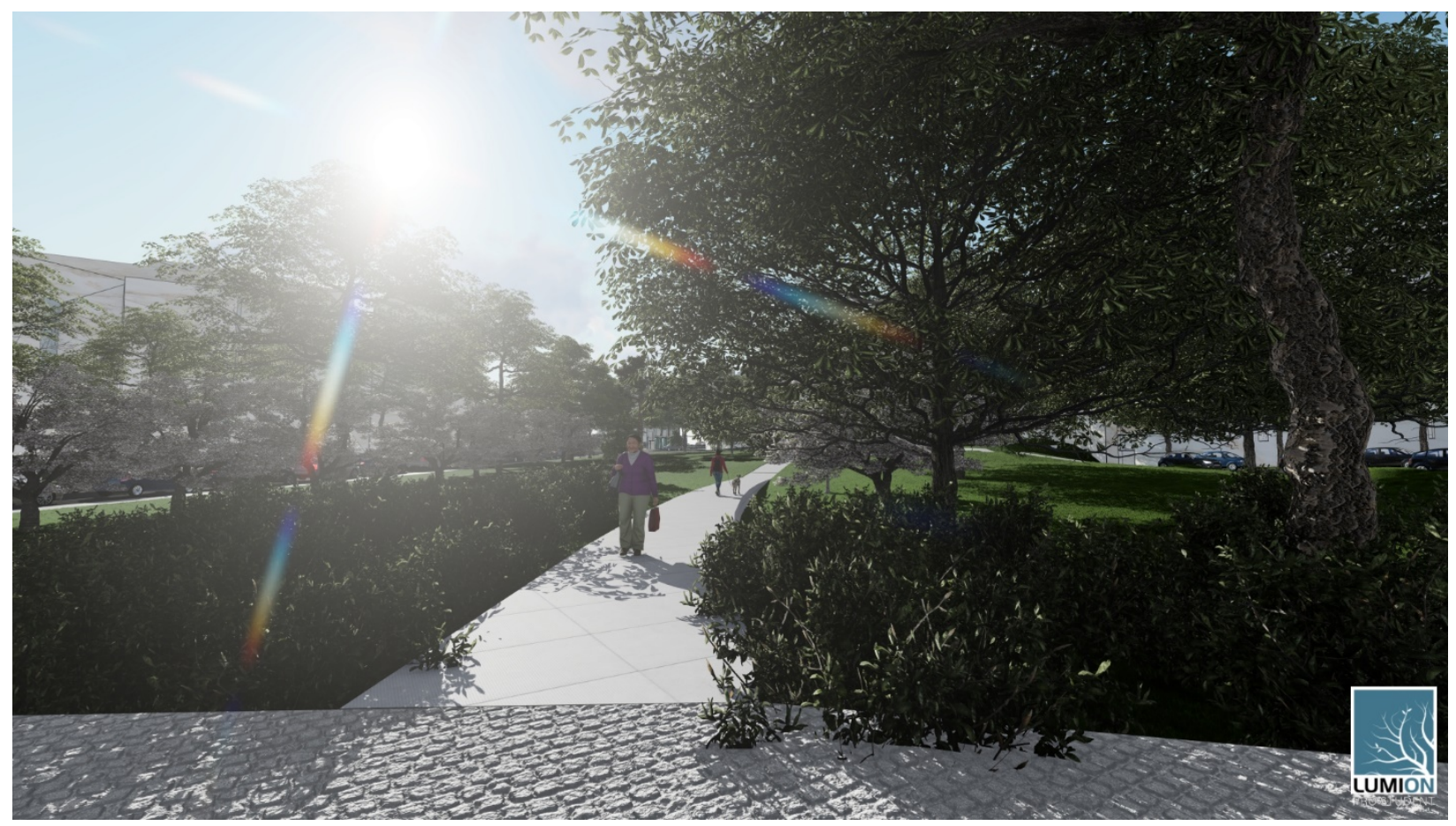

Figure 62: West View from General Jose De San Martin Memorial Plaza in Triangle Park (Gray)

To encourage societal sounds in Triangle Park, relatively minor alterations would be made in the existing space. The only soundscape management technique that would be a direct soundscape desugn choice would be the creative technique in making additional plantings throughout the park, but most heavily along Virginia Avenue and around the plaza to better frame the space and contribute natural sounds (Figure 62). Other design choices to increase societal noises through larger gathers includes the removal of the General Jose De San Martin statue from the center of the plaza (Figure 63), removing the pedestal from the statue, and placing the General Jose De San Martin statue at ground level around the back perimeter of the plaza where it can still be easily seen. As well as changing the shapes of the pathways planting around the new paths. Much like the paths in Walt Whitman Park, this will slowdown the walking rate of pedestrians as the increased natural sounds have been linked to improved perception of the soundscape and landscape encouraging users to stay longer (Maculewicz et al, 
2016).

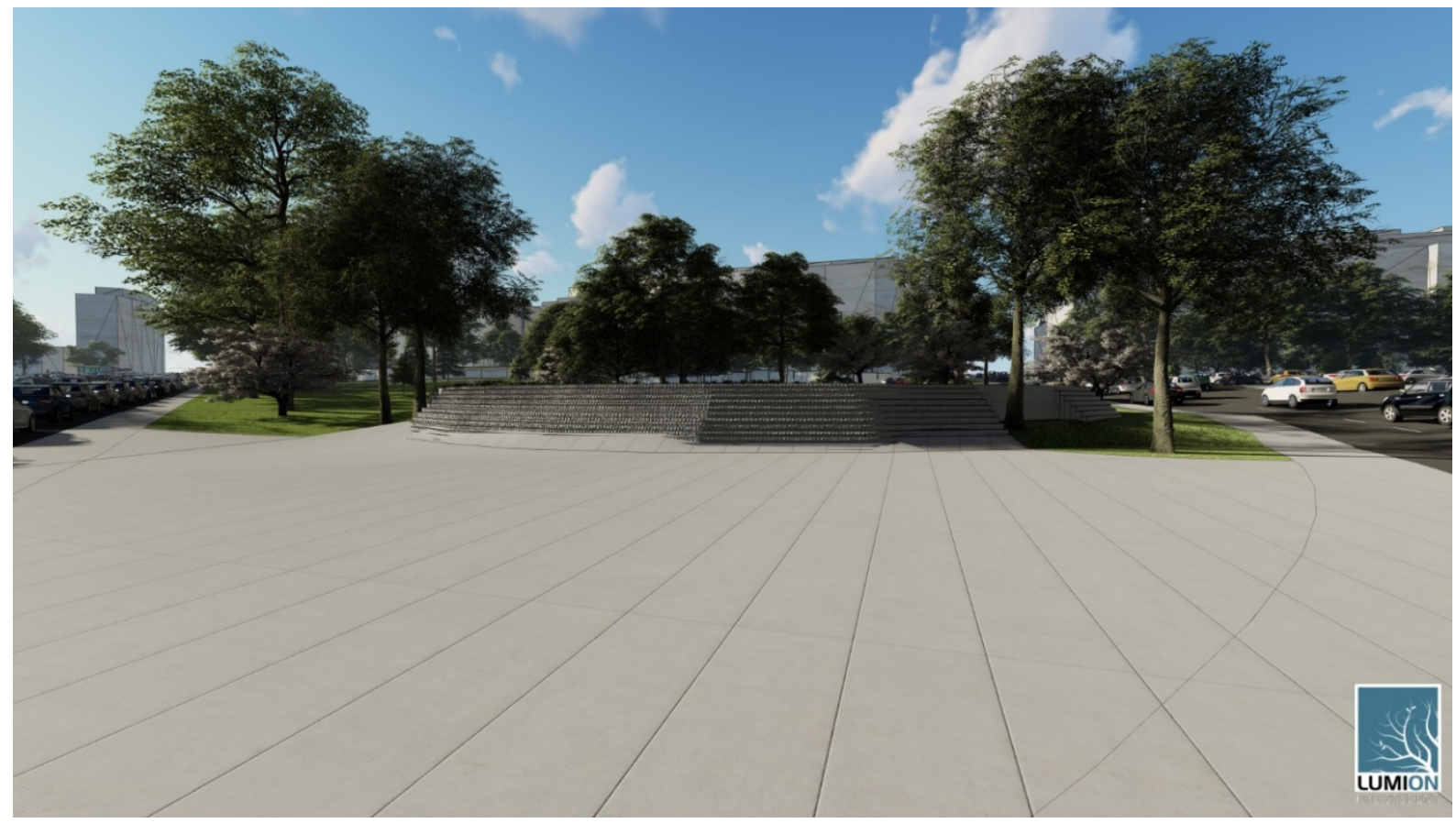

Figure 63: View of General Jose De San Martin Memorial Plaza in Triangle Park (Gray)

\subsection{Virginiana Ave Bus Plaza and Bernardo De Galvez Park Designs}

The intersection of Virginia Avenue and E Street, and Bernardo de Galvez Memorial Park, represent the western end of the E Street Park System as it currently exists. In the proposed plans at the broader scale, this portion of the site also functions as the center when planned along side the Rafael Viñoly plan to connect the Kennedy Center and the Reach at the Kennedy Center. This intersection not only connects the two sides of the thesis site, but also have links beyond the site through the bus hub and the route on Virginia Avenue leading straight to the Washington Monument. The essential role of this space is to function as the main thresholds for the site. The soundscape threshold is split between the two space, with both sides encountering high amounts of mechanical sounds produced from vehicular traffic, the bus stops, and loud ventilation 
systems on either side of Virginia Avenue. The Virginia Avenue Bus Hub receives the bulk of bus traffic between the two parts of the site and suffers from loud extremely loud sounds from a ventilation on the western and southern corners of the block. Because of the vital nature of these sound sources for the function of that site, mechanical sounds are the focus for that soundscape. Bernardo de Galvez Memorial Park also deals with sounds from bus stations and and vwentilation systems on its eastern border with Virginia Avenue. However, Bernardo de Galvez Memorial Park has the benefit of space creating more separation between listeners and those mechanical sound sources. This seperation allows for the constant sounds of silence to begin to cut through in this soundscape more so than any other recorded for this thesis. This fact in combination with the possibilties created with the Rafael Viñoly ${ }^{3}$ plan allow for this space to be dedicated to sounds of silence

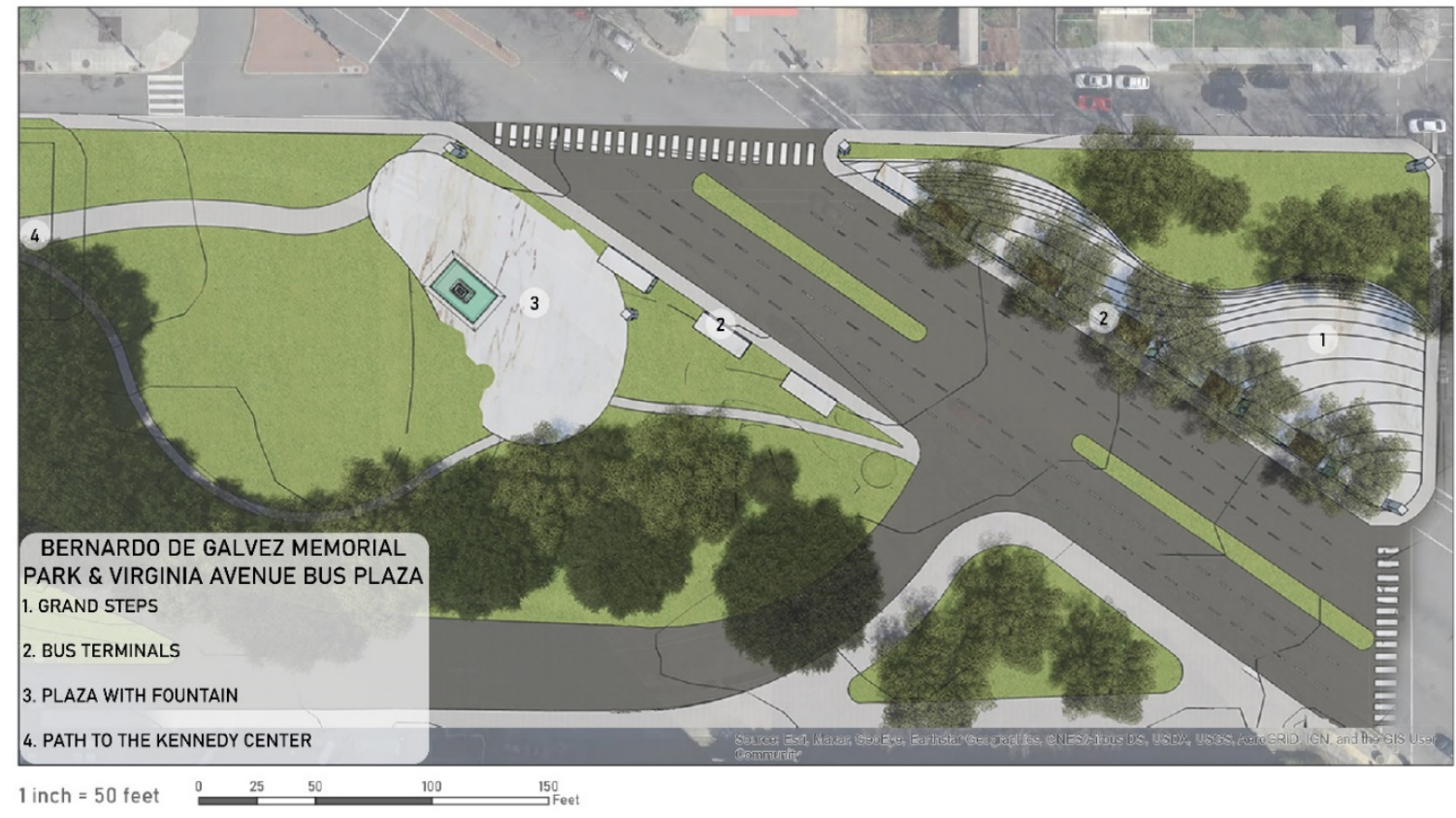

Figure 64: Site Plan for Virginia Avenue Bus Plaza and Bernardo de Galvez Memorial Park (Gray)

\footnotetext{
${ }^{3}$ Due to limited time given with thesis research, exploring the sounds of silence and the educational possibilities of ear cleaning would not be possible. Designing along the deck in Rafael Viñoly's plan that goes over Route 66 was not feasible at this time.
} 
A site plan was crafted to address the soundscape needs of both blocks as well as the important functions as thresholds for the larger scale (Figure 64). The site plan for the Virginia Avenue Bus Hub engaged the mechanical sound sources that were creating most of the soundscape for that block. Two types of sound management strategies were used to transform the Virginia Avenue Bus Hub into a plaza, green space, and bus station. First, the offensive soundscape management strategy was with the intent to draw attention to the buses and the vehicular traffic surrounding the site. Due to the size of the block and the number of motor vehicles contributing as sound sources, there would be no way to make any substantive change to the soundscape without constructing a building or stopping traffic. While trying to cover sound sources that are so close and loud would result in the in more discomfort. This leaves offensive soundscape management, which for this site meant increased visibility and acknowledgement of the sound sources.

The offensive design solution resulted in the conception of a grand set of stairs that would fit with themes from the rest of the park system, as well as those of the surrounding federal buildings of Washington D.C. These stairs with long treads and low risers will allow for easy movement and connectivity through the block, with clear site lines of traffic on all sides (Figure 65). See through bus stations also have been designed all for visibility across the block. A defensive method was also used to address the loud noise from the underground ventilation system. As they currently exist, the vents release large volumes of noise at ground level for both blocks, though most severely at the westerner corner of the Virginiana Avenue Bus Plaza. To remedy this situation, a defensive method of soundscape management was used to move the output of the vent. Tall stone structures (Figure 66) were design to function as extensions to the 
vent outlets release the sound above earshot, reducing the amount of audible sound emitted from the pipes.

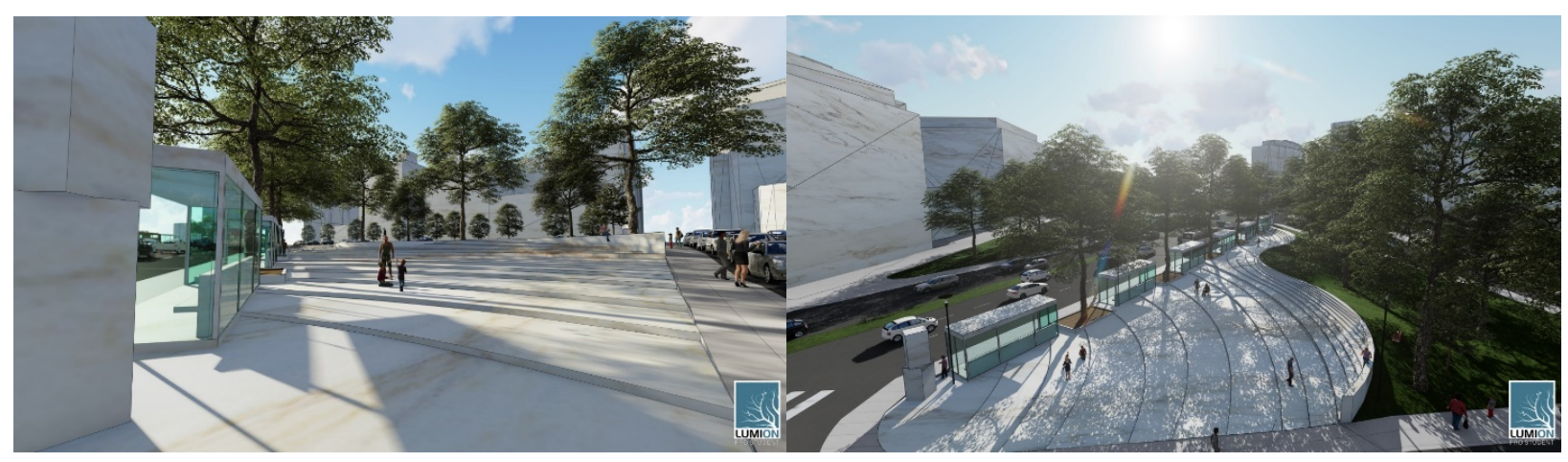

Left: Figure 65: View of Grand Stairs in Virginia Avenue Bus Plaza (Gray)

Right: Figure 66: Aerial View West from Virginia Avenue Bus Plaza (Gray)

Similar methods from the Virginia Avenue Bus Plaza were used for the western portion of Bernardo De Galvez Memorial Park. Glass structures for bus stations and an emphasis on visibility were key, as well as the stone structures to elevate the outfall of noise from the vent. Creative soundscape management strategies are used by creating a small plaza with a fountain making natural, human, cultural sounds, while still allowing for visibility near the roadways. Defenseive soundscape strategies are also used by the fountain at the plaza, as it works to lightly mask the sounds of nearby traffic. The fountain also calls back themes from Rawlins Park as users approach the path leading to the Kennedy Center. Other defensive methods are used through mounds and plantings in the southern side of Bernardo De Galvez Memorial Park, blocking the sounds of traffic emerging from the E Street Expressway (Figure 67). 


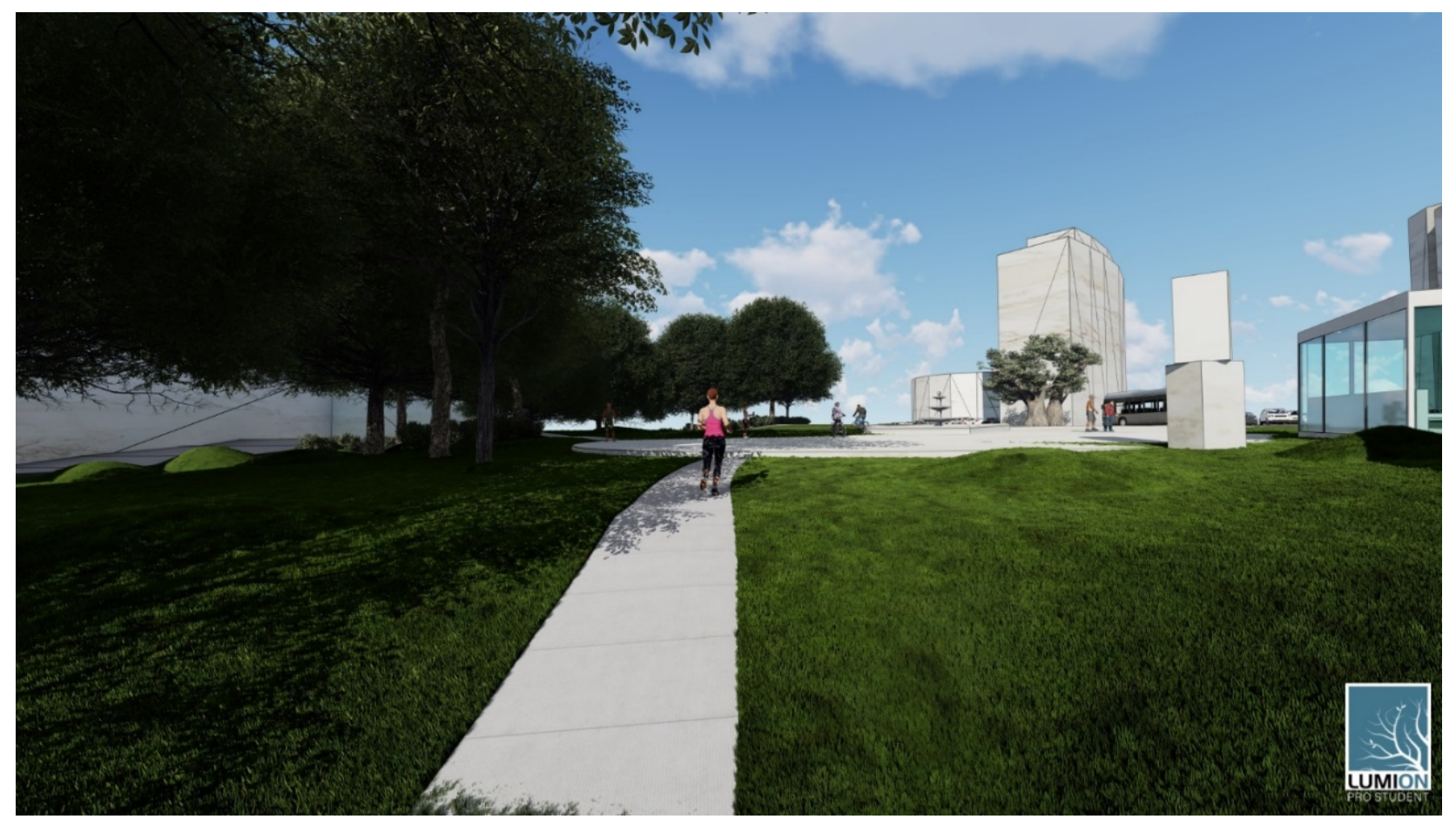

Figure 67: View of Plaza in Bernardo De Galvez Memorial Park (Gray) 


\section{Chapter 6: Closing}

\subsection{Reflection}

In this thesis, a theory for soundscape and landscape design was established through a literature review and showcased in a design. While assembling the theory in the literature review, a surveying system through soundscape scoring was created. This system documents the existing soundscape in a visual manner, using principles from Western Classical Music. John Cage, R. Murray Schafer, and Lawrence Halprin. With further development, this system has the opportunity for use beyond this thesis. As it currently functions, the score allows for largely quantitative analysis of a site, documenting what sounds have been heard by the surveyor, while still factoring some qualitative data based on the perceptions and preferences of the surveyor. The scores can be further explored by analyzing factors such as whether the documented sounds being recorded on the score are based on in-person experience of the soundscape versus that of a recording of a soundscape. As well as looking into factors of perception, preference, and biases of the surveyor. In further developing this soundscape score system, a more complete visual documentation of the soundscape can be achieved and used for design purposes.

\section{Exploration of the intersection between Landscape Architecture, Acoustics,} Psychoacoustics, and Music, has also led to visions of theoretical application beyond what had been previously imagined. The National Park Service's work documenting natural sounds of their more rural parks through programs such as PARKTRACKS, could be expanded by research such as this. Working in urban parks documenting the cultures and ecosystems of those spaces through soundscape recordings. Additionally, documenting these urban soundscapes as they continue to change surrounding the COVID-19 Pandemic could produce important information. 
This Pandemic disrupted what would have been the typical soundscape, creating conditions that will either be considered an anomaly or the beginning of new normal.

Other developments for this soundscape and landscape design theory may include working at the planning scale and emphasizing social justice and racial equity. Expanding this theory in planning will create larger scale soundscape policies that address noise pollution and soundscape design. The basis of this theory also allowing for cities that could be customized to the needs of the individual city. This theory's development will also require further research in social justice and racial inequity so that it can begin to acknowledge, address, and repair the need for social justice and racial equity in the soundscapes of urban areas that have been polluted with noise creating a disparity for urban populations that are more vulnerable. While both topics were breached in the research phase of this thesis, it was found that both topics were so beyond the scope of this particular thesis given the level of importance and the amount of subject matter of each topic. Further development of this multi-disciplinary field of research and design is imperative and could have real world benefits to people of all walks of life.

\section{$\underline{6.1 \text { Closing Words }}$}

The soundscape is often ignored or forgotten both in Landscape Architecture and in life. Regardless of whether the soundscape is acknowledged, it still holds immense power over humans and animals alike. By working with the soundscape, and the theories surrounding the soundscape, better, more thought through design can be achieved. 


\section{Appendix. Soundscape Scores}

\section{INDEX}

Sounding and Volume

\begin{tabular}{|cl|}
\hline- & No Sound for 30 \\
$\mathrm{pp}$ & Second Duration \\
$\mathrm{p}$ & Quiet \\
$\mathrm{mp}$ & Moderately Quite \\
$\mathrm{mf}$ & Moderately Loud \\
$\mathrm{f}$ & Loud \\
$\mathrm{ff}$ & Very Loud \\
& Becoming Louder \\
\hline & Becoming Quieter
\end{tabular}

Natural Sounds

\begin{tabular}{|c|c|}
\hline$M$ & Birds Fluttering \\
\hline$\therefore \therefore$ & Bird Song \\
\hline$+x$ & Dog Barking \\
\hline & Squirrels \\
\hline & Water \\
\hline & Wind \\
\hline
\end{tabular}

Human Sounds

\begin{tabular}{|ll}
\hline$\bullet$ & Clap \\
\hdashline & Footsteps \\
\hline
\end{tabular}

Societal Sounds

\begin{tabular}{|cl|}
\hline$\gamma \delta$ & Cart \\
11 & Construction \\
\hline
\end{tabular}

Mechanical Sounds

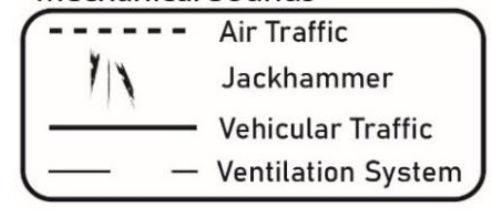

Sounds of Silence and Quiet

\begin{tabular}{|c|c|}
\hline \multicolumn{2}{|c|}{ QZZZZJ Silence } \\
\hline \multicolumn{2}{|c|}{ Sounds as Indicators } \\
\hline & Alarm \\
\hline & Bus Door \\
\hline 1 & Car Horn \\
\hline 0 & Truck Backing Up \\
\hline
\end{tabular}

Figure A1: Sound Index for Soundscape Scores (Gray) 


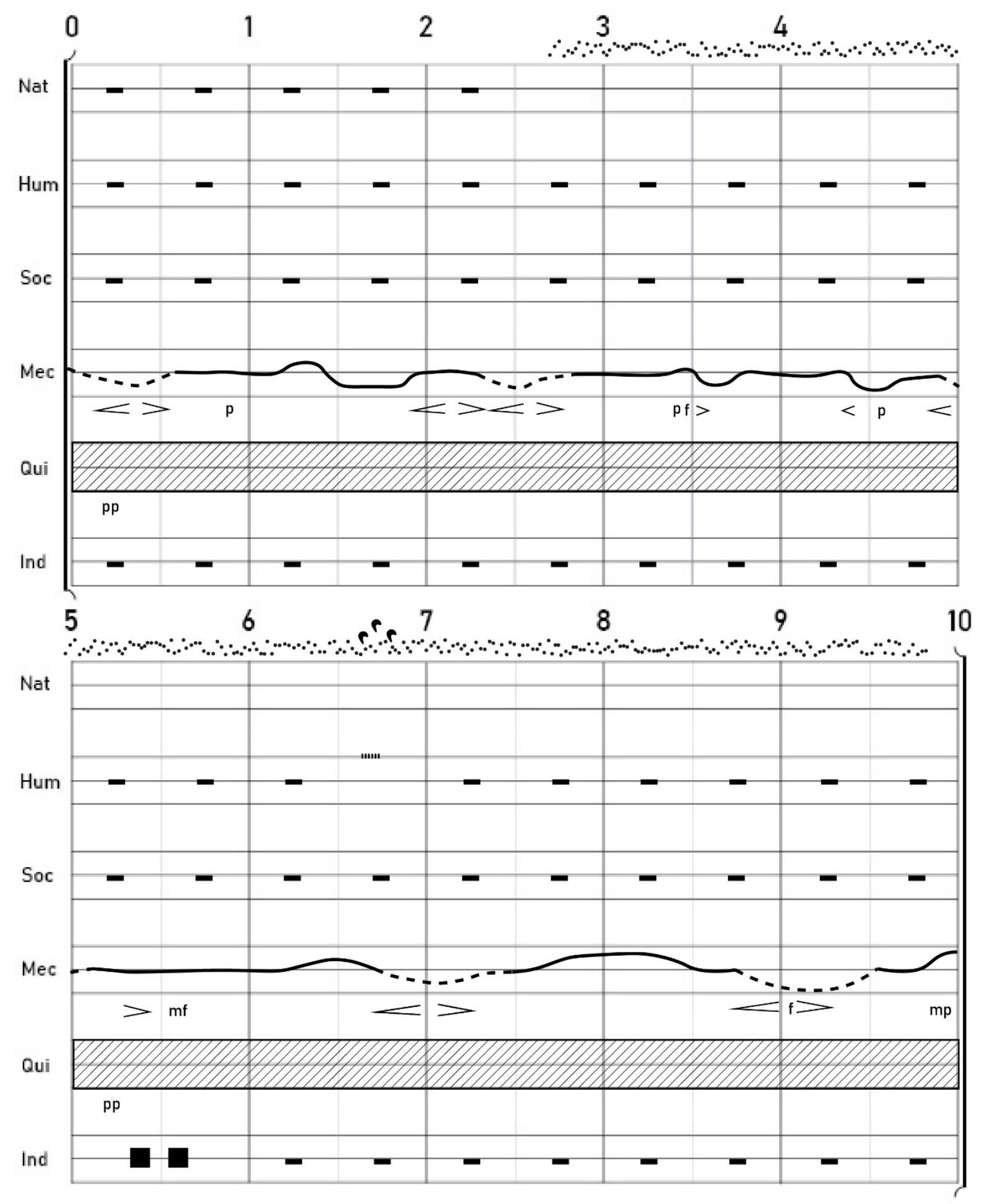

Figure A2: Sound Score for Rawlins Park: Tuesday Morning (Gray) 


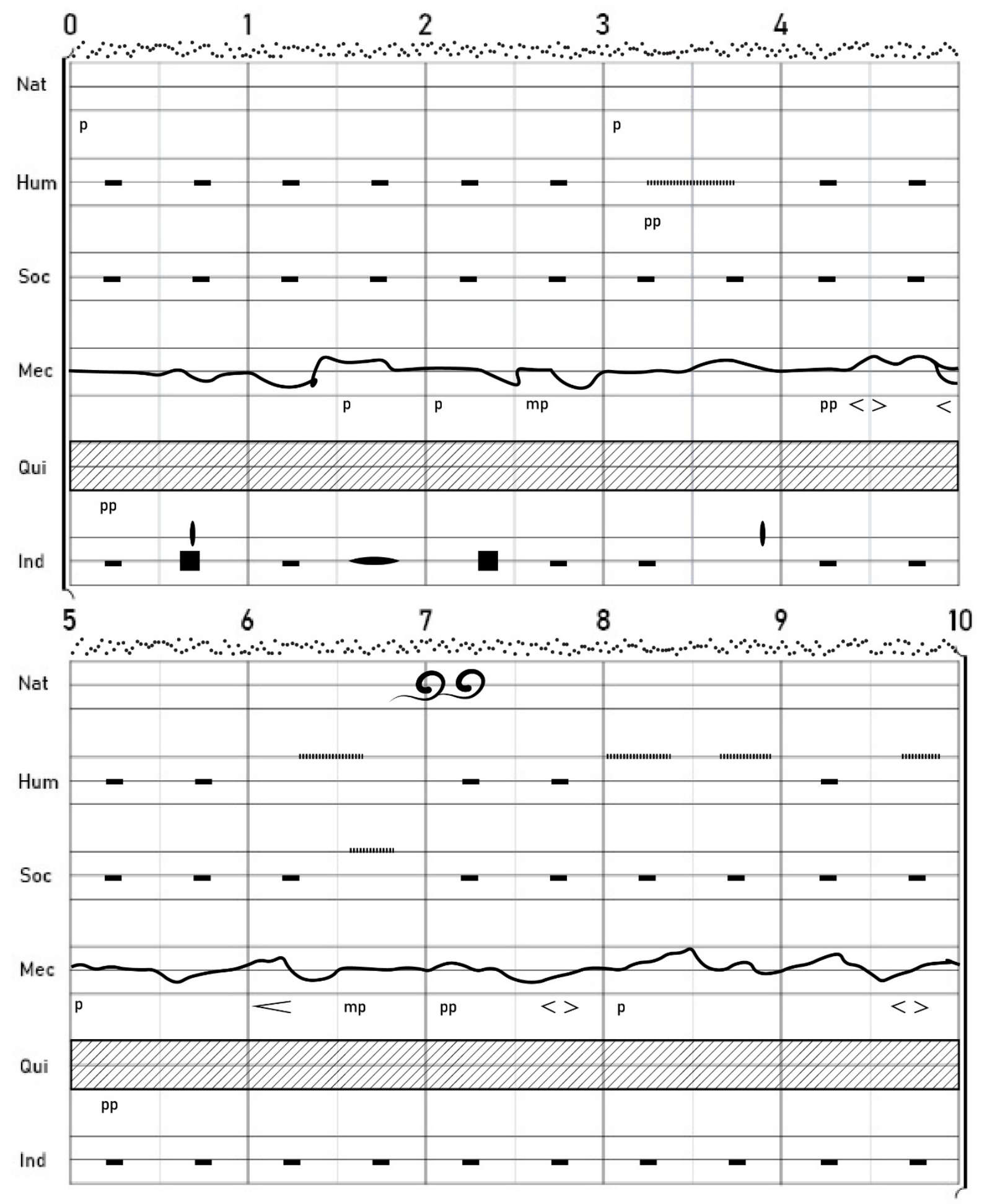

Figure A3: Sound Score for Rawlins Park: Tuesday Afternoon (Gray) 


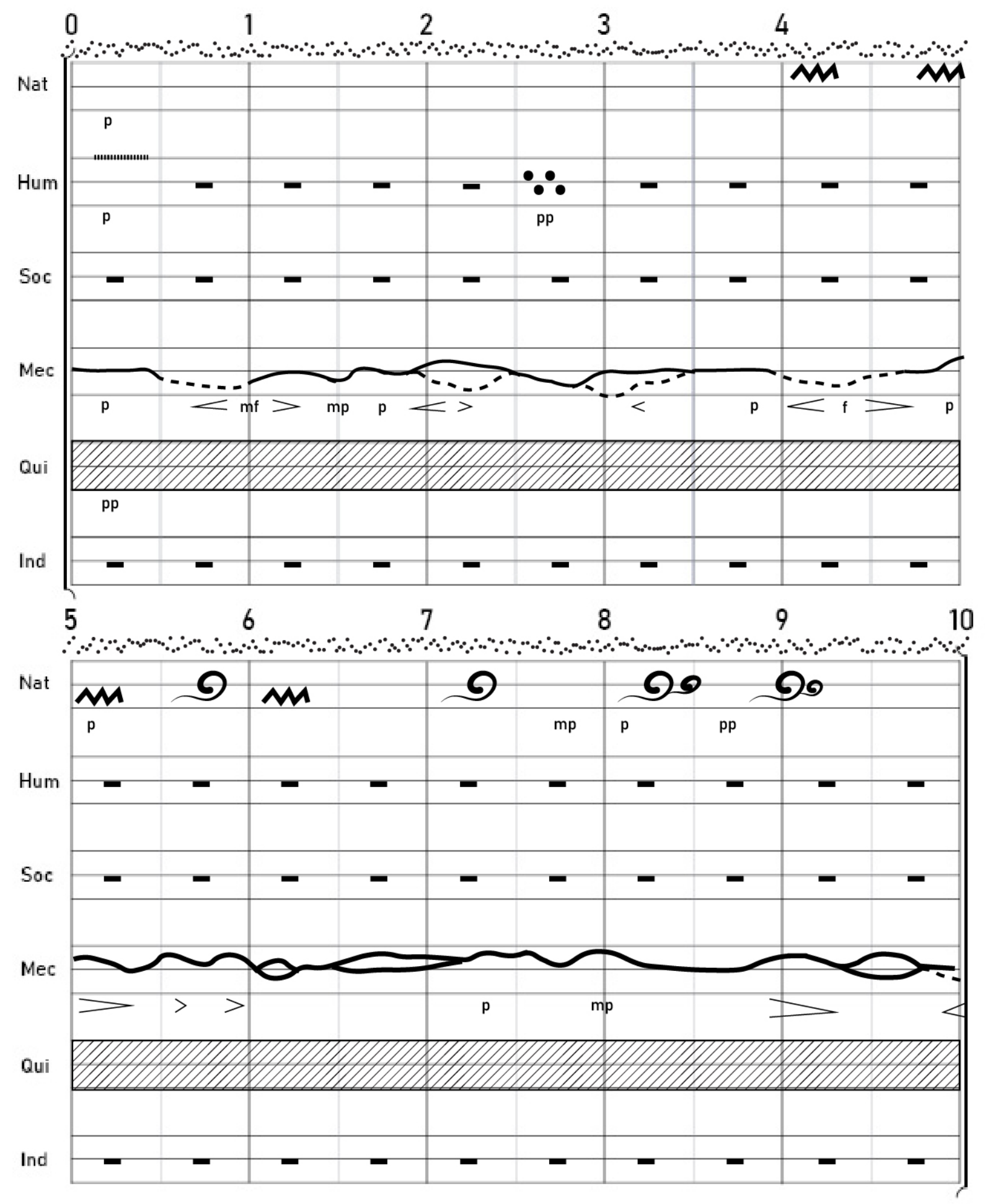

Figure A4: Sound Score for Rawlins Park: Tuesday Late Afternoon (Gray) 

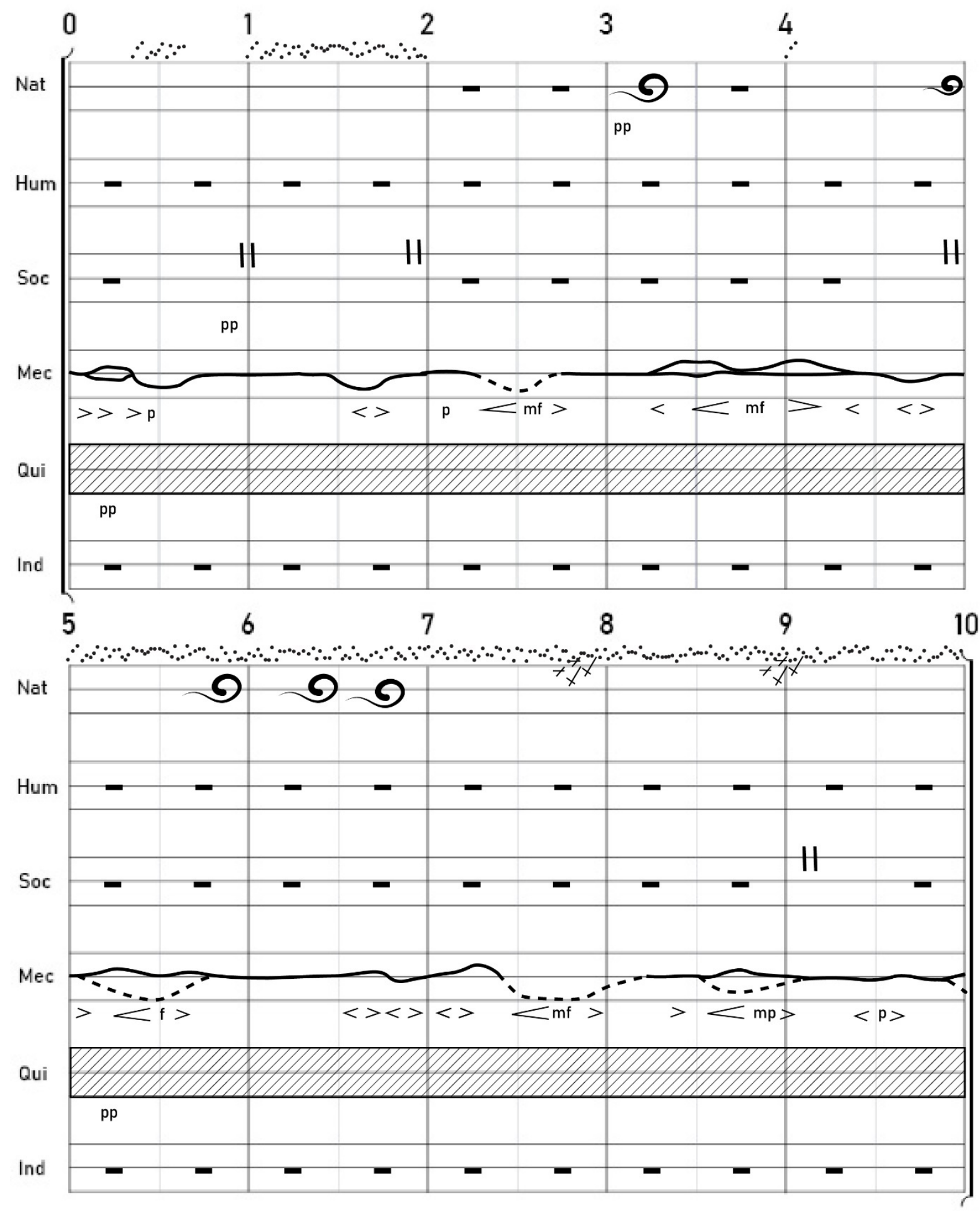

Figure A5: Sound Score for Rawlins Park: Saturday Morning (Gray) 

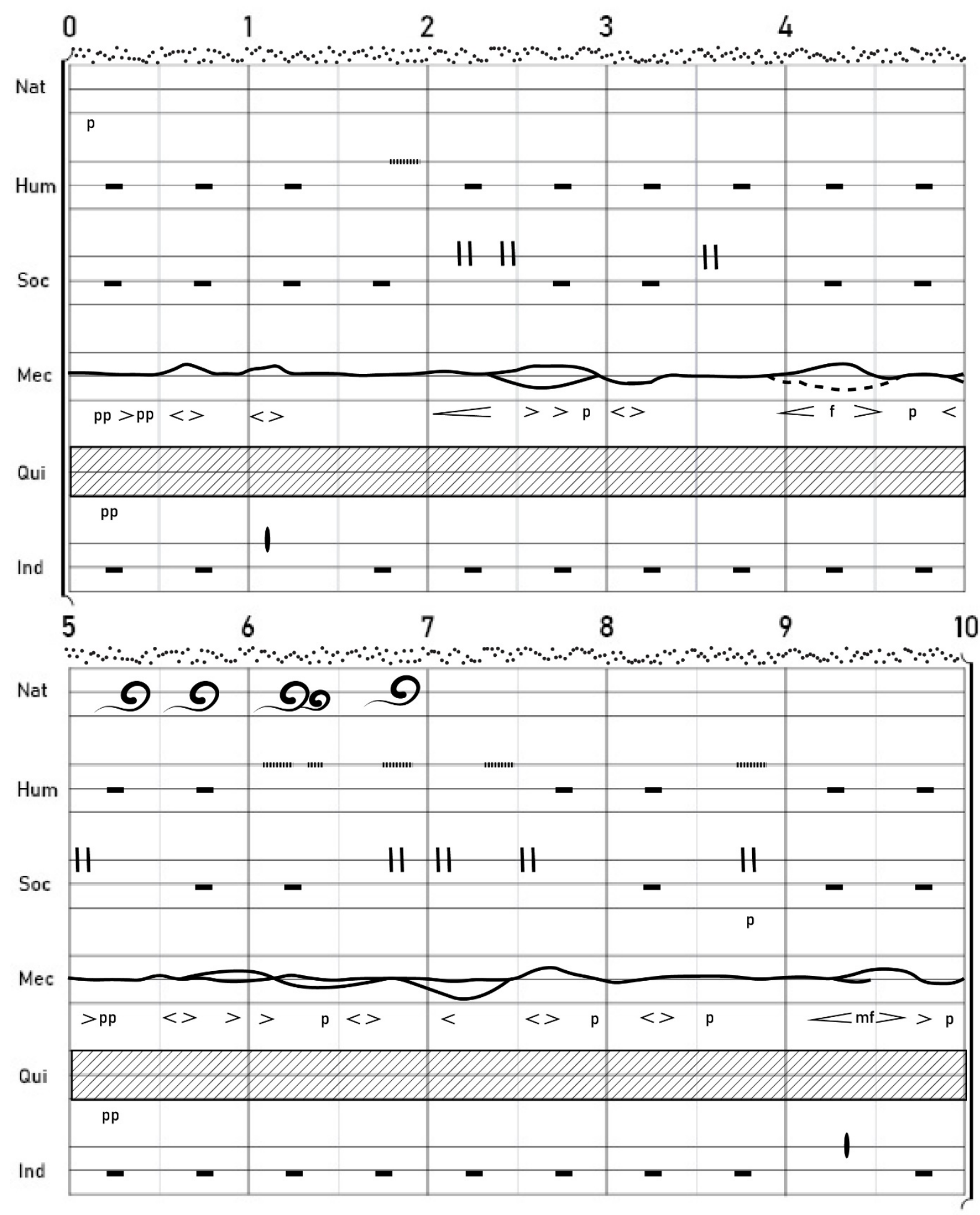

Figure A6: Sound Score for Rawlins Park: Saturday Afternoon (Gray) 

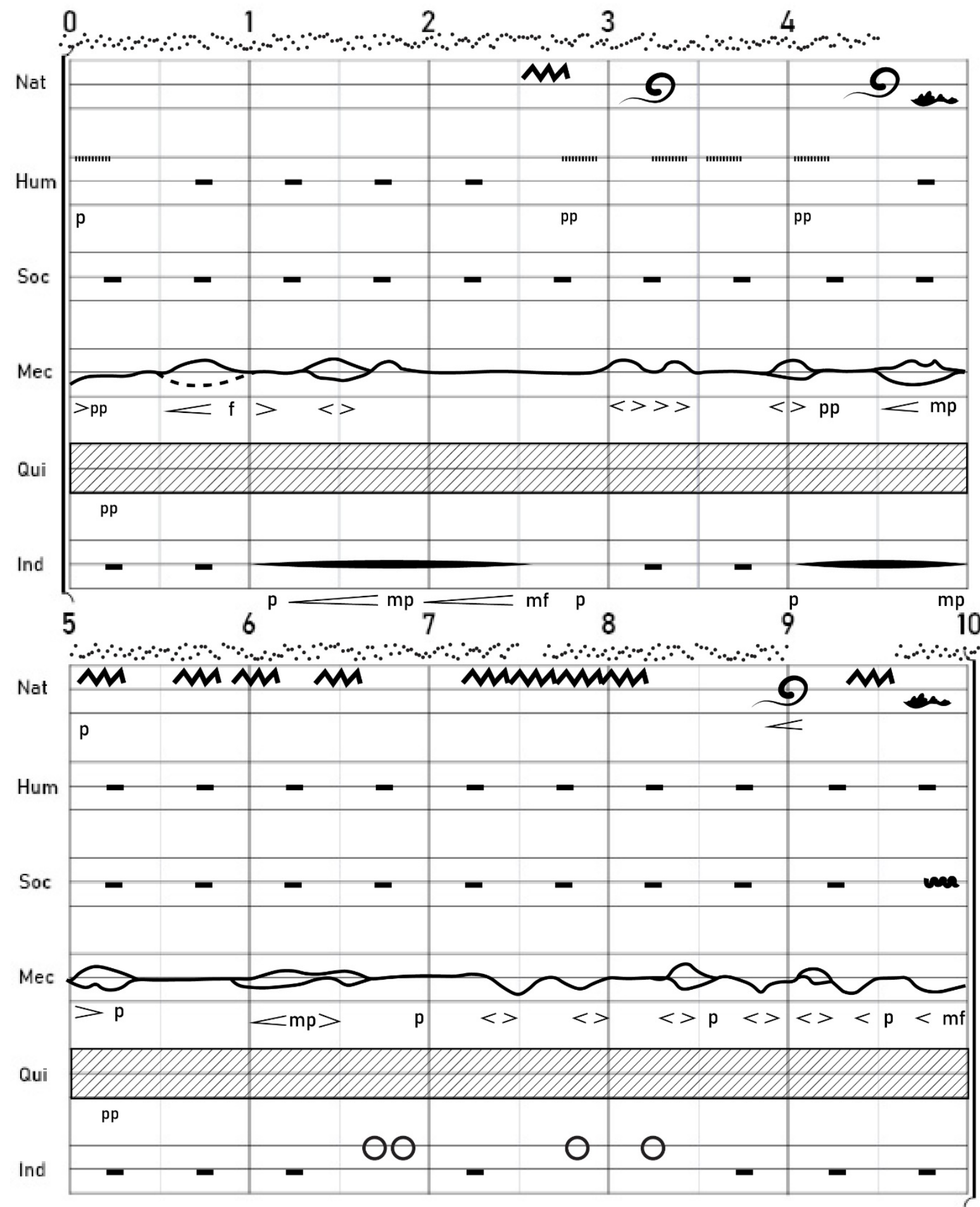

Figure A7: Sound Score for Rawlins Park: Saturday Late Afternoon (Gray) 

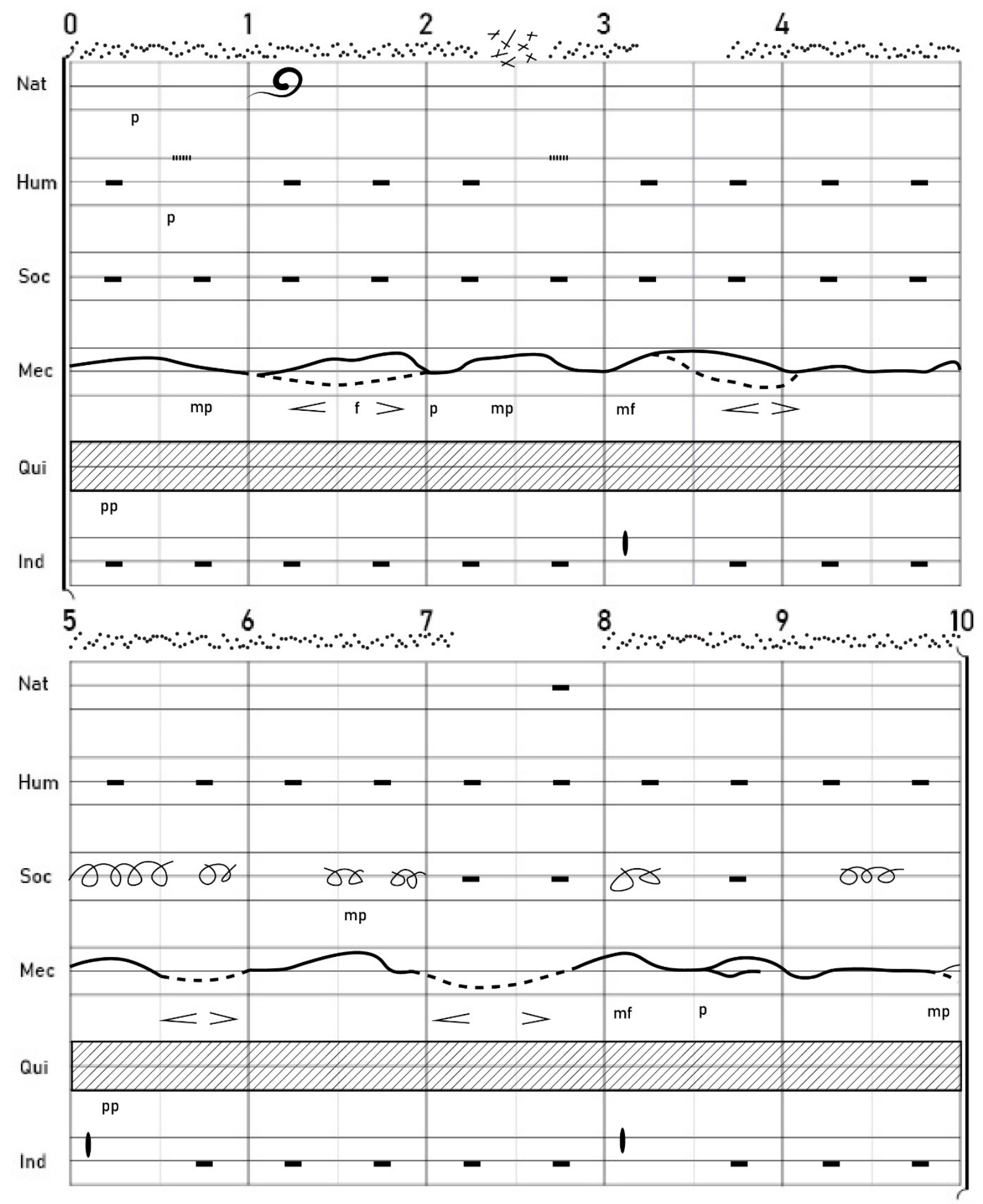

Figure A8: Sound Score for Walt Whitman Park: Tuesday Morning (Gray) 


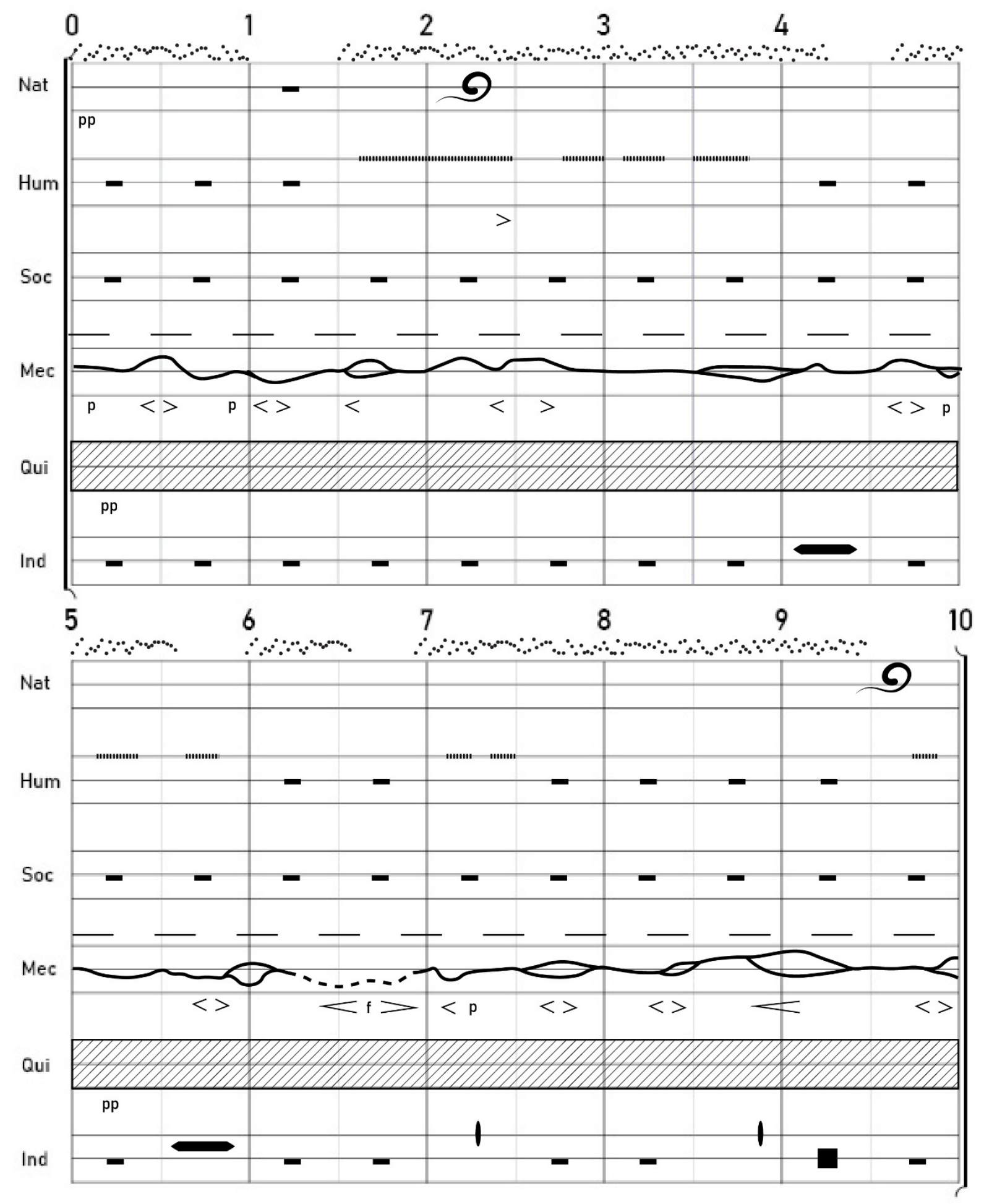

Figure A9: Sound Score for Walt Whitman Park: Tuesday Afternoon (Gray) 

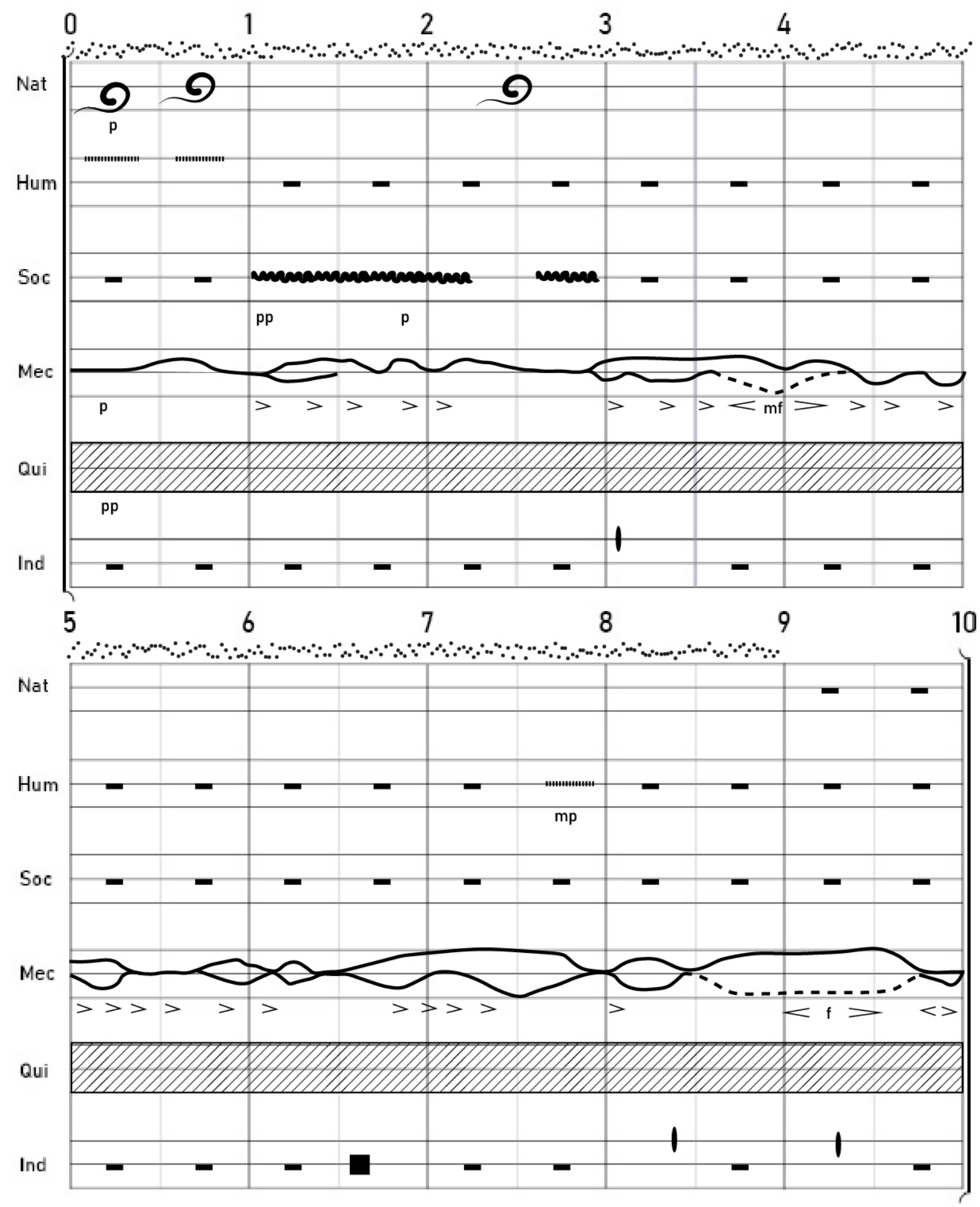

Figure A10: Sound Score for Walt Whitman Park: Tuesday Late Afternoon (Gray) 

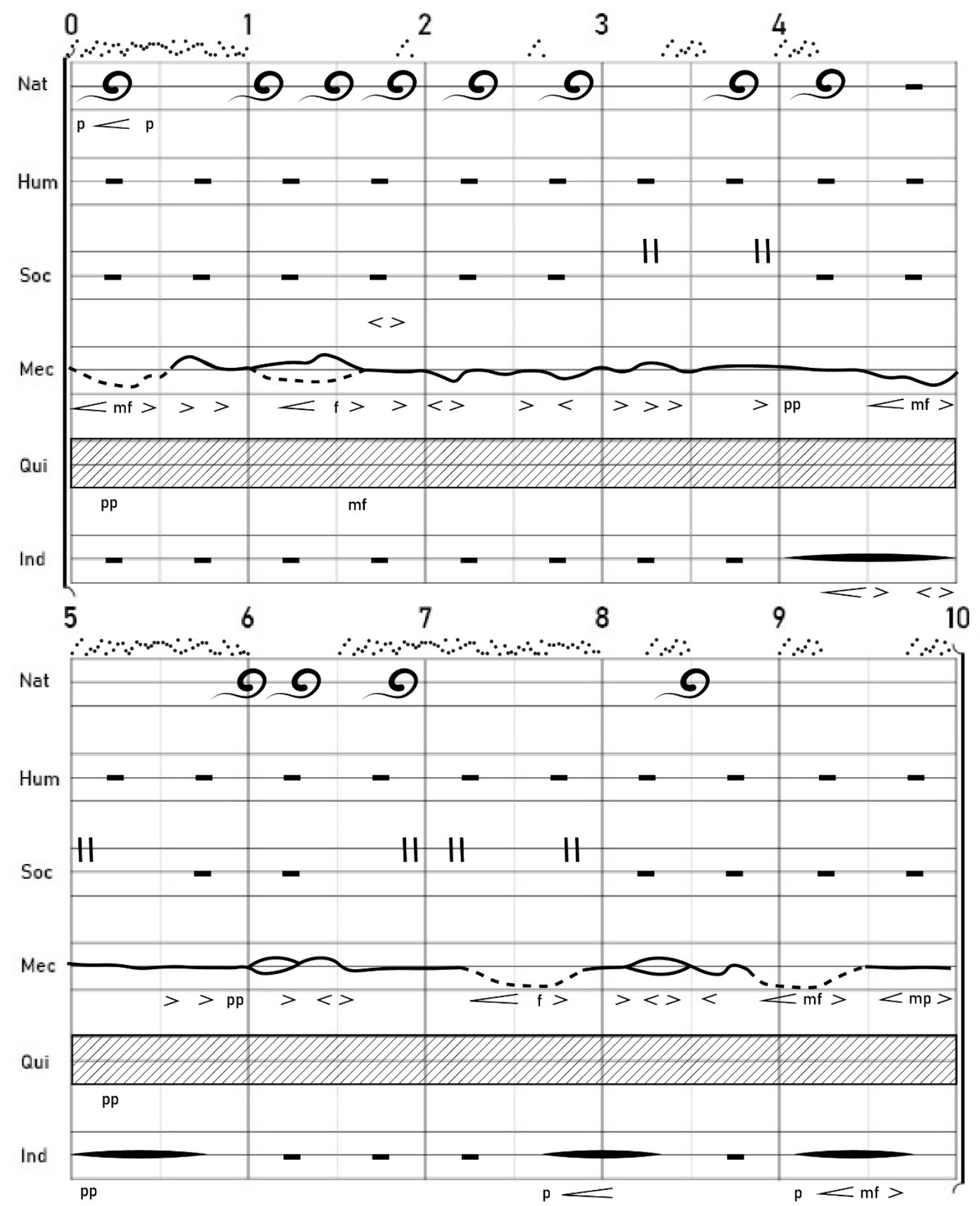

Figure A11: Sound Score for Walt Whitman Park: Saturday Morning (Gray) 

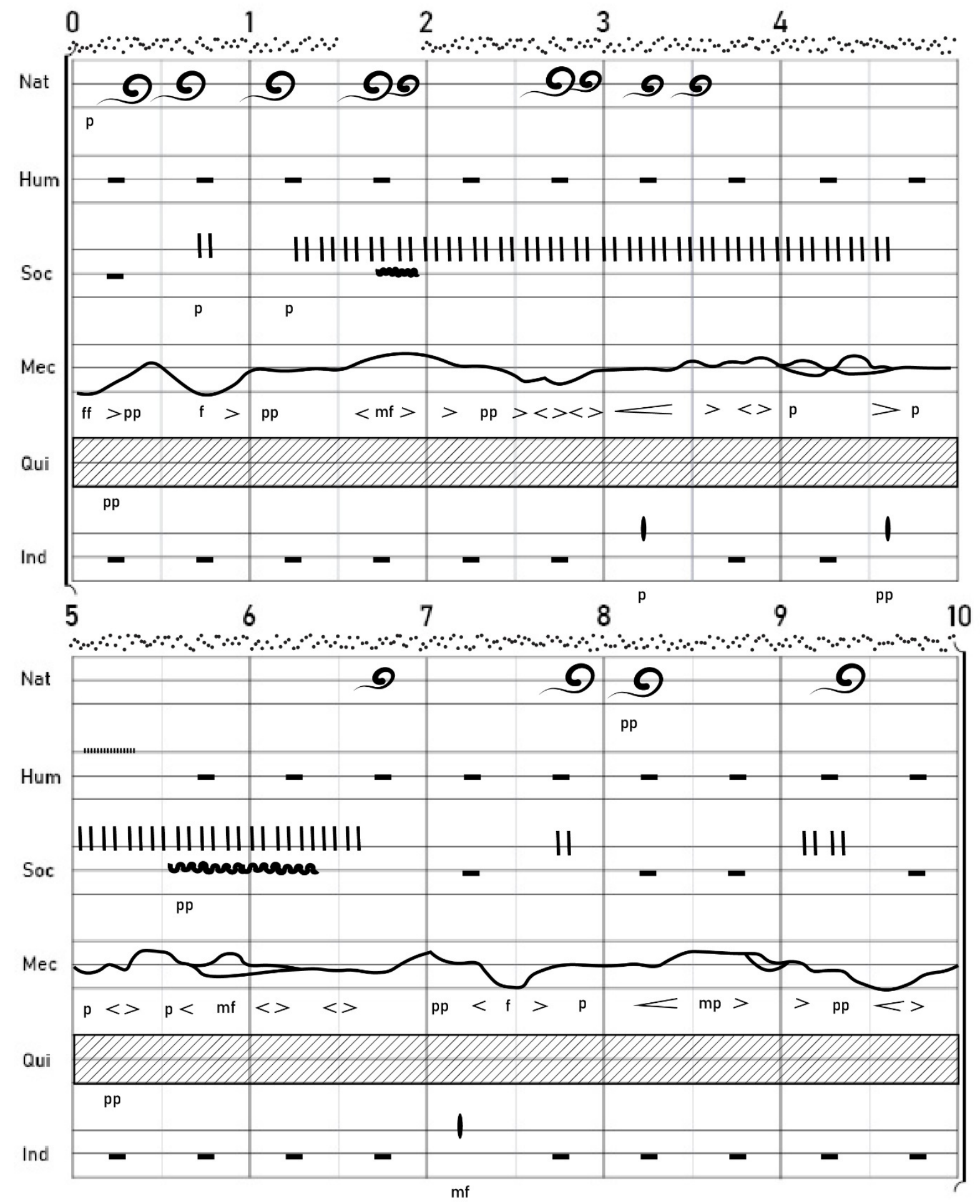

Figure A12: Sound Score for Walt Whitman Park: Saturday Afternoon (Gray) 

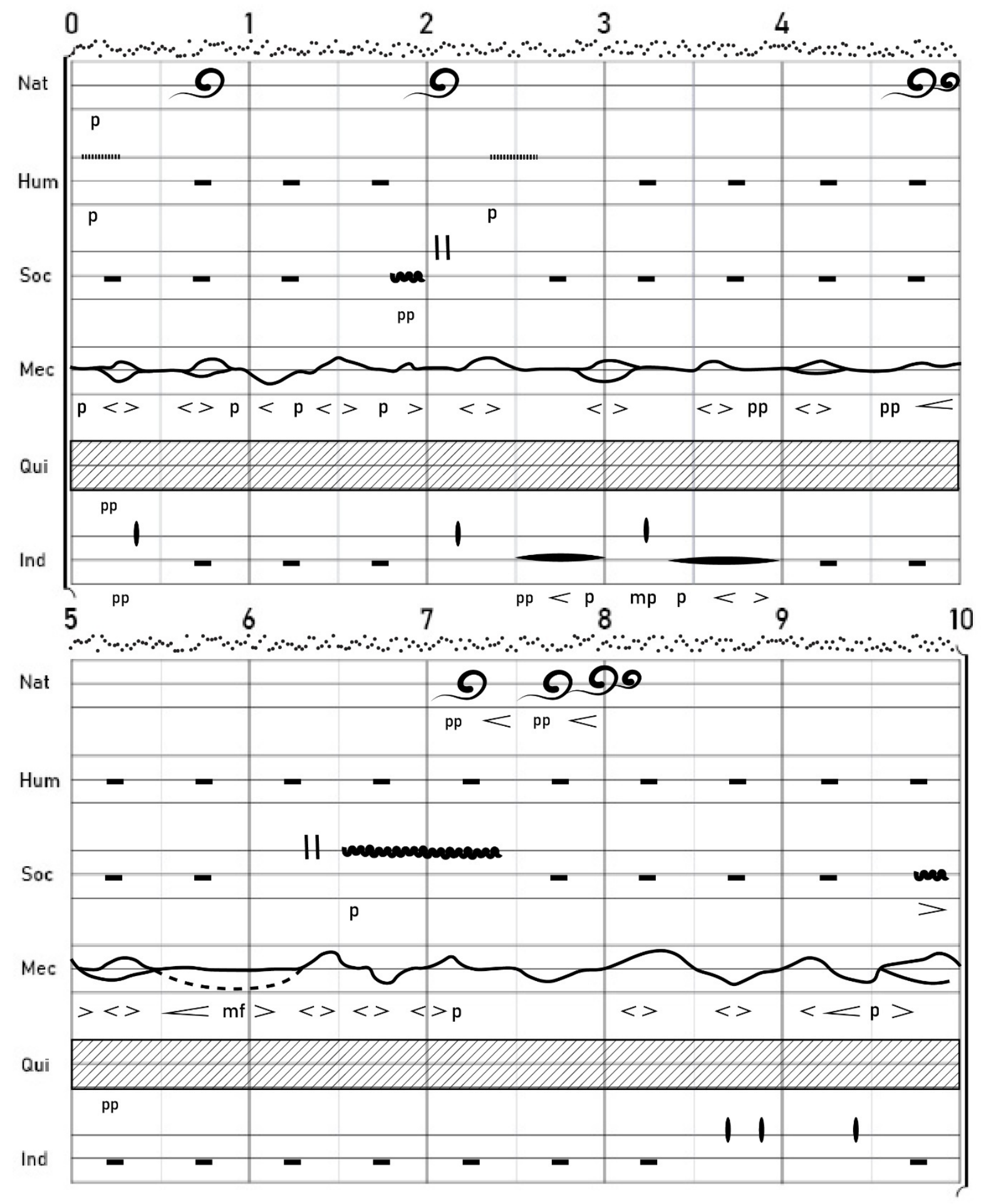

Figure A13: Sound Score for Walt Whitman Park: Saturday Late Afternoon (Gray) 


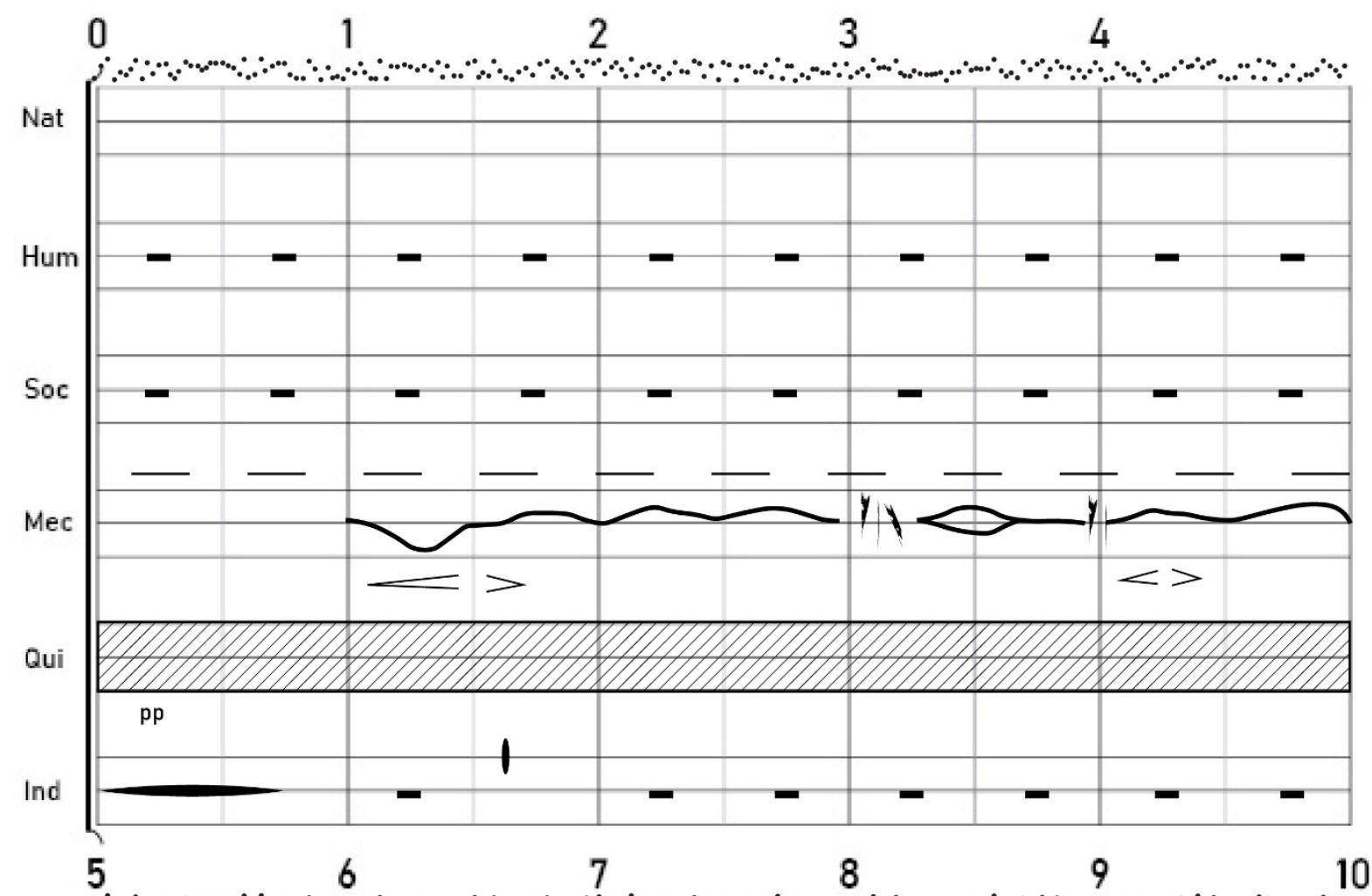

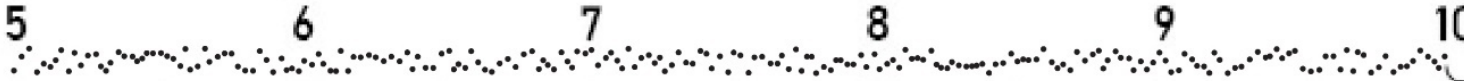

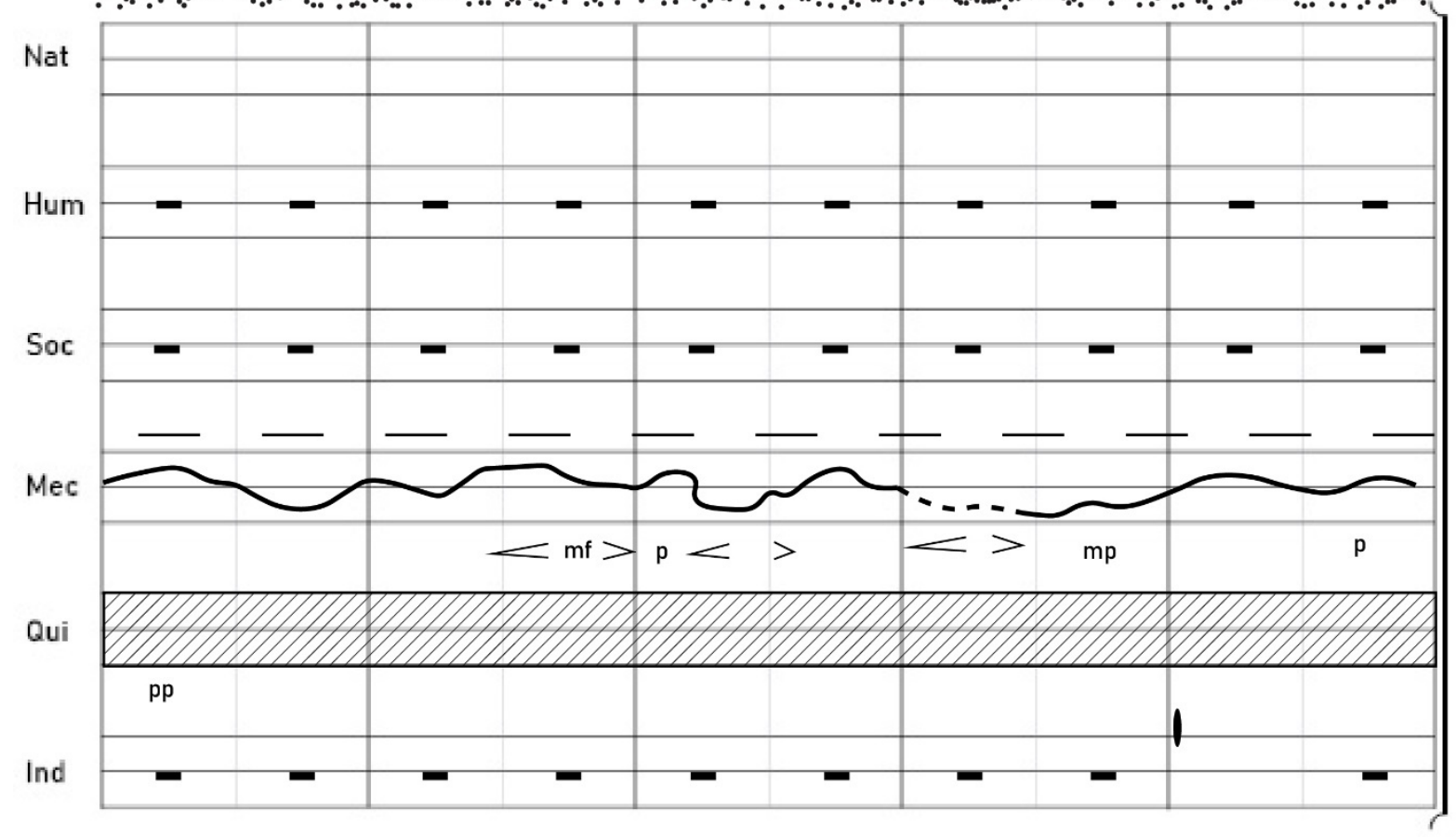

Figure A14: Sound Score for Triangle Park: Tuesday Morning (Gray) 


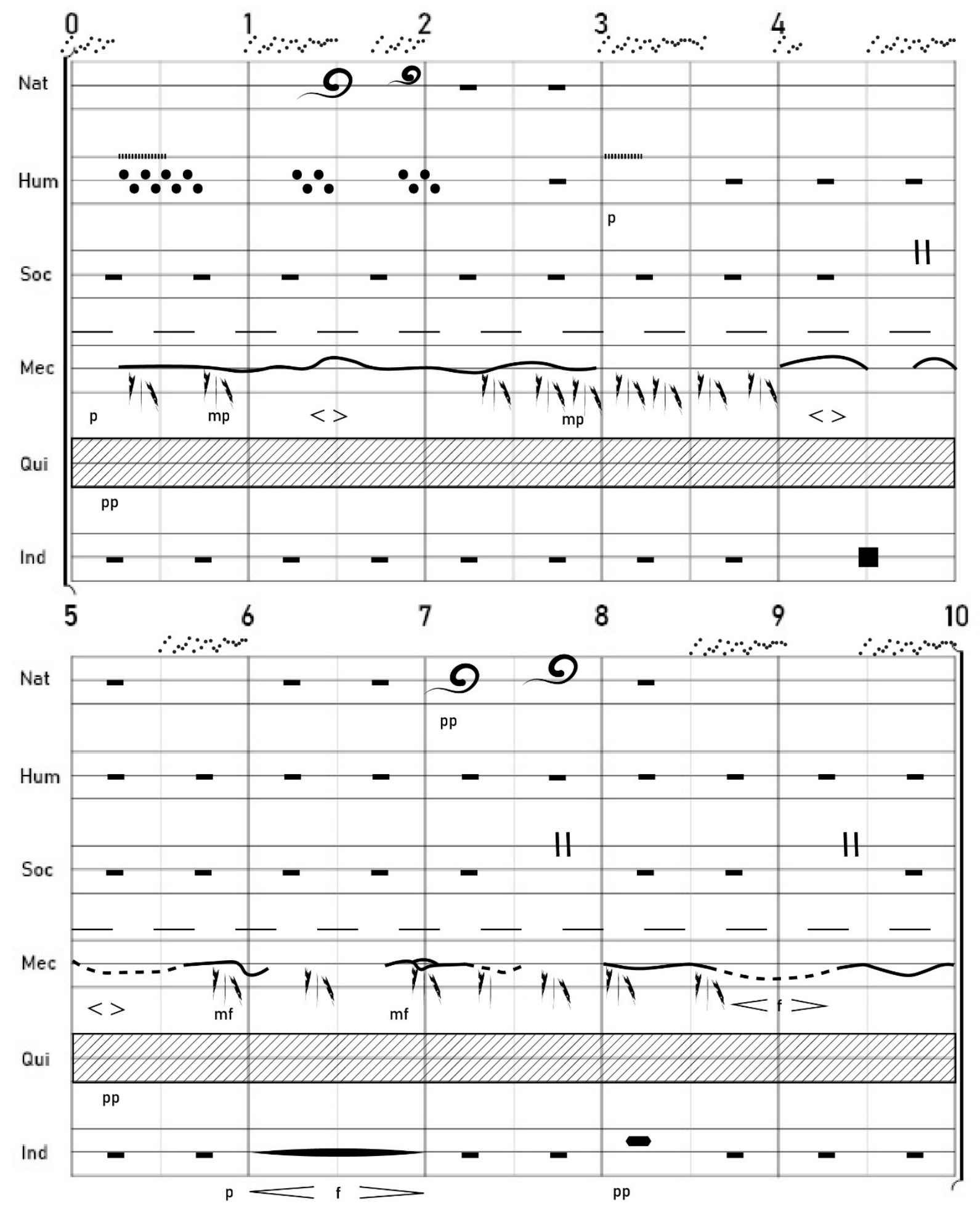

Figure A15: Sound Score for Triangle Park: Tuesday Afternoon (Gray) 

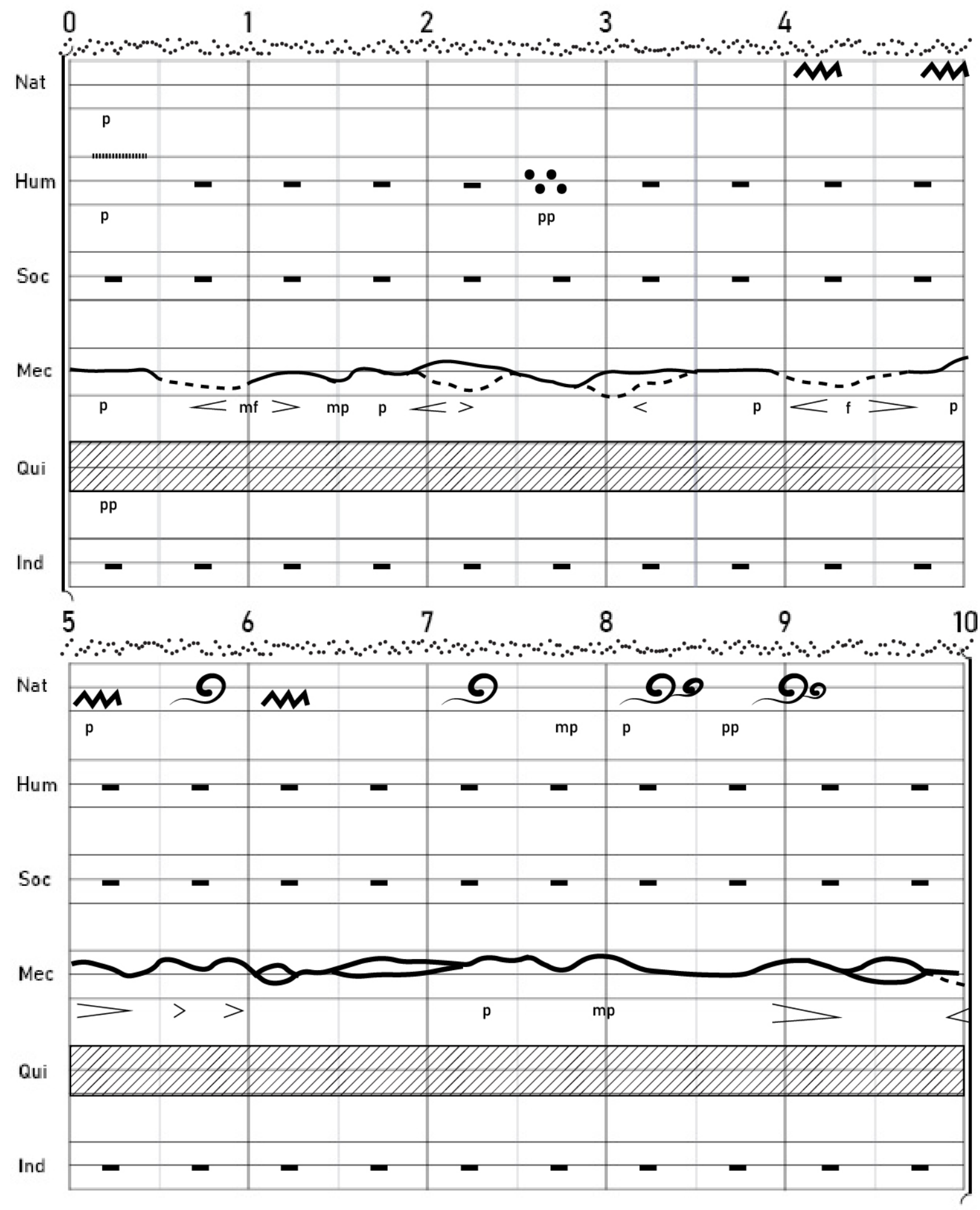

Figure A16: Sound Score for Triangle Park: Tuesday Late Afternoon (Gray) 


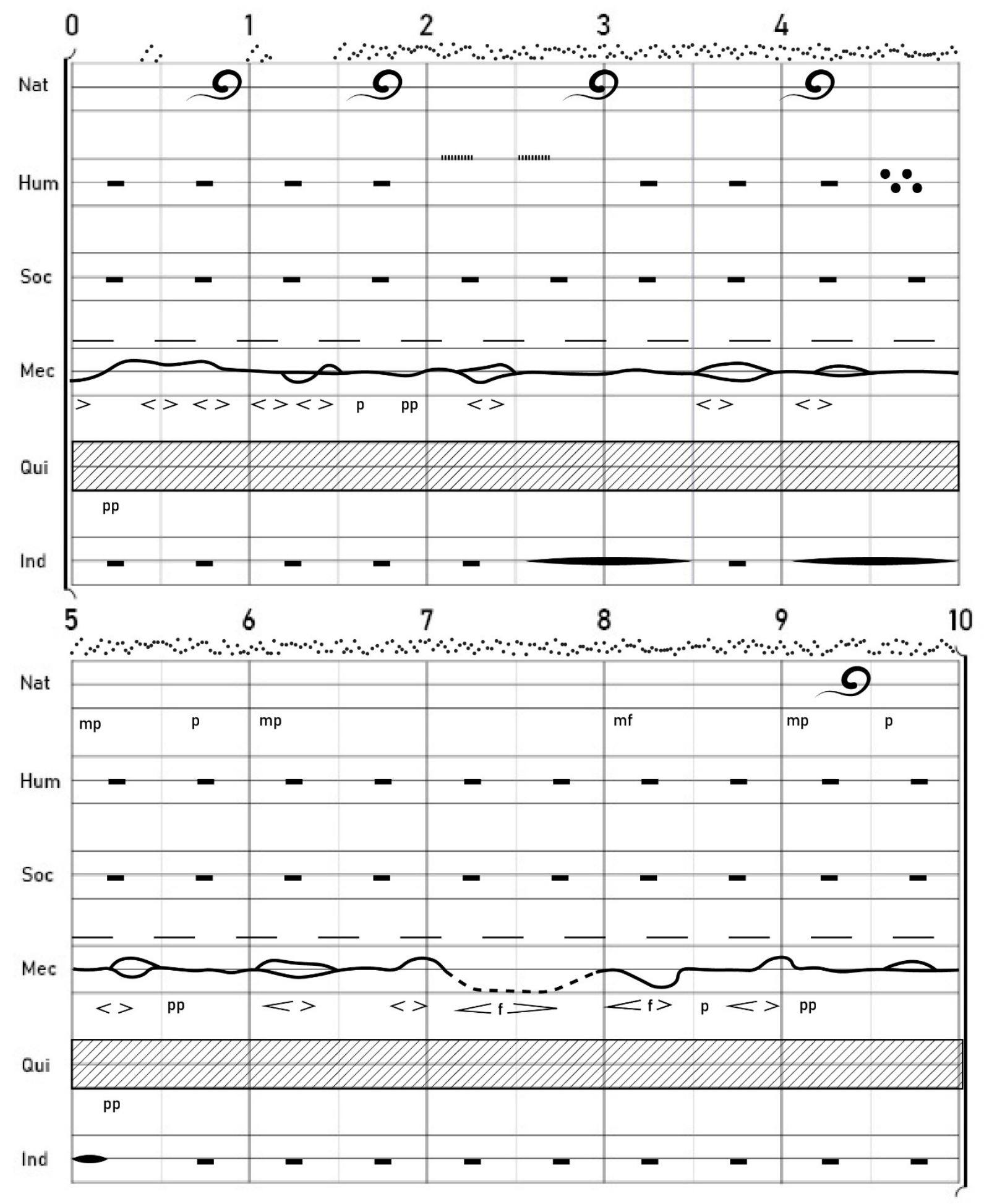

Figure A17: Sound Score for Triangle Park: Saturday Morning (Gray) 

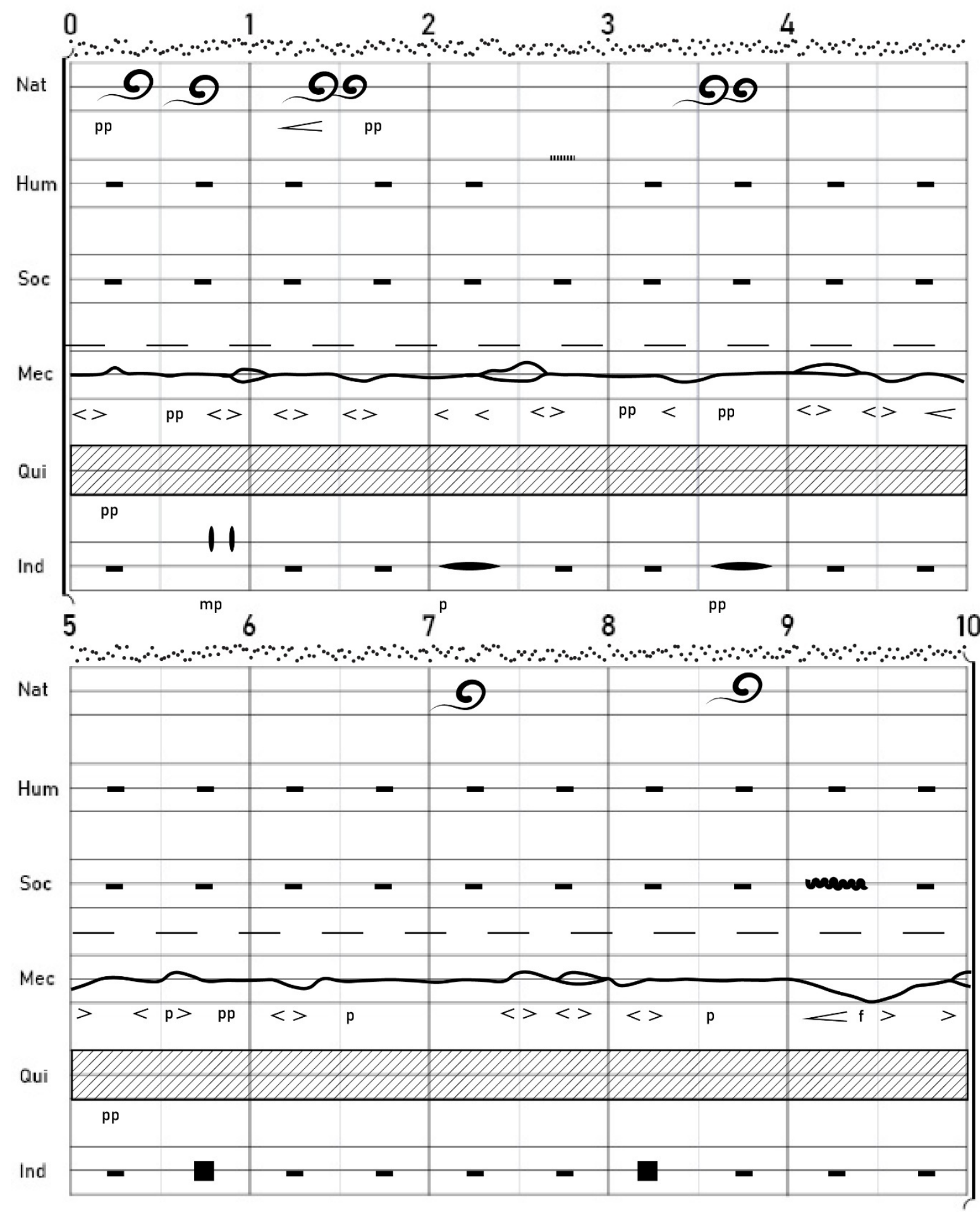

Figure A18: Sound Score for Triangle Park: Saturday Afternoon (Gray) 

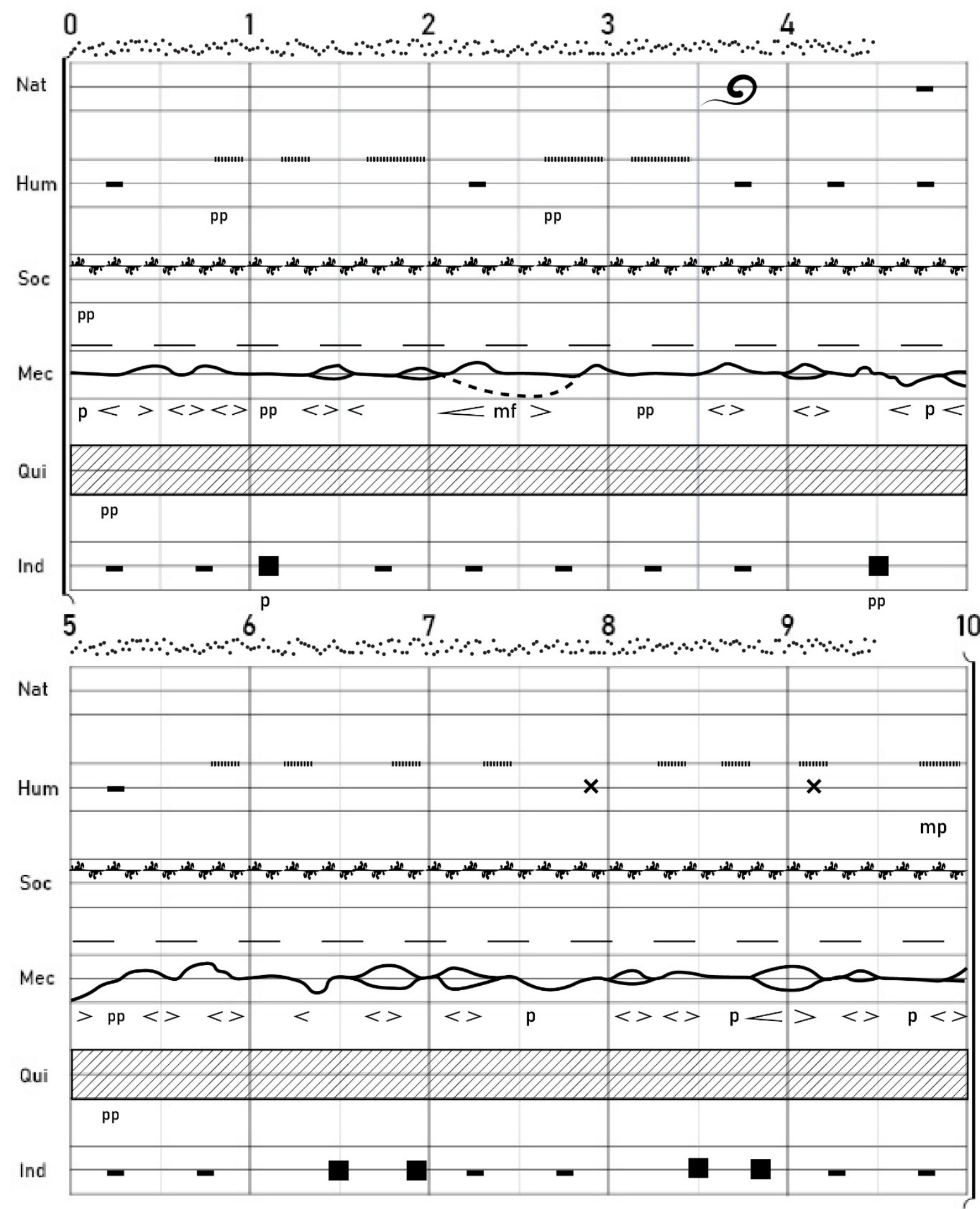

Figure A19: Sound Score for Triangle Park: Saturday Late Afternoon (Gray) 

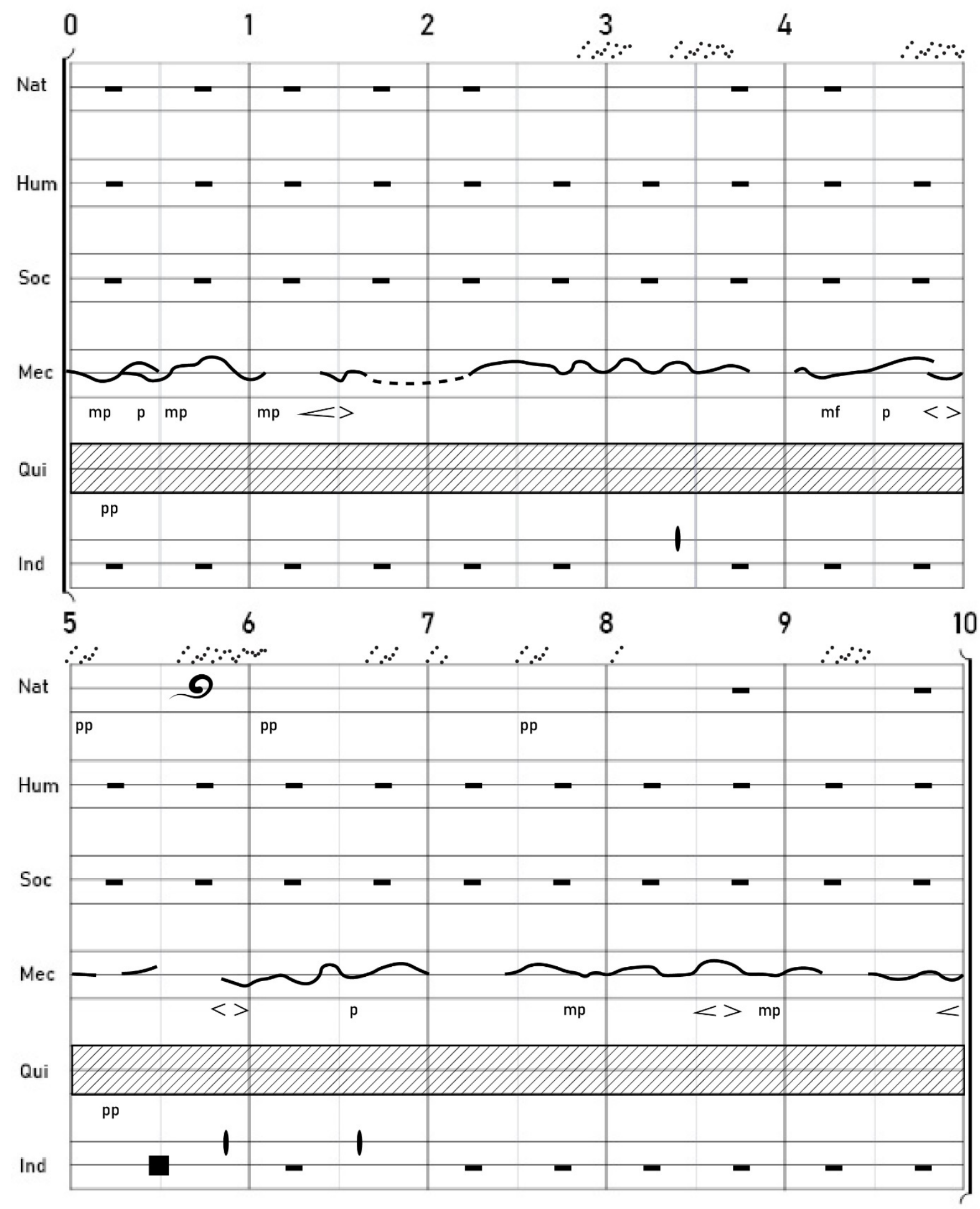

Figure A20: Sound Score for Bernardo De Galvez Memorial Park: Tuesday Morning (Gray) 


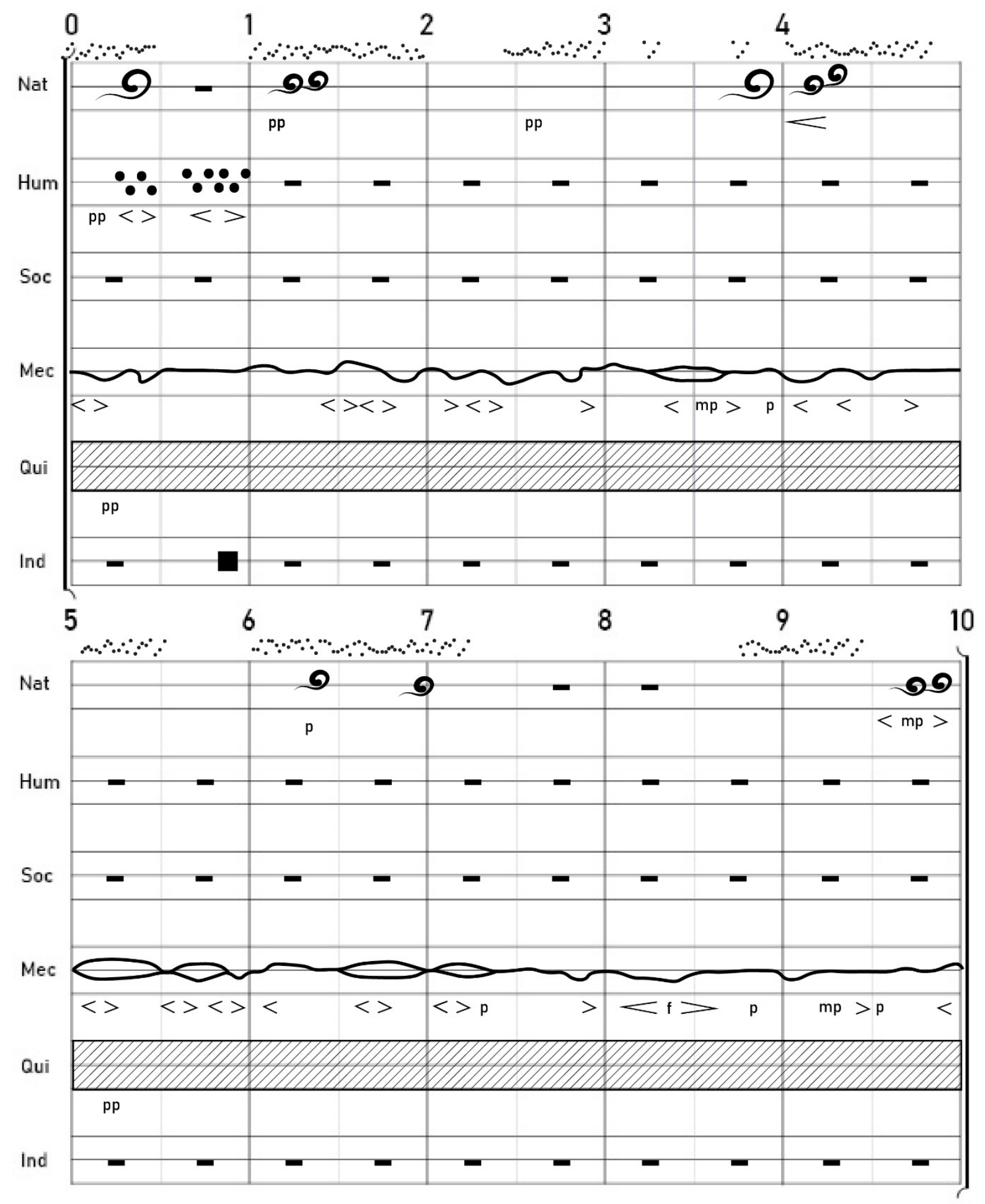

Figure A21: Sound Score for Bernardo De Galvez Memorial Park: Tuesday Afternoon (Gray) 


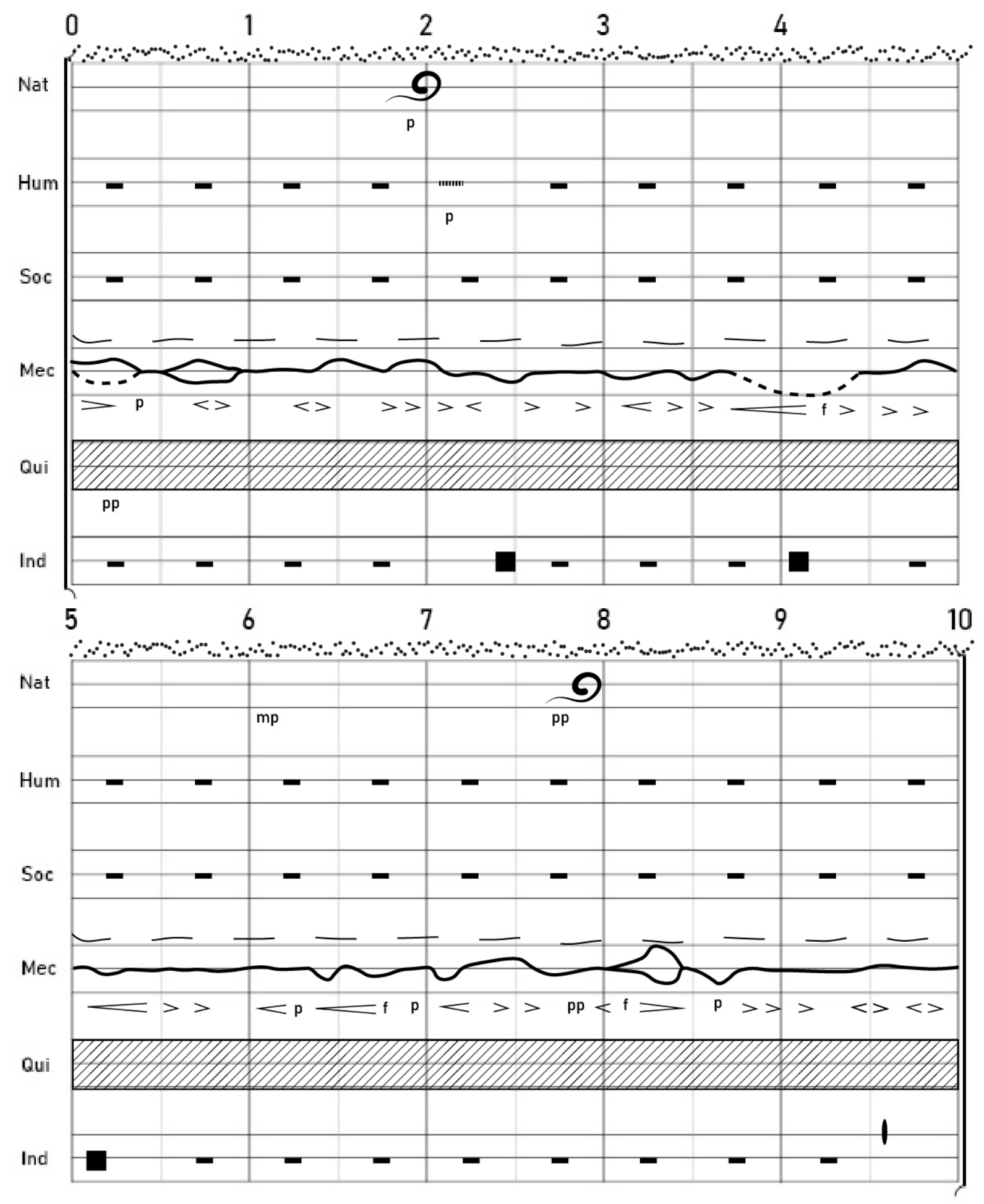

Figure A22: Sound Score for Bernardo De Galvez Memorial Park: Tuesday Late Afternoon (Gray) 


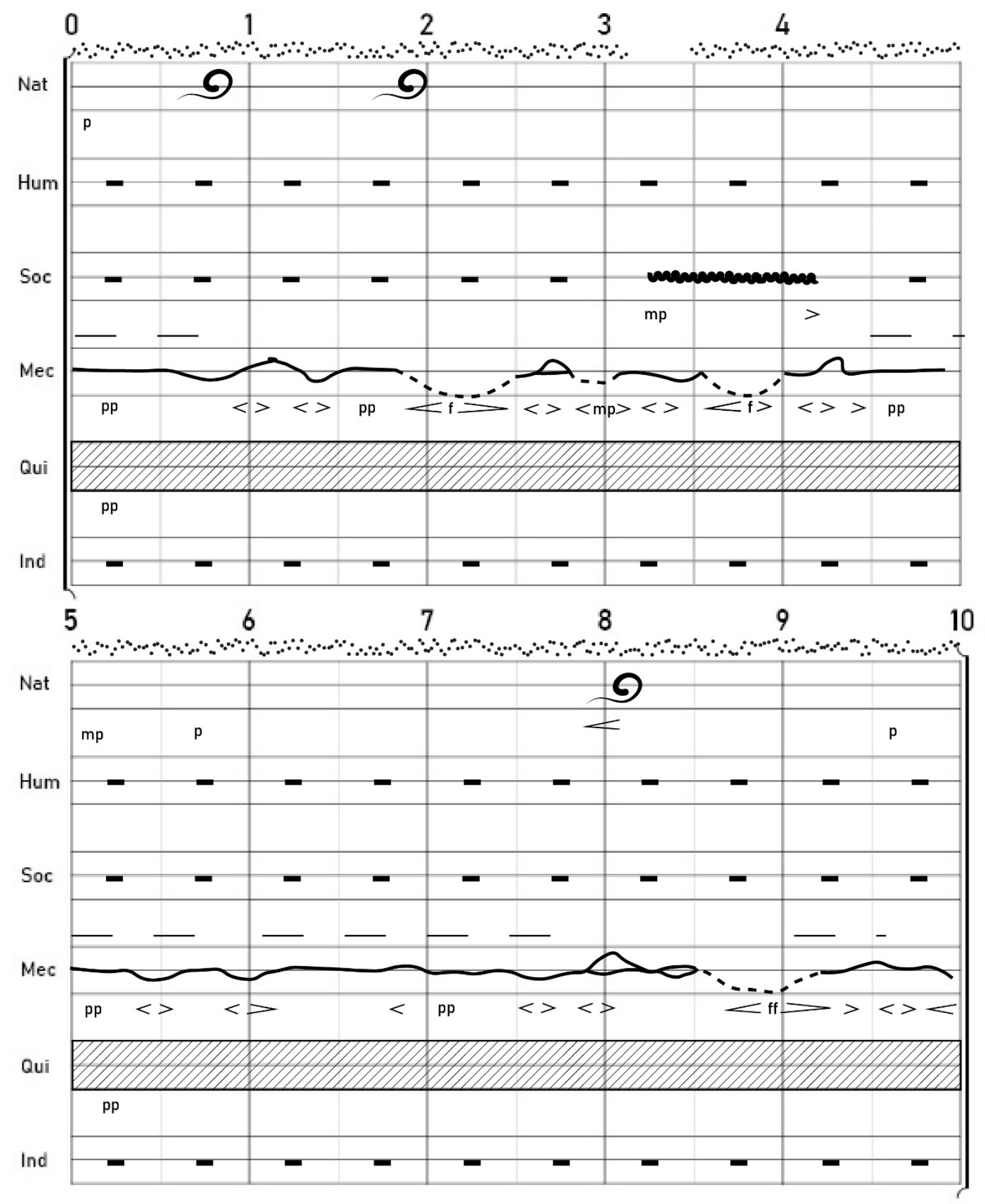

Figure A23: Sound Score for Bernardo De Galvez Memorial Park: Saturday Morning (Gray) 

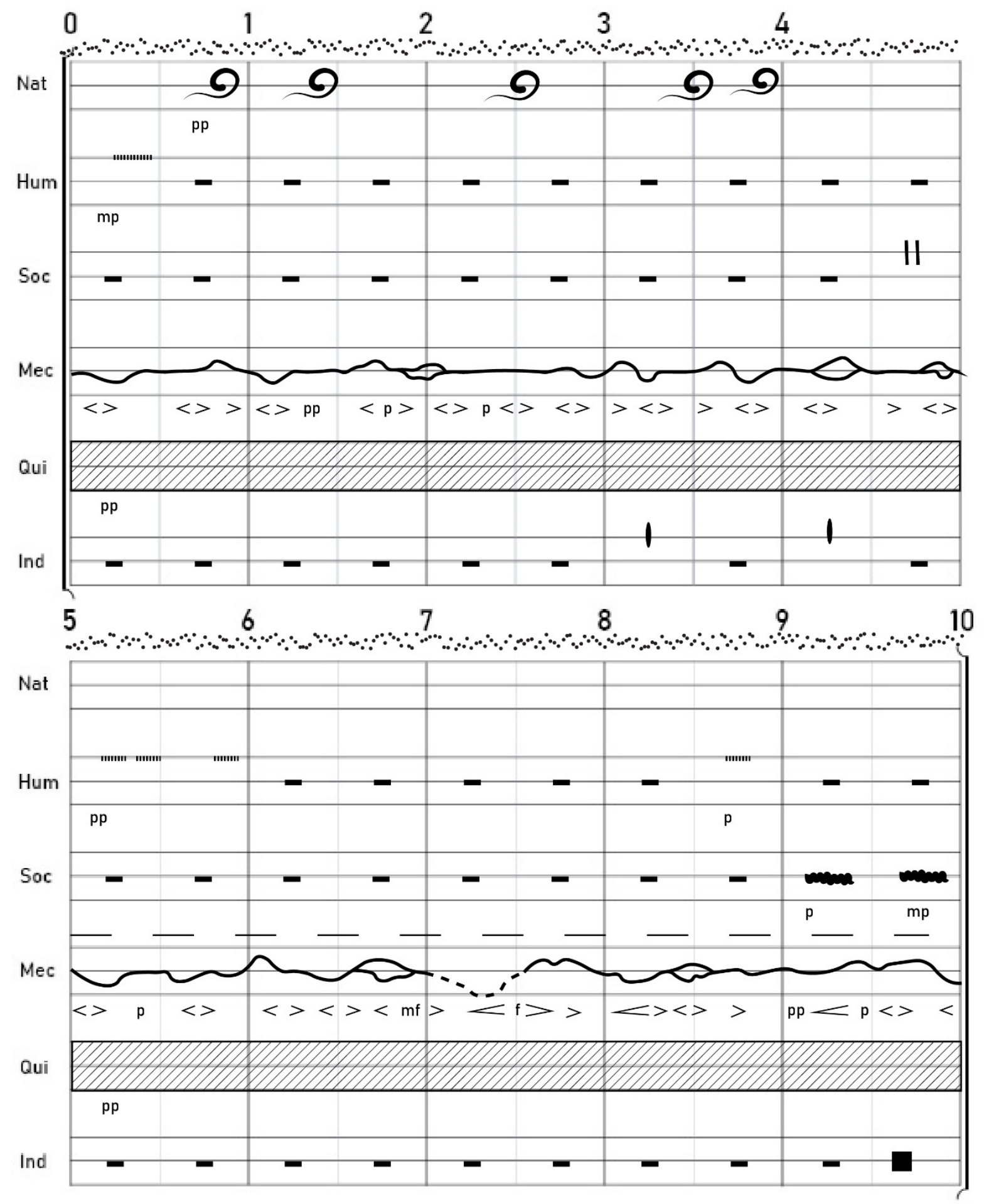

Figure A24: Sound Score for Bernardo De Galvez Memorial Park: Saturday Afternoon (Gray) 

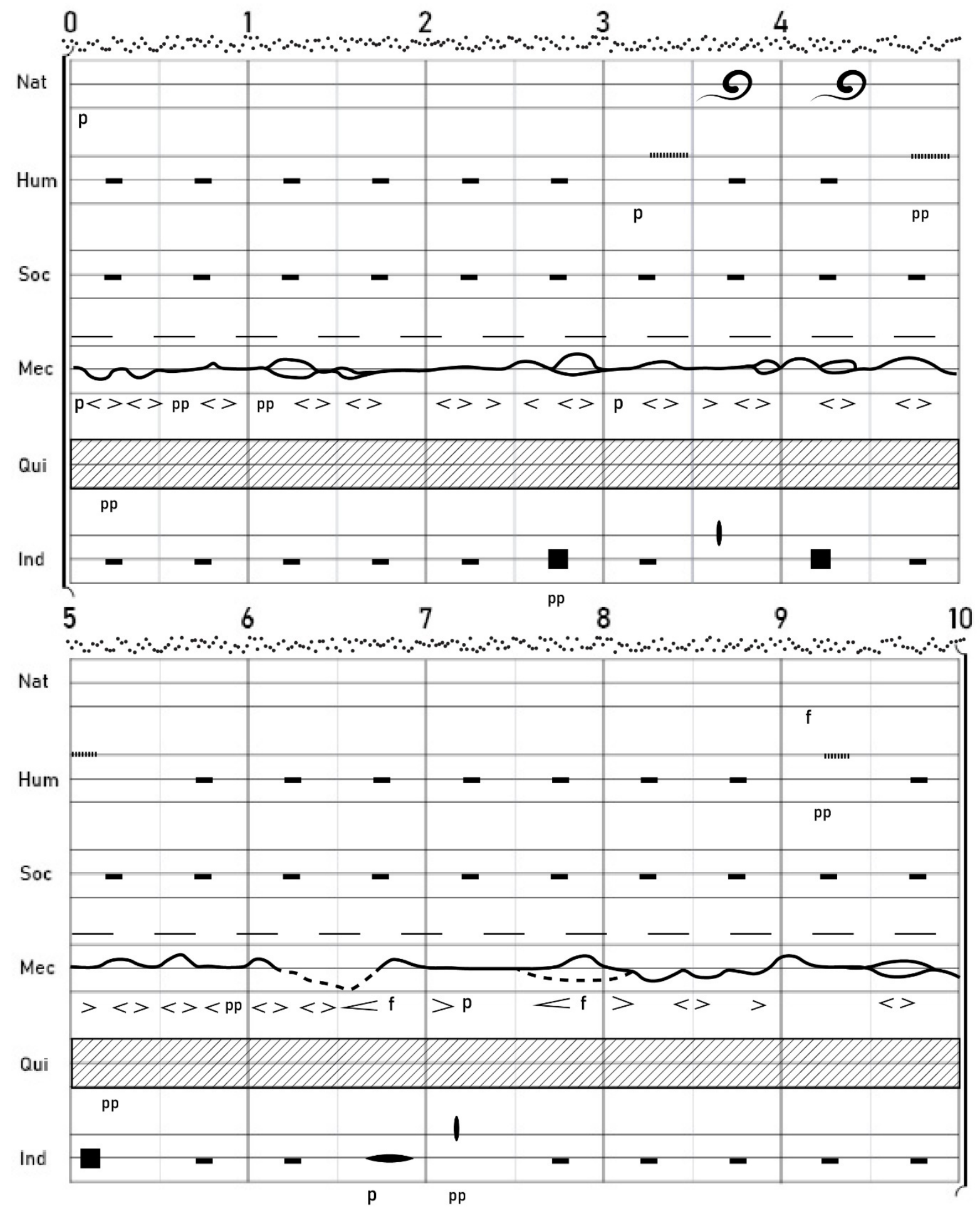

Figure A25: Sound Score for Bernardo De Galvez Memorial Park: Saturday Late Afternoon (Gray) 


\section{Bibliography}

Acoustical Society of America. (2013). AMERICAN NATIONAL STANDARD Acoustical

Terminology. https://webstore.ansi.org/preview-pages/ASA/preview_ANSI+ASA+S1.1-2013.pdf S

Agapito, D., Valle, P., \& Mendes, J. (2014). The sensory dimension of tourist experiences: Capturing meaningful sensory-informed themes in Southwest Portugal. Tourism Management, 42, 224-237. https://doi.org/10.1016/j.tourman.2013.11.011

Aletta, F., Kang, J., \& Axelsson, Ö. (2016). Soundscape descriptors and a conceptual framework for developing predictive soundscape models. Landscape and Urban Planning, 149, 65-74. https://doi.org/10.1016/j.landurbplan.2016.02.001

Axelsson, Ö. (2015). How to measure soundscape quality. In Proceedings of the Euronoise 2015 conference (pp. 1477-1481).

Brahms, J. (1876). Symphonie No. 1 in C Minor, Opus 68 [Orchestral Score]. Amazon.com. Retrieved 5/01/2021 from https://www.amazon.com/Brahms-Orchestral-JohannesSymphony-Completed/dp/B07C4PVCPY

Brambilla, G., Gallo, V., Asdrubali, F., \& D’Alessandro, F. (2013). The perceived quality of soundscape in three urban parks in Rome. The Journal of the Acoustical Society of America, 134(1), 832-839. https://doi.org/10.1121/1.4807811

Bratman, D., (2002, November). An Introduction to Symphonic Form. dbratman.net. Accessed 08/02/2021 and retrieved from https://www.dbratman.net/sonata.html

Cage, J. (1958a). Fontana Mix [Image of graphic score]. Media Arts Net. Retrieved 05/06/2020. http://www.medienkunstnetz.de/works/fontana-mix/ 
Cage, J. (1958b) Solo for Piano, Notation M, p. 9. [Piano Score]. Retrieved 12/03/2020. Philip Thomas: Performing the Solo for Piano https://cageconcert.org/performing-theconcert/solo-for-piano/

Cage, J. (2011). Silence: Lectures and Writings, 50th Anniversary Edition. Wesleyan University Press. Kindle Edition.

Cerwén, G. (2016). Urban soundscapes: A quasi-experiment in landscape architecture. Landscape Research, 41(5), 481-494. https://doi.org/10.1080/01426397.2015.1117062

Counts, M., \& Newman, G. (2019). Sound Parks: Invisible Agents of Urban Well-Being. Research Journal, 11.02, 45-62.

Fastl, H., Akustik, A. T., Eberhardsteiner, J., Mang, H. A., Waubke, H., \& Fastl, H. (2006). Psychoacoustic basis of sound quality evaluation and sound engineering. Proc. 13th Intern. Congress on Sound and Vibration, Vienna (2006) 19 Th 6 INTERNATIONAL CONGRESS ON ACOUSTICS - ICA2007.

Fastl, H. (2013). Basics and applications of psychoacoustics. The Journal of the Acoustical Society of America, 133(5), 3306-3306. https://doi.org/10.1121/1.4805482

Guo, J. (2019). The Assessment of Soundscape Quality in Urban Parks-A Case Study in Penn Park. University of Pennsylvania. 88.

Halprin, L. (n.d.) Motation's \& Eco Scores. [Image]. Retrieved 12/03/2020. Pinterist.com https://www.pinterest.com/pin/67342956898801105/

Hong, J. Y., \& Jeon, J. Y. (2013). Designing sound and visual components for enhancement of urban soundscapes. The Journal of the Acoustical Society of America, 134(3), 20262036. https://doi.org/10.1121/1.4817924 
Jo, H. I., \& Jeon, J. Y. (2020). Effect of the appropriateness of sound environment on urban soundscape assessment. Building and Environment, 179, 106975. https://doi.org/10.1016/j.buildenv.2020.106975

Maculewicz, J., Erkut, C., \& Serafin, S. (2016). How can soundscapes affect the preferred walking pace? Applied Acoustics, 114, 230-239. https://doi.org/10.1016/j.apacoust.2016.07.031

Michael Van Valkenburgh Associates Inc. (n.d.). Brooklyn Bridge Park [Images of park]. mvvainc. Accessed 04/21/2021. https://www.mvvainc.com/project.php?id=3

National Capital Planning Commission. (1997). Legacy Plan. Retrieved May 1, 2021, from https://www.ncpc.gov/plans/legacy/

National Capital Planning Commission. (2001). Memorials \& Museums Master Plan. Retrieved May 1, 2021, from https://www.ncpc.gov/plans/memorials/

National Capital Planning Commission. (2009, March). Monumental Core Framework Plan. Retrieved May 1, 2021, from https://www.ncpc.gov/plans/framework/

Pogrebin, R. (2013, January). Kennedy Arts Center Unveils Plans For Expansion. The New York Times. https://www.nytimes.com/2013/01/30/arts/design/kennedy-center-unveilsexpansion-plan.html

Schafer, R. Murray. (1977). The tuning of the world. Knopf. https://catalog.hathitrust.org/Record/000086818

Schulte-Fortkamp, B., Brooks, B. M., \& Bray, W. R. (2007). Soundscape: An Approach to Rely on Human Perception and Expertise in the Post-Modern Community Noise Era. Acoustics Today, 3(1), 7. https://doi.org/10.1121/1.2961148

The Cultural Landscape Foundation. (n.d.). Bryant Park. Tclf.org. 
https://tclf.org/landscapes/bryant-park

The Cultural Landscape Foundation. (n.d.). Paley Park. Tclf.org.

https://tclf.org/landscapes/paley-park

The REACH Expansion at the Kennedy Center Opens to the Public. [Image]. Retrieved

2/04/2021. ArchDaily. https://www.archdaily.com/924359/the-reach-expansion-at-thekennedy-center-opens-to-the-public

United States Department of Transportation. (2021 March). National Transportation Noise Map [Map]. Bureau of Transportation. Retrieved 04/21/2021.

https://maps.dot.gov/BTS/NationalTransportationNoiseMap/

United States Department of Transportation. U.S. Department of Transportation Completes Study of Ways to Improve Access to Kennedy Center | FHWA. (March 2001). Retrieved May 1, 2021, from https://cms8.fhwa.dot.gov/newsroom/us-department-transportationcompletes-study-ways-improve-access-kennedy-center

Vialma. (n.d.). The evolution of the symphony. vialma.com. accessed 05/02/2021 from https://www.vialma.com/en/articles/164/The-evolution-of-thesymphony\#: : :text=The $\% 20$ first $\% 20$ symphonies $\% 20$ came $\% 20$ into,'voice $\% 2 \mathrm{C} \% 20$ or $\% 20$ sound'.

west8 (n.d.). MIAMI BEACH SOUNDSCAPE [Images of park]. West8.com Accessed $04 / 21 / 2021$ https://www.west8.com/projects/miami_beach_soundscape/ World Health Organization. (2018) ENVIRONMENTAL NOISE GUIDELINES for the European Region. https://www.euro.who.int/_ data/assets/pdf_file/0008/383921/noiseguidelines-eng.pdf 
World Health Organization. (September 18, 2019). Safe listening. Who.int. https://www.who.int/news-room/q-a-detail/deafness-prevention

Yang, W., \& Kang, J. (2005). Soundscape and Sound Preferences in Urban Squares: A Case Study in Sheffield. Journal of Urban Design, 10(1), 61-80. https://doi.org/10.1080/13574800500062395

Yang, M., \& Kang, J. (2013). Psychoacoustical evaluation of natural and urban sounds in soundscapes. The Journal of the Acoustical Society of America, 134(1), 840-851. https://doi.org/10.1121/1.4807800 